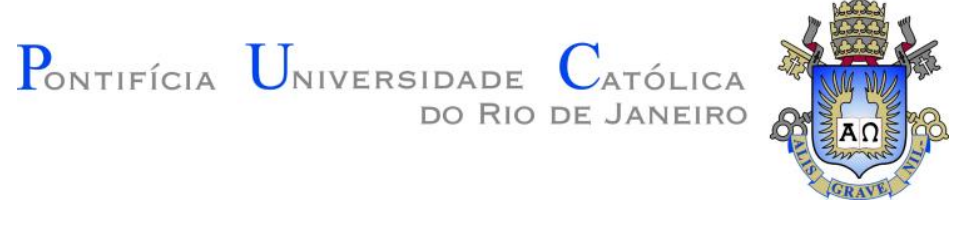

Eros Danilo Monteiro de Carvalho

\title{
Modelo em Código Aberto de Cootimização da Energia e Reservas com restrição de Unit Commitment para a Programação Diária da Operação sob critério N-K
}

Dissertação de Mestrado

Dissertação apresentada como requisito parcial para obtenção do grau de Mestre pelo Programa de Pós-graduação em Engenharia Elétrica do Departamento de Engenharia Elétrica da PUCRio.

Orientador: Prof. Alexandre Street de Aguiar 

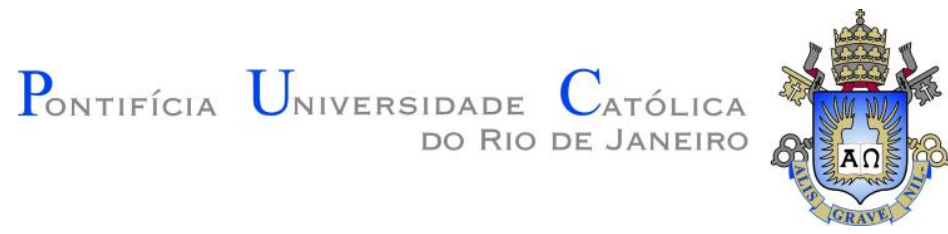

Eros Danilo Monteiro de Carvalho

\section{Modelo em Código Aberto de Cootimização da Energia e Reservas com restrição de Unit Commitment para a Programação Diária da Operação sob critério N-K}

Dissertação apresentada como requisito parcial para obtenção do grau de Mestre pelo Programa de Pós-graduação em Engenharia Elétrica do Departamento de Engenharia Elétrica da PUCRio. Aprovada pela Comissão Examinadora abaixo.

Prof. Alexandre Street de Aguiar

Orientador

Departamento de Engenharia Elétrica - PUC-Rio

Dr. André Luiz Diniz Souto Lima

Centro de Pesquisas de Energia Elétrica - CEPEL

Prof. Reinaldo Castro Souza

Departamento de Engenharia Industrial - PUC-Rio

Dr. Rodrigo Sacchi

Câmara de Comercialização de Energia Elétrica - CCEE

Rio de Janeiro, 11 de Setembro de 2019 
Todos os direitos reservados. É proibida a reprodução total ou parcial do trabalho sem autorização da universidade, do autor e do orientador.

Eros Danilo Monteiro de Carvalho

Graduou-se em Engenharia Elétrica na Universidade Federal de Juiz de Fora (Minas Gerais, Brasil) em 2013. Desde 2013 é Engenheiro Eletricista do Operador Nacional do Sistema Elétrico - ONS.

Ficha Catalográfica

Carvalho, Eros Danilo Monteiro de

Modelo em Código Aberto de Cootimização da Energia e Reservas com restrição de Unit Commitment para a Programação Diária da Operação sob critério N-K / Eros Danilo Monteiro de Carvalho; orientador: Alexandre Street de Aguiar. - Rio de janeiro: PUC-Rio, Departamento de Engenharia Elétrica , 2019.

v., 68 f: il. color. ; $30 \mathrm{~cm}$

Dissertação (mestrado) - Pontifícia Universidade Católica do Rio de Janeiro, Departamento de Engenharia Elétrica .

Inclui bibliografia

1. Engenharia Elétrica - Teses. 2. Cootimização de Energia e Reserva;. 3. Critério de Segurança $N-K ;$. 4. Comprometimento de Unidades;. 5. Programação Diária da Operação. I. Aguiar, Alexandre Street de. II. Pontifícia Universidade Católica do Rio de Janeiro. Departamento de Engenharia Elétrica . III. Título. 
Ao meu filho Enzo, minha esposa Debora e minha mãe Marília (em memória). 


\section{Agradecimentos}

Este importante momento da minha vida, me faz refletir, olhar para trás e ver, o quão pedregosa foi essa jornada, como esses obstáculos foram postos para chegar hoje e perceber o quanto cresci e aprendi, que "a missão foi cumprida" e que, as vezes, "enquanto a gente descansa a gente carrega pedras". Lembro de minha mãe dizer "Você mede o valor da conquista pelo quanto se sacrificou para alcançá-la", e é por isso que esta etapa que concluo hoje tem um valor enorme. Assim não poderia deixar de registrar também as pessoas de valor que direta e indiretamente participaram, dividiram angústias e torceram por mim nesta caminhada.

Agradeço ao ser supremo, criador, Deus, acredito que independente de credo, ser único e que ilumina nossos caminhos. Obrigado por nos proporcionar saúde e determinação para continuar em frente.

Ao meu orientador, Professor Alexandre Street, que desde o momento que o procurei aceitou o desafio de desenvolver a presente pesquisa. Muito agradecido pela paciência, apoio, zelo, reuniões e conversas, grato pela orientação.

Meu agradecimento especial ao Professor Reinaldo que além de ser da minha banca, também contribuiu grandemente em a minha formação. Tive a oportunidade de cursar suas disciplinas. Muito obrigado pelo apoio ao longo do mestrado.

Não poderia deixar de expressar meus agradecimentos a PUC-Rio e aos professores que me transmitiram seus conhecimentos ao longo do curso. À Capes por financiar a pesquisa, grato.

Aos colegas que cursaram as disciplinas comigo, em especial a Lívia, Túlio, Daniel e Rodrigo. Muito obrigado pelos momentos de estudo, ajuda e torcida.

Aos integrantes do LAMPS, sempre que precisei estavam disposto a me ajudar. Obrigado João, Marcelo, Raphael, Thuenere Ana.

Meus sinceros agredecimentos a todos colegas da Gerência de Programação do Operador Nacional do Sistema Elétrico - ONS, em especial aos quatro otimizadores do Sistema Interligado Nacional - SIN, José Mauro Abreu Pinto, Adilson Simões, Leandro Jorge Gomes e Fabiano Pinho Mourão, por me ensinarem incondicionalmente tudo que sei hoje sobre operação e otimização, me tornando o quinto otimizador. Não poderia nunca deixar de registrar meus agradecimentos aos gerentes e amigos, Ney Fukui da Silveira e Vagner dos Santos Begni, pelos ensinamentos, pela compreensão em todos os momentos e liberações para cursar as disciplinas. Aos colegas que me ajudaram e 
torceram Maria Cândida, Carlos Villas Bôas, Carlos Júnior, Marcelo Luna, Janaína, Roger, Thámires, Diana, Letícia e Desireé.

Meu filho Enzo, obrigado por ser esse menino incrível, que toda vez que pedia para eu brincar com ele e compreendia quando eu dizia "Papai precisa estudar". Sei que fiquei ausente muito tempo, quando você aprender a ler espero que leia essa dissertação e veja o recado "As palavras convencem, os exemplos arrastam".

Obrigado minha querida namorada, esposa, companheira Debora "Namorada". Repito o que você colocou na sua tese pois tivemos que "nos reconhecer no temporal", você escrevendo a tese e eu a dissertação não foi fácil. Nós somos uma dupla e tanto. Te amo.

Ao meu pai, Léo, que mesmo nas dificuldades de criar uma familia com 4 filhos e poucos recursos sempre proporcionou a mim e aos meus irmãos os estudos, sendo sempre muito exigente.

Mãe, minha mãe Marília, sei que esta aí, olhando por nós. Calma, paciente, pessoa que tinha a pressão 10/6, nada a abalava. Grato por me ensinar o que é a "Gratidão". Saudades.

"Brothers and Sister" amo por demais vocês. Cada vez somos mais fortes e unidos, sei que torceram muito por mim.

Meu agradecimento carinhoso aos meus avós, Maria Eda e José Amadeu, Elza e Manuel, um beijo grande.

Grato ao meu sogro Jejé, sogra Rubinha e cunhado Bruno, sei que se orgulham muito de mim e desde a graduação torcem por mim.

Meus agradecimentos aos Tios e Tias. À Tia Marcia por todas as orações. Tias Cidinha, Ana, Andréia e Adriana, após o falecimento da minha mãe, ganhei quatro mães.

À Danielle, minha analista e amiga que me acompanha e acompanhou durante todo esse processo de dissertação. Fica aqui meu agradecimento especial.

O presente trabalho foi realizado com o apoio da Coordenação deAperfeiçoamento de pessoal de Nível Superior - Brasil (CAPES) - Código de Financiamento 001.

Gratidão. 


\section{Resumo}

Carvalho, Eros Danilo Monteiro de; Aguiar, Alexandre Street de. Modelo em Código Aberto de Cootimização da Energia e Reservas com restrição de Unit Commitment para a Programação Diária da Operação sob critério N-K. Rio de Janeiro, 2019. 68p. Dissertação de Mestrado - Departamento de Engenharia Elétrica, Pontifícia Universidade Católica do Rio de Janeiro.

O sistema elétrico de potência brasileiro, denominado Sistema Interligado Nacional-SIN, possui como órgão responsável pela operação o Operador Nacional do Sistema Elétrico - ONS. A fim de utilizar os recursos energéticos de forma a garantir a qualidade, confiabilidade e segurança no suprimento de energia elétrica ao menor custo total de operação, o operador utiliza uma cadeia de modelos de otimização que subsidia a tomada de decisão no Programa Diário de Operação, implementado diariamente nas salas de controle do ONS e de agentes de geração para operação em tempo real. A etapa de Programação Diária do Operador Nacional do Sistema Elétrico busca estabelecer o despacho centralizado da geração e das reservas de potência a fim de atender à demanda prevista de energia elétrica considerando os limites da rede elétrica, das tecnologias de geração e a incerteza de disponibilidade das unidades geradores e linhas de transmissão. Este trabalho propõe um modelo computacional programado em código aberto para a programação diária implementado na linguagem Julia. $\mathrm{O}$ modelo pertence à classe de modelos de unit commitment e considera a cootimização do despacho de geração e definição dos níveis de reservas em cada gerador do SIN para atender a critérios de segurança do tipo $N-K$.

\section{Palavras-chave}

Cootimização de Energia e Reserva; Critério de Segurança $N-K$; Comprometimento de Unidades; Programação Diária da Operação. 


\section{Abstract}

Carvalho, Eros Danilo Monteiro de; Aguiar, Alexandre Street de (Advisor). Open Source Energy and Reserve Cooptimization Model for Day-ahead Scheduling with Unit Commitment Constraints Considering N-K Criterion. Rio de Janeiro, 2019. 68p. Dissertação de Mestrado - Departamento de Engenharia Elétrica , Pontifícia Universidade Católica do Rio de Janeiro.

The Brazilian electric power system, called the National Interconnected System - SIN ( Sistema Interligado Nacional), has as its responsible institution for operation the National Electric System Operator - ONS (Operador Nacional do Sistema Elétrico). In order to manage energy resources to ensure quality, reliability and security of electricity supply at the lowest total operating cost, the operator uses a chain of optimization models that feeds the Daily Operation Program for decision-making, which is implemented everyday in the ONS and generators control rooms for real-time operation. The Daily Scheduling phase of the National Electric System Operator seeks to establish the centralized dispatch of generation and power reserves in order to meet the expected demand for electricity considering the limits of both the electrical grid and the generation technologies, along with the uncertainty of availability of generator units and transmission lines. This work proposes a computational model programmed in open-source for daily operation programming, implemented in the Julia language. The model belongs to the unit commitment model class and it considers the generation dispatch co-optimization and reserve levels definition in each SIN generator to meet $\mathrm{N}-\mathrm{K}$ safety criteria.

\section{Keywords}

Energy and Reserve Co-Optimization; $N-K$ Safety Criteria; Unit Commitment; Generation Scheduling Day-Ahead. 


\section{Sumário}

1 Introdução 14

$\begin{array}{ll}1.1 \text { Considerações gerais } & 14\end{array}$

$\begin{array}{lll}1.2 & \text { Objetivos } & 16\end{array}$

$\begin{array}{lll}1.3 & \text { Estrutura do trabalho } & 17\end{array}$

2 Formulação do Problema para o Programa Diário da Operação 18

2.1 Função Objetivo 18

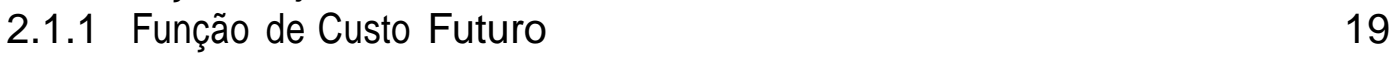

$\begin{array}{ll}2.2 \text { Restrições Energéticas } & 19\end{array}$

2.2.1 Restrição de Balanço Energético 20

2.2.2 Restrições Físicas das Unidades Geradoras 20

2.2.3 Restrições das Usinas Hidráulicas 26

2.2.4 Função de Produção Hidráulica Aproximada - FPHA 29

2.3 Restrições de Contingência de Unidades Geradoras 31

2.4 Representação das Restrições da Rede de transmissão de Energia Elétrica 32

3 Método de Solução 34

4 Sistemas Simulados $\quad 38$

4.1 Sistema teste 3 barras 38

4.2 Sistema teste 30 barras 44

4.3 Subsistema Norte do SIN isolado 46

4.4 Sistema Interligado Nacional 48

4.5 Índices de Desempenho e Sinal Econômico 53

5 Conclusão $\quad 57$

$\begin{array}{ll}\text { Referências bibliográficas } & 59\end{array}$

A Apêndice A $\quad 62$

B Apêndice B $\quad 64$ 


\section{Lista de figuras}

Figura 1 Função de Custo Futuro 19

Figura 2 Representação do Despacho para atendimento a restrições físicas 22

Figura 3 Exemplo de garantia do Tempo Mínimo de Permanência Ligado

Figura 4 Composição dos armazenamento aos reservatórios $n$ no período $t \quad 27$

Figura 5 Habilitação para operação de vertimento 28

Figura 6 Função de Produção Hidráulica Aproximada 30

Figura 7 Algoritmo de solução para o Programa Diário de Operação 34

Figura 8 Resultado do processo iterativo para o sistema de 3 barras 36

Figura 9 Ponto de operação final para o sistema de 3 barras $\quad 37$

Figura 10 Curva de Carga utilizada no Sistema de 3 barras 38

Figura 11 Resultado do despacho total hidráulico de potência - 3 barras - $N-0-0$

Figura 12 Resultado do despacho total térmico de potência e reservas - 3 barras $-\mathrm{N}-\mathrm{O}-0$

Figura 13 Resultado do despacho total hidráulico de potência e reservas - Sistema 3 barras - N-1-0

Figura 14 Resultado do despacho total térmico de potência e reservas - Sistema 3 barras - N-1-0

Figura 15 Balanço de potência e alocação de reservas - 3 barras $N-1-0$

Figura 16 Resultado do despacho total hidráulico de potência e reservas - 3 barras $-N-1-1$

Figura 17 Resultado do despacho total térmico de potência e reservas - 3 barras $-N-1-1$

Figura 18 Balanço de potência e alocação de reservas - 3 barras $N-1-1$

Figura 19 Sistema teste 30 barras e violações para o critério $N-1-144$

Figura 20 Balanço de potência e alocação de reservas - 30 barras 45

Figura 21 Contingência Linha 230 kV SE Lechuga-Manaus com sobrecarga no circuito remanescente - Subsistema Norte - N $1-1$

Figura 22 Contingência das Linhas 500 kV SE Tucuruí-Xingú e Xingú-Jurupari com sobrecarga no circuito remanescente Subsistema Norte $-N-1-1$

Figura 23 Balanço de potência e reservas - Subsistema Norte $N-1-1$

Figura 24 Subsistemas e Conexões do Sistema Interligado Nacional 49

Figura 25 Resultado do despacho total térmico de potência e reservas - Sudeste e Sul - $N-1-1$ 
Figura 26 Resultado do despacho total térmico de potência e reservas - Norte e Nordeste - N-1-1

Figura 27 Operação da UG 1 da UTE Gov. Leonel Brizola e UG 1 da UTE Celso Furtado - N - 1-1

Figura 28 Resultado do despacho balanço potência e reservas por Subsistema - Brasil - N-1-1

Figura 29 Resultado do despacho balanço potência e reservas por Subsistema - Brasil - N-1-1

Figura 30 Reservas alocadas por Subsistema - Brasil - N-1-1

Figura 31 Resultado do despacho de potência e reservas UG térmica 1 - 3 barras $-N-1-1$

Figura 32 Resultado do despacho de potência e reservas UG térmica 3 - 3 barras $-N-1-1$

Figura 33 Resultado do despacho de potência e reservas UG térmica 7 - 3 barras $-N-1-1$

Figura 34 Resultado do despacho de potência e reservas UG térmica 6 - 30 barras - N-1-1

Figura 35 Resultado do despacho de potência e reservas UG térmica 10 - 30 barras $-N-1-1$

Figura 36 Resultado do despacho de potência e reservas UG térmica 4 - 30 barras $-N-1-1$

Figura 37 Resultado do despacho de potência e reservas UG térmica 5 - 30 barras - N-1-1

Figura 38 Resultado do despacho de potência e reservas UG térmica 1 - 30 barras $-N-1-1$

Figura 39 Resultado do despacho de potência e reservas UG térmica 2 - 30 barras $-N-1-1$

Figura 40 Resultado do despacho de potência e reservas UG térmica 3 - 30 barras $-N-1-1$

Figura 41 Resultado do despacho de potência e reservas UG térmica 9 - 30 barras $-N-1-1$

Figura 42 Resultado do despacho de potência e reservas UG térmica 8 - 30 barras $-N-1-1$ 


\section{Lista de tabelas}

Tabela 1 Dados Unidades Hidráulicas Sistema teste 3 barras 35

Tabela 2 Dados Unidades Térmicas Sistema teste 3 barras 35

Tabela 3 Processo Iterativo do Método de Solução 37

Tabela 4 Variável Dual Circuito 2 dentro dos critérios simulados - Sistema 3 barras 43

Tabela $5 \quad$ Dados Unidades Térmicas Sistema com 30 barras 45

Tabela $6 \quad$ Resultado do processo iterativo - Sistema 30 barras 45

Tabela 7 Tempo de Processamento para os Casos de Estudo 54

Tabela 8 Índices de Desempenho e Sinal Econômico para os Casos de Estudo Simulados 55

Tabela 9 Custos de Operação para os Casos de Estudo 56 


\section{Lista de Abreviaturas}

SIN - Sistema Interligado Nacional

ONS - Operador Nacional do Sistema Elétrico

ANEEL - Agência Nacional de Energia Elétrica

UCT - Unit Commmitment Térmico

UCH - Unit Commitment Hidráulico

CAG - Controle Automático de Geração

PDO - Programação Diária da Operação

RPO - Reserva de Potência Operativa

UG - Unidade Geradora

CVU - Custo Variável Unitário

FCF - Função de Custo Futuro

FPHA - Função de Produção Hidroelétrica Aproximada

MILP - Mixed Integer Linear Programming

RNE - Recebimento pela Região Nordeste

FNS - Fluxo Norte Sul

UTE - Usina Termoelétrica

UHE - Usina Hidrelétrica 


\section{Introdução}

\section{1}

\section{Considerações gerais}

O sistema elétrico de potência brasileiro é denominado Sistema Interligado Nacional, o SIN, por conectar através de grandes troncos de transmissão de energia elétrica as regiões Norte, Nordeste, Sudeste/Centro-Oeste e Sul, formando assim quatro subsistemas. Tal sistema tem como órgão responsável pela coordenação, controle e operação o Operador Nacional do Sistema Elétrico - ONS, criado por lei para atuar de forma neutra, equânime e transparente no gerenciamento de ativos de geração e transmissão pertencentes aos seus respectivos agentes proprietários [1], [2], [3].

O ONS no cumprimento de suas atribuições legais, dentro da cadeia de planejamento da operação do sistema elétrico brasileiro, desenvolve estudos elétricos e energéticos fundamentados em processos de otimização e análise de redes elétricas, em horizontes de médio e curto prazo [3]. No horizonte de curto prazo, a Programação Diária da Operação - PDO precede a operação em tempo real, baseia-se nos resultados da cadeia de modelos de otimização do setor elétrico, NEWAVE e DECOMP [4], para estabelecer o programa diário de geração de energia elétrica das diversas usinas sob supervisão do ONS. Além disso, nesta etapa outras restrições são consideradas: o comprometimento de unidades geradoras - UG, rampa de alívio e tomada de carga, tempo de permanência ligado ou desligado, limites da rede de transmissão, granularidade dos estágios semi-horário [5].

Além disso as restrições de segurança visam atender, para cada estágio, o critério determinístico para perda de elementos de rede e unidades geradoras constantes nas instruções de operação. Este critério de segurança é conhecido como $\mathrm{N}-\mathrm{K}$, ou seja, o sistema possui $N$ elementos e, na perda de $K$ elementos o mesmo deve permanecer em equilíbrio. A alocação de reserva de potência é feita sob usinas hidrelétricas que estão selecionadas para operar no Controle Automático de Geração - CAG e são remuneradas via serviço ancilar [6], [7], [8].

O procedimento atual da Programação Diária do ONS baseia-se 
nos insumos dos modelos de otimização, atualização dos cenários climáticos/hidrológicos, limites de transmissão, diretrizes e políticas de operação préestabelecidas, além de um know-how da equipe que compõem essa etapa. Em uma primeira fase, o programador estabelece os despachos de geração e alocação de Reserva de Potência Operativa - RPO para atendimento à demanda, respeitando a restrição de balanço de energia e a reserva em uma modelagem de barra infinita, ou seja, sem considerar a rede elétrica. Desta forma, o sistema, deve suportar a perda de $K^{G}$ unidades geradoras ou variações da previsão de carga, onde as reservas estão alocadas, na ordem de $5 \%$ da previsão de demanda do SIN, em unidades geradoras hidráulicas. Em uma segunda etapa o validador elétrico verifica a viabilidade do programa de despacho de geração através da execução do fluxo de potência linearizado. São monitoradas inequações, estabelecidas por estudos elétricos, que limitam os fluxos de potência atendendo ao critério de segurança para perda de $K^{L}$ elementos da rede. Caso não ocorra violação nesta etapa, os despachos são viáveis e podem ser implementados na sala de controle para operação em tempo real, caso contrário, será necessário um redespacho de geração e uma nova validação elétrica até a convergência do processo e consequente eliminação das violações elétricas.

O programa de geração e reservas para o dia seguinte respeita restrições físicas, operacionais e de segurança que nem sempre estão explicitamente incluídas nos modelos de otimização do Setor Elétrico Brasileiro. Isso torna a programação mais robusta no atendimento às necessidades de tempo real, porém não garantem a otimalidade do ponto de operação e a coerência do uso dos recursos do sistema. A cootimização da energia e reservas é uma alternativa para garantir os pontos anteriormente mencionados, que, em última análise, refletem em preços mais coerentes. Discussões sobre o desenho de mercado, a incorporação de restrições físicas e operacionais, que podem ou não fazer parte do processo de formação de preço, assim como as ações tomadas no processo de programação do dia seguinte e tempo real, não incluídas nos modelos, que influenciam no preço da energia e reserva são apresentadas em [9] e [10].

Outras abordagens de unit commitment vem sendo modeladas na literatura. Em [11] foi proposta uma eficiente modelagem para otimização de energia tendo como resultado um programa de geração e comprometimento de unidades geradoras térmicas atendendo às restrições de rampa, tempo de permanência ligado e desligado. Em um problema de programação inteira mista, tal formulação permite um número reduzido de variáveis binárias, o que reduz o tempo computacional. Uma proposta de cootimização de energia e reserva apresentada em [12] usa notação de restrições guarda-chuva atendendo ao critério $N-K$ de contingências em uma modelagem de barra infinita. Neste 
modelo, o resultado do problema inteiro misto é realizado em dois níveis sendo equivalente à solução em um único nível. Em [13] é apresentada uma abordagem de solução para o scheduling de energia e reserva com restrições de transmissão sob critério $\mathrm{N}-\mathrm{K}$ de unidades geradoras e linhas de transmissão. Uma formulação usando otimização robusta ajustável em três níveis é utilizada. Uma topologia ótima da rede de transmissão é apresentada em [14], ou seja, equipamentos de transmissão podem ser ligados ou desligados, para a cootimização de energia e reserva, atendendo ao critério de segurança $N-K$, no problema de unit commitment.

\section{2}

\section{Objetivos}

O objetivo desse trabalho é desenvolver um modelo computacional de unit commitment, programado em código aberto na linguagem Julia (https://julialang.org/), para realizar a programação diária via cootimização do despacho de geração e da alocação das reservas. Esta cootimização caracteriza um avanço com relação aos modelos do setor e proporciona, não só um benchmark para as soluções obtidas pelos softwares oficiais, mas também possibilita que os geradores realizem ofertas conjuntas ou separadas para mercados de fornecimento de energia e reservas. Além disso, neste trabalho aplicamos esse modelo a um sistema hidrotérmico de grande porte, utilizando a maior parte das premissas utilizadas pelo ONS. Ressaltamos que a aplicação de modelos de cootimização de energia e reserva, onde o critério de segurança é descrito por restrições guarda-chuva [13], em sistemas hidrotérmicos de larga escala não foi coberta na literatura.

Os custos de alocação de reserva serão considerados como entrada do modelo. Deste modo, tal modelo permite uma programação das reservas que considere um possível mercado de oferta para o custo dos serviços ancilares. Essa programação deverá garantir o critério de segurança, para perda de $K^{L}$ elementos de rede e $K^{G}$ geradores, previsto pela programação diária a mínimo custo global (energia mais reservas). Neste contexto, os níveis e alocações ótimas de reserva são obtidos de maneira endógena e cootimizada com o ponto operativo, garantindo a entregabilidade pela rede das reservas em caso de contingências. Além de todos os outputs típicos operativos, como geração, reserva, fluxos nas linhas, etc., o modelo também fornecerá os custos marginais de operação já contemplando o impacto das reservas. Este modelo permite, portanto, além de uma programação ótima da energia e serviços ancillares conjunta, maior transparência ao operador e previsibilidade aos diversos agentes, uma vez que terá seu código aberto. Utilizaremos uma 
metodologia de decomposição deste problemabaseada em um algoritmo de geração de restrições.

Esta cootimização de energia e reservas caracteriza um avanço com relação aos modelos do setor e proporciona, não só um benchmark para as soluções obtidas pelos softwares oficiais, mas também possibilita que os geradores realizem ofertas conjuntas ou separadas para mercados de fornecimento de energia e reservas.

As principais contribuições deste trabalho são:

- Um modelo de unit commitment para a cootimização da programação diária da energia e reserva do ONS considerando restrições elétricas;

- Programa computacional em código aberto que permita maior transparência ao operador e aos diversos agentes a respeito da otimização dos recursos energéticos de curto prazo;

- Incorporação de critérios de segurança do tipo N-K, alocação ótima das reservas, e variantes com flexibilidade de seleção de grupos de contingências .

\section{3}

\section{Estrutura do trabalho}

No Capítulo 2 é abordada a formulação para o problema de unit commitment térmico e hidráulico a luz das premissas observadas pela programação diária. Nele é definido a função objetivo de minimização do custo total de operação e os conjuntos de restrições. São apresentadas as restrições de balanço de potência, a representação das restrições associados as unidades geradoras, e como é feito o acoplamento da Função de Produção Hidráulica Aproximada com as unidades hidráulicas. A modelagem da rede e contingências também é abortado neste capítulo.

No Capítulo 3 é apresentado o algoritmo de solução da formulação proposta no capítulo 2. Esta etapa mostra a resolução do problema energético para cootimização da energia e reserva, e posterior verificação das violações de fluxo na rede, onde nesta etapa são inseridas as restrições guarda-chuva utilizando o algoritmo de geração de colunas e restrições.

Já no Capítulo 4, serão discutidos e analisados os principais resultados para os sistemas teste, bem como para dias tipos do SIN, sistema de grande porte.

O Capítulo 5 compõe das conclusões e sugestões para trabalhos futuros. 


\section{2 \\ Formulação do Problema para o Programa Diário da Opera- ção}

A resolução do problema de unit commitment com restrição de contingência estabelece o despacho de geração e a alocação de reserva, de modo que a demanda de energia elétrica seja atendida sob os estados pré e pós contingência. A modelagem proposta é dividida em restrições energéticas que garantem o comprometimento de unidades geradoras hidráulicas e térmicas. Um segundo grupo de restrições garante a alocação de reserva para cobrir a perda de $K^{G}$ geradores. No terceiro grupo de restrições são adicionadas ao problema de maneira iterativa as restrições de limite de fluxo nas linhas que se verifiquem violadas para todos os estados pós-contingência.

\section{1}

\section{Função Objetivo}

A função objetivo 2.1 é minimizar o custo total de operação, onde as variáveis de decisão são as gerações das unidades geradoras $g_{i, t}^{T}$ e $g_{j, t}^{H}$, térmicas $i$, e hidráulicas $j$, respectivamente, bem como a alocação de reserva $r_{i, t}^{T_{u p}} \mathrm{e}$ $r_{j, t}^{H_{u p}}$, respectivamente. A variável, $v_{n, T}$, representa o volume armazenado nos $n$ reservatórios ao final do horizonte de estudo, maior elemento do conjunto de períodos $T$. Os custos de produção $C_{i}^{\text {prod }}$ e reserva $C_{i}^{T_{\text {up }}}$ das UGs térmicas, bem como os custos de reserva $C_{j}^{H_{u p}}$ para UGs hidráulicas são dados de entrada. A variável $\alpha$ representa a função de custo futuro, ou seja, o impacto do uso da água no custo da operação futura [15].

$$
\begin{aligned}
& \left.\operatorname{minimize}_{g_{i, t}^{T}, g_{j, t}^{H}, r_{i, t}^{T u p}, r_{j, t}^{H u p}, \alpha, t \in T}-\underset{i \in I}{-}\left(C_{i}^{p r o d} g_{i, t}^{T}+C_{i}^{T_{u p}} r_{i, t}^{T_{u p}}\right)+{ }_{h \in H}^{-}\left(C_{j}^{H_{u p}} r_{j, t}^{H_{u p}}\right)\right]+\alpha \\
& s_{i, t}, w_{i, t}, u_{i, t}, x_{j, t}, y_{j, t}
\end{aligned}
$$

Podemos dividir a função em duas parcelas, o custo presente e custo futuro. A primeira, custo presente, é composta pelos custos de produção térmica e alocação de reserva em fontes térmicas e hidráulicas. A segunda parcela, custo futuro, está definida na seção 2.1.1 onde a decisão do modelo de utilizar a geração de unidades hidráulicas reflete no custo através do impacto no volume nos reservatórios ao final do período $T$. 


\subsection{1}

\section{Função de Custo Futuro}

O acoplamento das decisões de curto prazo com suas consequências operativas futuras se dá através da Função de Custo Futuro - FCF. Tal função é representada como uma função linear por partes, figura 1, em função do vetor de armazenamentos dos reservatórios das usinas hidráulicas ao final do horizonte de estudo. Essa função é fornecida por modelos de médio e longo prazo.

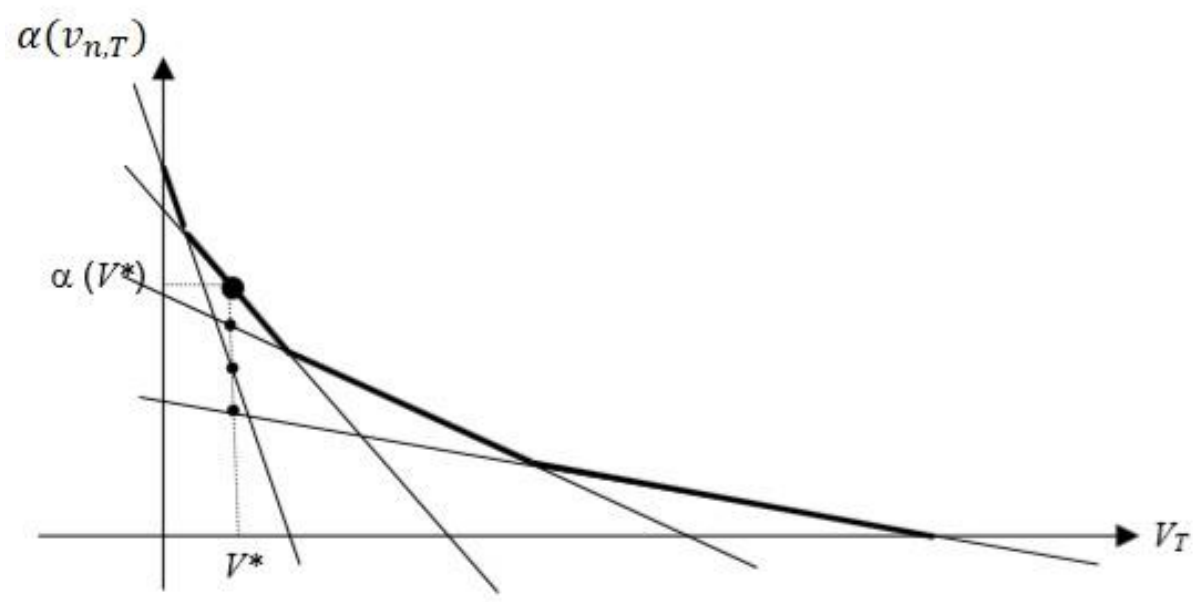

Figura 1: Função de Custo Futuro

A FCF (2.2) é formada por $K$ retas, cortes da função, com seus respectivos coeficientes angular $A_{n, k}$ e termo independente $B_{n, k}$ para cada reservatório hidráulico $n$. O resultado de $\alpha$ é dado em Reais em função dos níveis de armazenamento, volume $v_{n, T}$ em $h m^{3}$, nos aproveitamentos hidráulicos.

$$
\alpha \geq{ }_{n=1}^{* N} A_{n, k} v_{n, T}+B_{n, k} ; \forall k \in K
$$

Desta forma podemos representar como impacto do desestoque de água no presente afeta o custo no futuro. Dadas as incertezas das afluências aos reservatórios, quanto de água deve ser gasto, ou não, no presente, de forma que, além de se garantir o atendimento à demanda no futuro, minimize o custo de operação total.

\section{2}

\section{Restrições Energéticas}

As restrições energéticas, que serão apresentadas nesta seção, buscam atender o despacho de energia e atendimento à demanda. Para tanto são modeladas as restrições de balanço energético, estado das unidades geradoras, 
restrições físicas de UGs, função de produção das usinas hidráulicas e restrições físicas dos reservatórios hidráulicos.

\subsection{1}

\section{Restrição de Balanço Energético}

A restrição de balanço de energia (2.3), garante o atendimento a previsão de demanda em cada período $t$. O somatório dos despachos de geração de cada UG térmica $i$ e hidráulica $j$ em cada estágio deve ser igual a demanda $d_{t}$.

$$
g_{i, t}^{T}+\underset{j \in J}{-} g_{j, t}^{H}=d_{t} ; \forall t \in T
$$

A demanda considerada na metodologia é a carga liquida, resultante da previsão da carga global e deduzida a parcela atendida pela geração das usinas não simuladas individualmente. Esta previsão de demanda é distribuída de forma espacial entre as barras correspondente as respectivas áreas elétricas do caso base de fluxo de potência no processo de verificação da rede elétrica.

\subsection{2}

\section{Restrições Físicas das Unidades Geradoras}

As características físicas operativas das unidades geradoras, seja térmica ou hidráulica, apresentam impactos relevantes à operação do sistema. A decisão da utilização do recurso de uma determinada unidade geradora, acarreta em atendimento de restrições, a rampa de tomada de carga até pelo menos a potência minima ou, uma vez sincronizada, a restrição de tempo mínimo de permanência ligado. Tais restrições são exemplos de aspectos físicos das UGs, equipamentos mecânicos de alta complexidade, onde o não atendimento pode levar a um aumento dos custos de manutenções e tempo de indisponibilidade das máquinas.

O primeiro conjunto de restrições monitora o estado, ligado ou desligado, das unidades geradoras, bem como os momentos de parada e partida. São apresentadas a seguir:

1. Unidades Geradoras Térmicas

$$
\begin{gathered}
s_{i, t}, w_{i, t} \geq 0 ; \forall i \in I, \forall t \in T \\
w_{i, t} \leq u_{i, t-1} ; \forall i \in I, \forall t \in T \\
s_{i, t} \leq 1-u_{i, t-1} ; \forall i \in I, \forall t \in T \\
s_{i, t}-w_{i, t}=u_{i, t}-u_{i, t-1} ; \forall i \in I, \forall t \in T
\end{gathered}
$$


onde:

- $u_{i, t}$ é a variável binária para o estado da unidade térmica $i$ no instante $t, 1$ para ligado e 0 para desligado;

- $s_{i, t}$ é a variável para o acionamento da unidade térmica i no instante $t, 1$ quando for acionada e 0 caso não seja acionada;

- $w_{i, t}$ é a variável para desligamento da unidade térmica $i$ no instante $t, 1$ quando for desligada e 0 para os demais casos.

2. Unidades Geradoras Hidráulicas

$$
\begin{gathered}
y_{j, t}, z_{j, t} \geq 0 ; \forall j \in J, \forall t \in T \\
z_{j, t} \leq x_{j, t-1} ; \forall j \in J, \forall t \in T \\
y_{j, t} \leq 1-x_{j, t-1} ; \forall j \in J, \forall t \in T \\
y_{j, t}-z_{j, t}=x_{j, t}-x_{j, t-1} ; \forall j \in J, \forall t \in T
\end{gathered}
$$

onde:

- $x_{j, t}$ é a variável binária para o estado da unidade hidráulica $j$ no instante $t, 1$ para ligado e 0 para desligado;

- $y_{j, t}$ é a variável para o acionamento da unidade hidráulica $j$ no instante $t, 1$ quando for acionada e 0 caso não seja acionada;

- $z_{j, t}$ é a variável para desligamento da unidade hidráulica $j$ no instante $t, 1$ quando for desligada e 0 para os demais casos.

O problema de comprometimento de unidades geradoras é altamente influenciado pela quantidade de variáveis inteiras, neste caso binárias, que acarreta em aumento no tempo de processamento na busca da solução. A fim de reduzir o número de variáveis binárias as equações 2.4 a 2.11 permitem que as variáveis que marcam o momento de acionamento e desligamento das UG's sejam representadas como contínuas. Em outras palavras, a formulação 


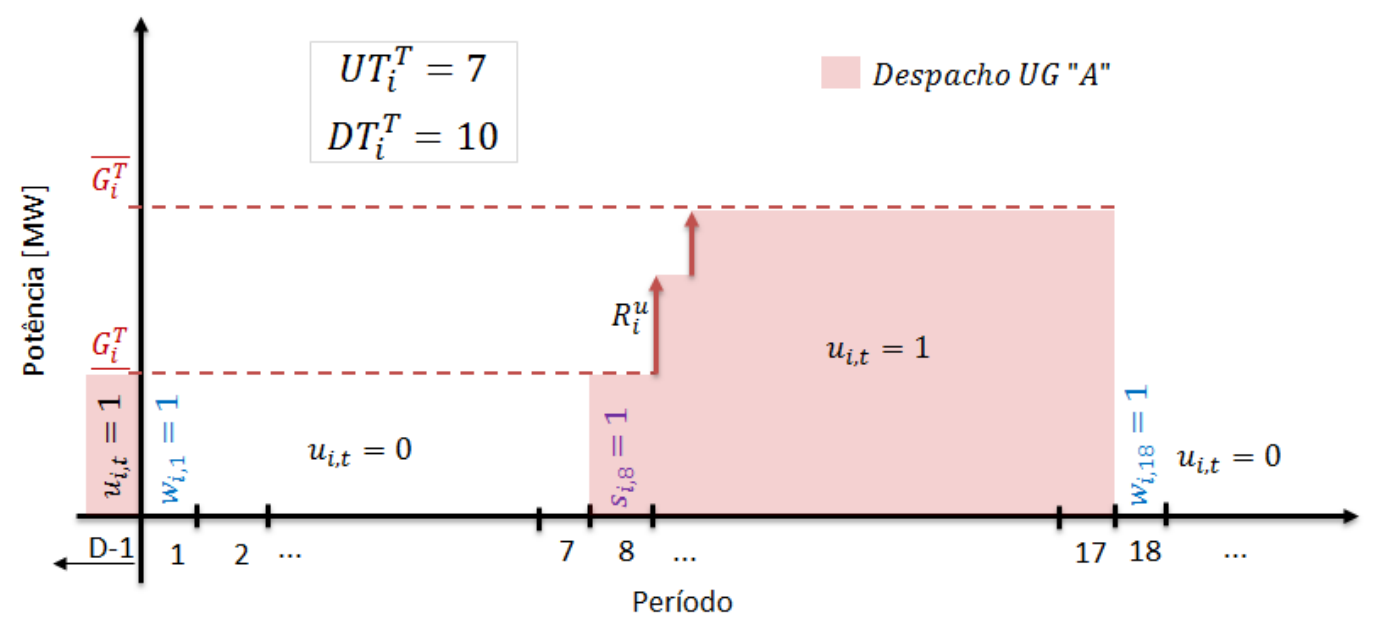

Figura 2: Representação do Despacho para atendimento a restrições físicas

garante que todas as soluções possíveis para variáveis sejam binárias, mesmo que sejam modeladas como contínuas [14].

Seguindo as características físicas das unidades geradoras, as restrições de faixa operativa, alivio e tomada de carga são apresentadas de 2.12 a 2.17. O comportamento dessas restrições podem ser ilustradas pela figura 2 .

1. Unidades Geradoras Térmicas

$$
\begin{aligned}
& \underline{G_{i}^{T}} u_{i, t} \leq g_{i, t}^{T} \leq \overline{G_{i}^{T}} u_{i, t} ; \forall i \in I, \forall t \in T \\
& g_{i, t}^{T}-g_{i, t-1}^{T} \leq R_{i}^{u p} u_{i, t} \bar{G}_{i}^{T} s_{i, t} ; \forall i \in I, \forall t \in T \\
& g_{i, t-1}^{T}-g_{i, t}^{T} \leq R_{i}^{d} n u_{i, t} \overline{G_{i}^{T}} w_{i, t} ; \forall i \in I, \forall t \in T
\end{aligned}
$$

onde:

- $\overline{G_{i}^{T}}$ é a potência máxima em MW da unidade térmica $\dot{i}$;

- $\underline{G}_{i}^{T}$ é a potência mínima em MW da unidade térmica $i$;

- $R_{i}^{u p}$ é a rampa de subida dado a maior taxa de variação para a unidade térmica $i$

- $R_{i}^{d} n$ é a rampa de descida dado a maior taxa de variação para a unidade térmica $i$. 
2. Unidades Geradoras Hidráulicas

$$
\begin{gathered}
\underline{G_{j}^{H}} x_{j, t} \leq g_{j, t}^{H} \leq \overline{G_{j}^{H}} x_{j, t} ; \forall j \in J, \forall t \in T \\
g_{j, t}^{H}-g_{j, t-1}^{H} \leq R_{j} x_{j, t} \overline{G_{j}^{H}} y_{j, t} ; \forall j \in J, \forall t \in T \\
g_{j, t-1}^{H}-g_{j, t}^{H} \leq R_{j} x_{j, t} \overline{G_{j}^{H}} z_{j, t} ; \forall j \in J, \forall t \in T
\end{gathered}
$$

onde:

- $\overline{G_{j}^{H}}$ é a potência máxima em MW da unidade hidráulica $j$;

- $\underline{G_{j}^{H}}$ é a potência mínima em MW da unidade hidráulica $j$;

- $R_{j}$ é a rampa de subida ou descida dado a maior taxa de variação para a unidade hidráulica $j$.

Com os parâmetros até aqui apresentados, podemos estabelecer o comprometimento das unidades geradoras. Porém um comportamento altamente indesejado e que pode acarretar desgastes significativos nas UGs é a operação conhecida como "liga e desliga", ou seja, em um dado período o modelo toma a decisão de sincronizar uma determinada unidade e no instante seguinte efetua seu desligamento. As restrições de 2.18 a 2.29 monitoram os tempos mínimos de permanência em cada estado, ligado ou desligado. Tal comportamento também pode ser observado na figura 2 .

Ao monitorar os tempos mínimos de permanência ligado ou desligado, podemos encontrar 3 situações. Primeiro caso, a unidade começa o estudo ainda precisando cumprir o tempo mínimo de permanência ligado ou desligado, nesta situação as restrições $2.18,2.21,2.24$ e 2.27, garantem que a unidade permaneça neste estado até o fim do tempo mínimo restante. No segundo caso, as restrições 2.19, 2.22, 2.25 e 2.28, asseguram o tempo mínimo dentro do horizonte do estudo, caso o modelo decida, em algum instante do estudo, ligar ou desligar uma UG. No último caso o modelo decide o estado da unidade e o tempo mínimo de permanecia invade períodos posteriores ao de interesse, este caso é atendido pelas restrições 2.20, 2.23, 2.26 e 2.29. Como exemplo ilustrativo, as restrições de tempo mínimo ligado são apresentadas na figura 3.

1. Unidades Geradoras Térmicas

$$
{ }_{t=1}^{\boldsymbol{G}_{i}^{T}} 1-u_{i, t}=0 ; \forall i \in I
$$


Capítulo 2. Formulação do Problema para o Programa Diário da Operação 24

$\rightarrow$ Situação 1

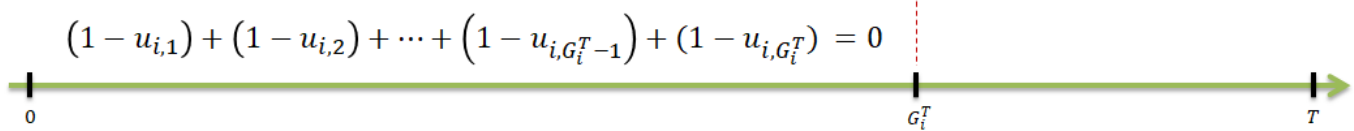

$\rightarrow$ Situação 2

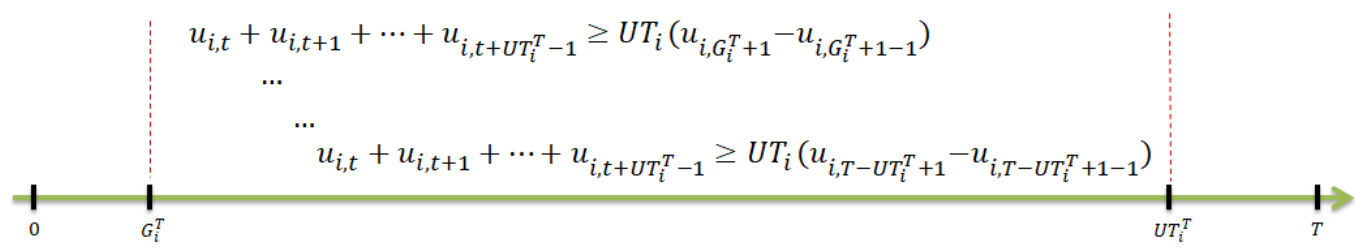

$\rightarrow$ Situação 3

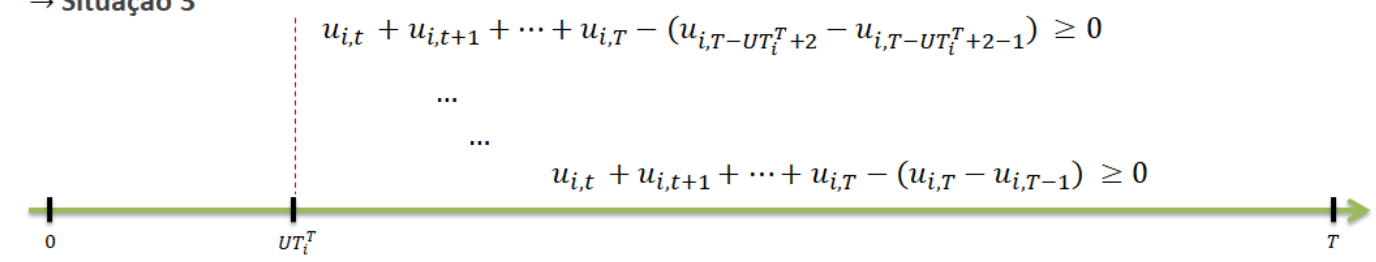

Figura 3: Exemplo de garantia do Tempo Mínimo de Permanência Ligado

$$
\begin{aligned}
& \quad \forall t=T-U T_{i}^{T}+2 \ldots T \\
& \boldsymbol{L}_{i}^{T} u_{i, t}=0 ; \forall i \in I
\end{aligned}
$$

$$
\begin{aligned}
{ }_{p=t}^{t+D \mathcal{L}^{T}-1} 1-u_{i, p} \geq D T_{i}^{T}\left(u_{i, t-1}-u_{i, t}\right) & ; \forall i \in I, \\
& \forall t=L_{i}^{T}+1 \ldots T-D T_{i}^{T}+1
\end{aligned}
$$

onde:

$$
\begin{aligned}
\underset{p=t}{T} 1-u_{i, p}-\left(u_{i, t-1}-u_{i, t}\right) \geq 0 ; & \forall i \in I, \\
\forall t & =T-D T_{i}^{T}+2 \ldots T
\end{aligned}
$$


Capítulo 2. Formulação do Problema para o Programa Diário da Operação 25

- $G_{i}^{T}$ é o tempo restante para cumprir o tempo mínimo ligado da unidade térmica $i$;

- UT $T_{i}^{T}$ é o tempo mínimo ligado unidade térmica $i$;

- $L_{i}^{T}$ é o tempo restante para cumprir o tempo mínimo desligado da unidade térmica $i$;

- $D T_{i}$ é o tempo mínimo desligado unidade térmica $i$.

2. Unidades Geradoras Hidráulicas

$$
{ }_{t=1}^{G_{j}^{H}} 1-u_{j, t}=0 ; \forall j \in J
$$

$$
\begin{gathered}
{ }_{p=t}^{t+U T_{\boldsymbol{H}}^{H-1}} u_{j, p} \geq U T_{j}^{H}\left(u_{j, t}-u_{j, t-1}\right) ; \forall j \in J, \\
\forall t=G_{j}^{H}+1 \ldots T-U T_{j}^{H}+1 \\
\underset{p=t}{++1, u_{j, p}-\left(u_{j, t}-u_{j, t-1}\right) \geq 0 ; \forall j \in J,} \\
\qquad t=T-U T_{j}^{H}+2 \ldots T \\
L_{j=1}^{H} u_{j, t}=0 ; \forall j \in J
\end{gathered}
$$

$$
\begin{aligned}
{ }_{p=t}^{t+D \zeta_{j}^{H}-1} 1-u_{j, p} \geq D T_{j}^{H}\left(u_{j, t-1}-u_{j, t}\right) ; \forall i \in I, & \\
& \forall t=L_{j}^{H}+1 \ldots T-D T_{j}^{H}+1
\end{aligned}
$$

$$
\underset{p=t}{F} 1-u_{j, p}-\left(u_{j, t-1}-u_{j, t}\right) \geq 0 ; \forall j \in J,
$$

$$
\forall t=T-D T_{j}^{H}+2 \ldots T
$$

onde:

- $G_{j}^{H}$ é o tempo restante para cumprir o tempo minimo ligado da unidade hidráulica $j$; 
- UT, é o tempo mínimo ligado unidade hidráulica j;

- $L_{j}^{H}$ é o tempo restante para cumprir o tempo mínimo desligado da unidade hidráulica $j$;

- $D T_{j}$ é o tempo mínimo desligado unidade hidráulica $j$.

As restrições de unit commmitment representam o comportamento das unidades geradoras, seja térmica ou hidráulica. Tais restrições aproximam as decisões na etapa de programação ao que acontece na operação. Uma vez capturada no modelo de programação, tais restrições estarão refletidas no custo da operação mais próximas as ações de tempo real.

\subsection{3}

\section{Restrições das Usinas Hidráulicas}

Na seção 2.2.2 descrevemos a representação das características físicas das unidades geradoras térmicas e hidráulicas. As usinas hidráulicas são compostas por casas de máquinas com suas respectivas unidades geradoras que compartilham o mesmo reservatório de armazenamento. Neste tópico serão apresentadas as restrições hidráulicas e na subseção 2.2.4 veremos o acoplamento com as unidades geradoras hidráulicas. A restrição 2.30 representa o comportamento do volume armazenado em cada aproveitamento hidráulico $n$.

O volume no estágio $t$ é composto pelo volume no estágio anterior, $t-1$, somado a previsão de vazão afluência lateral, menos a vazão turbinada $q_{n, t}$, vazão vertida $s_{n, t}$ e a vazão desviada $d v_{n, t}$, caso exista desvio deste reservatório. Compondo ainda o volume no estágio $t$ é somado as defluências totais dos reservatórios à montante $m$ do aproveitamento em questão. Esta defluência total pode estar defasada, ou não, de $T$, em outras palavras, o tempo de viagem da água de um reservatório a outro. Existem ainda, defasagens que estão dentro do horizonte de estudo, que a decisão de turbinar de uma usina à montante afeta o reservatório de jusante ainda dentro dos períodos em estudo, e estão representadas no primeiro conjunto de somatórios. Há defasagens que a decisão da defluência foi tomada anteriormente ao estudo, como por exemplo o tempo de viagem de 15 dias entre a Usina de Três Marias e a Usina de Sobradinho, no rio São Francisco, que é representada no segundo conjunto de somatórios. A última parcela da restrição de balanço hídrico corresponde ao recebimento de água por desvio de outra usina, caso exista. A figura 4 exemplifica os termos que compõem o armazenamento dos reservatórios. 


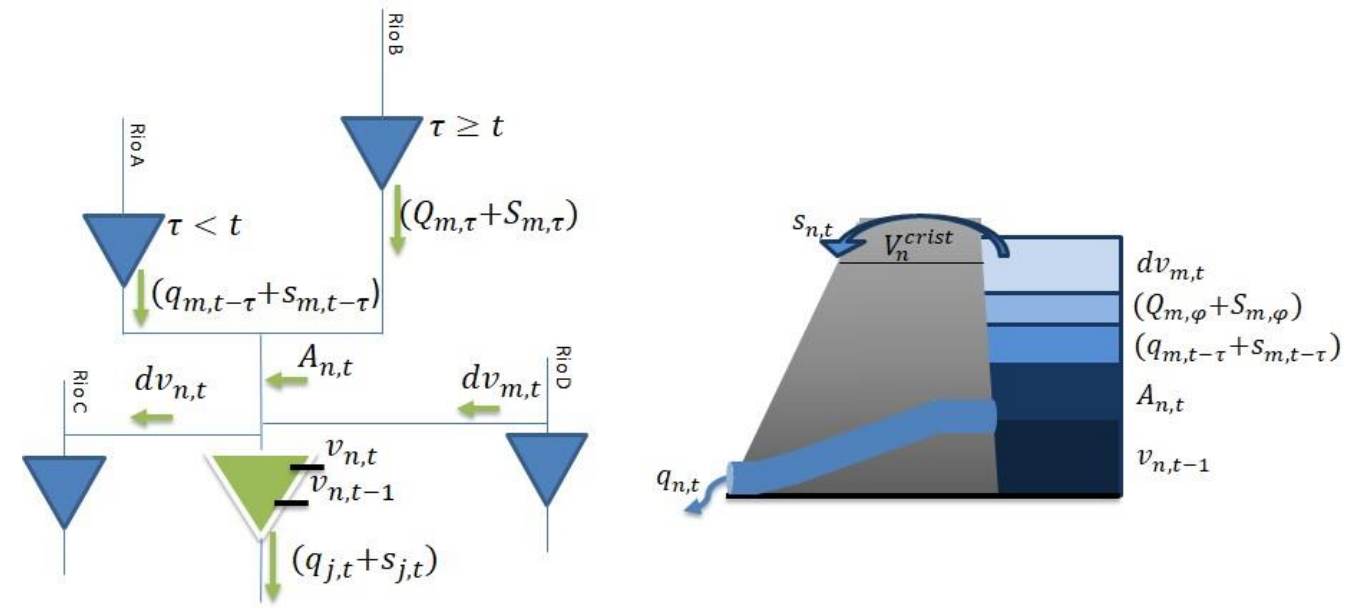

Figura 4: Composição dos armazenamento aos reservatórios $n$ no período $t$

$$
\begin{aligned}
v_{n, t} & =v_{n, t-1}+A_{n, t}-\left(q_{n, t}+s_{n, t}+d v_{n, t}\right)+ \\
& +{ }_{t=0}^{t=1}-\underbrace{}_{m \in M_{T}}\left(q_{m, t-\tau}+s_{m, t-\tau}\right)+\underbrace{}_{T=t m \in M_{T}}\left(Q_{m, t-\tau}+S_{m, t-\tau}\right)+ \\
& +\underset{m \in M_{d V} v}{d v_{m}}, t ; \forall n \in N, \forall t \in T
\end{aligned}
$$

Outras características dos reservatórios hidráulicos podem ser representados pelas restrições $2.31,2.32$ e 2.33. Estas restrições modelam os limites físicos de volume máximo e mínimo, volume de espera e desvio máximo e mínimo.

$$
\begin{gathered}
\underline{V_{n, t}} \leq v_{n, t} \leq \overline{V_{n, t}} ; \forall n \in N, \forall t \in T \\
v_{n, t} \leq V_{n}^{\text {espera. }} ; \forall n \in N, \forall t \in T \\
\underline{D v_{n}} \leq d n_{n, t} \leq \overline{D v_{n}} ; \forall n \in N, \forall t \in T
\end{gathered}
$$

onde:

- $\underline{V}_{\underline{n}}$ é o volume mínimo físico da usina hidráulica $n$;

- $\overline{V_{n}}$ é o volume máximo físico da usina hidráulica $n$;

- $V_{n}^{\text {espera }}$ é o volume de espera para a usina hidráulica $n$;

- $\underline{D} \underline{v}_{n}$ é o desvio mínimo da usina hidráulica $n$; 


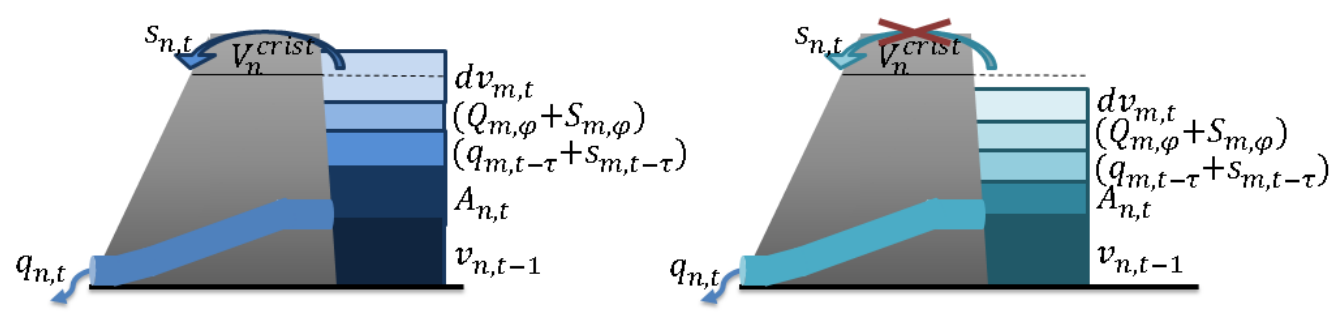

a) Operação de vertimento habilitada b) Operação de vertimento desabilitada

Figura 5: Habilitação para operação de vertimento

- $\overline{D v_{n}}$ é o desvio máximo da usina hidráulica $n$;

Ainda buscando a melhor representação das usinas hidráulicas, as restrições apresentadas em 2.34 a 2.36 capturam a possibilidade de vertimento ou não da usina. Algumas restrições como, defluência mínima e de operação energética para aumentar os recursos energéticos de uma usina de jusante, são atendidas com vertimentos e não necessariamente os reservatórios estão em sua capacidade máxima de armazenamento. O vertedouro está habilitado para operação uma vez que o nível do reservatório está a cima da crista do vertedouro, as duas situações apresentadas na figura 5 mostram esse comportamento.

$$
\begin{aligned}
& s_{n, t} \leq v_{n, t-1}+A_{n, t}-\left(q_{n, t}\right)+ \\
& +{ }_{\tau=0}^{t=1}\left(q_{m, t-\tau}+s_{m, t-\tau}\right)+{ }_{\tau=t m \in M_{T}}^{\bar{T}}\left(Q_{m, t-\tau}+S_{m, t-\tau}\right)+
\end{aligned}
$$

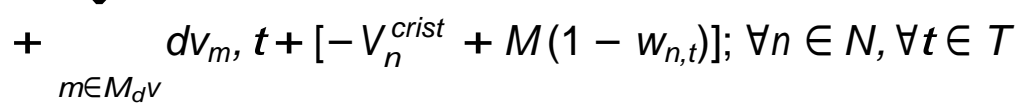

$$
\begin{aligned}
& v_{n, t-1}+A_{n, t}-\left(q_{n, t}\right)+ \\
& +{ }_{\tau=0}^{=1}-\left(q_{m, t-\tau}+s_{m, t-\tau}\right)+{ }_{T=t m \in M_{T}}^{-}\left(Q_{m, t-\tau}+S_{m, t-\tau}\right)+
\end{aligned}
$$

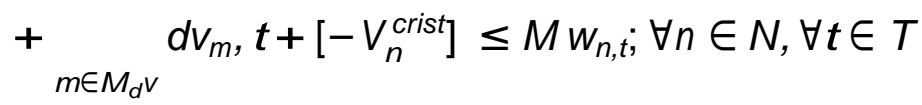

$$
\begin{aligned}
& s_{n, t} \leq \bar{S}_{n, t} w_{n, t} ; \forall n \in N, \forall t \in T
\end{aligned}
$$

onde:

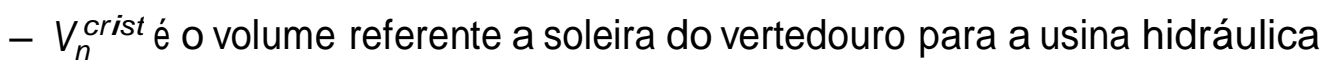
$n$; 
- $w_{n, t}$ é a variável binária para ativação da operação do vertedouro da usina hidráulica $n, 1$ habilitado e 0 desabilitado.

- $M$ é um número muito grande "Big number".

A estratégia utilizada para modelar a operação do vertedouro consiste em habilitar ou desabilitar o vertimento. Para habilitar, a variável $w_{n, t}$ fica igual a 1 e a restrição 2.35 fica relaxada, ou seja, o lado direito $M w_{n, t}$ é igual a um valo muito grande. Para desabilitar,a variável $w_{n, t}$ fica igual a 0 , a restrição 2.34 fica relaxada pois o termo $M\left(1-w_{n, t}\right)$ é igual a um valor muito grande e a restrição 2.36 garante que $s_{n, t}$ seja igual a 0 .

\subsection{4}

\section{Função de Produção Hidráulica Aproximada - FPHA}

A geração de energia elétrica de uma usina hidrelétrica depende, além das características de projeto do aproveitamento, de parâmetros como altura de queda líquida, volume armazenado, vazão turbinada, vazão vertida e rendimento das unidades geradoras, compondo assim uma função não linear. Neste trabalho, tal função será modelada como uma função linear por partes, que formam planos através de triangulações com os pontos obtidos em função do volume armazenado e, por simplificação, vazão turbinada [17], [16].

Com a modelagem proposta neste trabalho, a função de produção da usina hidráulica é acopla as respectivas unidades geradoras. Desta forma o somatório de geração das UGs da usina $n$ fica conforme equação 2.37.

$$
\underset{j \in J_{n}}{g_{j, t}^{H}}=\boldsymbol{f}_{n}\left(v_{n, t}, v_{n, t+1}, q_{n, t}\right)
$$

A função é construída a partir da expressão 2.38, onde é calculada a geração da usina pela multiplicação da produtibilidade específica $\rho_{n}$ com a vazão turbinada $Q_{n}$, vezes a altura de queda liquida, composta pela diferença entre altura de montante $H_{n}^{\text {mont }}$, altura de jusante $H_{n}^{\text {jus }}$ e perdas $H_{n}^{\text {perda }}$. A altura de montante é obtida pela utilização do polinômio cota x volume, equação 2.39, a altura de jusante é pelo polinômio de jusante, equação 2.40, e de posse destes valores podemos obter pontos da função para valores fixos do volume (um ponto para usinas a fio d'água e 2 pontos para reservatório) e variando a vazão turbinada da usina do zero ao máximo (5 pontos). Desta forma a construção da envoltória da Função de Produção Hidráulica Aproximada para usinas a fio d'água e reservatório é apresentada na figura 6 (a) e (b), respectivamente. 


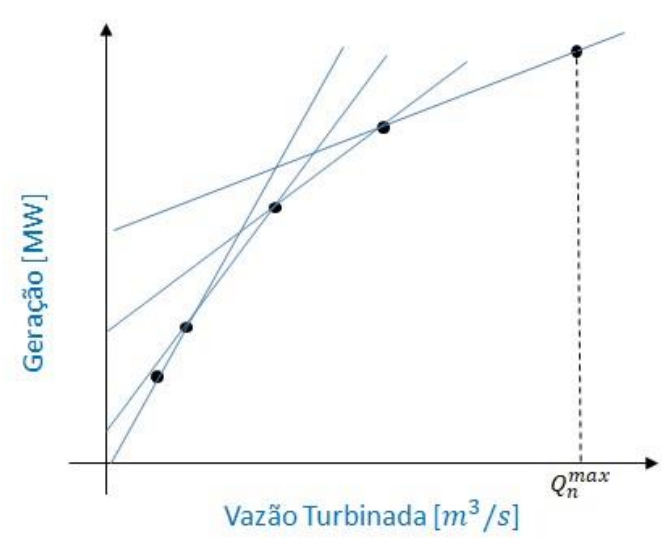

a) Volume Fixo

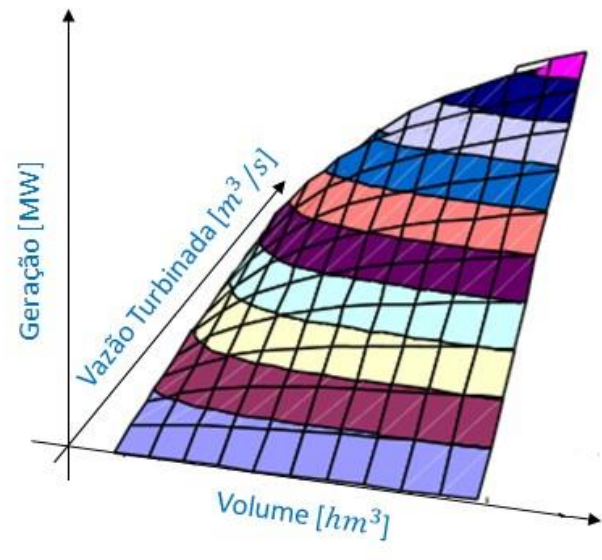

b) Variando o Volume

Figura 6: Função de Produção Hidráulica Aproximada

$$
\begin{gathered}
G H_{n}=\rho_{n} Q_{n}\left(H_{n}^{\text {mont }}-H_{n}^{\text {mont }}-H_{n}^{\text {perda }}\right) \\
H_{n}^{\text {mont }}=A_{n}+A_{n}^{\prime} V_{n}+A_{n}^{\prime \prime} V_{n}^{2}+A_{n}^{\prime \prime \prime} V_{n}^{3}+A_{n}^{\prime V} V_{n}^{4} \\
H_{n}^{j u s}=B_{n}+B_{n}^{\prime} Q_{n}+B_{n}^{\prime \prime} Q_{n}^{2}+B_{n}^{\prime \prime \prime} Q_{n}^{3}+B_{n}^{\prime V} Q_{n}^{4}
\end{gathered}
$$

onde:

- $A_{n}, A_{n}^{\prime}, A_{n}^{\prime \prime}, A_{n}^{\prime \prime \prime}, A_{n}^{\prime V}$ são os coeficientes do polinômio cota x volume do reservatório $n$;

- $B_{n}, B_{n}^{\prime}, B_{n}^{\prime \prime}, B_{n}^{\prime \prime \prime}, B_{n}^{\prime V}$ são os coeficientes do polinômio de jusante da usina $n$;

- $V_{n}$ é o volume da usina $n$;

- $Q_{n}$ é a vazão turbinada da usina $n$.

onde:

$$
{ }_{j \in J_{n}} g_{j, t}^{H} \leq \delta_{n, p}^{i n d}+\delta_{n, p}^{v}\left(\frac{v_{n, t-1}+v_{n, t}}{2}\right)+\delta_{n, p}^{q}
$$


- $\delta_{n, p}^{\text {ind }}$ é o coeficiente independente da função para o reservatório $n$ no corte $p$;

- $\delta_{n, p}^{v}$ é o coeficiente da função relativo ao volume para o reservatório $n$ no corte $p$;

- $\delta_{n, p}^{q}$ é o coeficiente independente da função relativo a vazão turbinada para a usina $n$ no corte $p$.

Do ponto de vista prático quanto as variações dos reservatórios hidráulicos a fio d'água e reservatório ao longo de 24 horas, a função é construída em torno do volume de partida, ou seja, as zeros horas do dia em análise. Desta forma os coeficientes da função são obtidas e a geração é apresentada na equação 2.41 .

\section{3}

\section{Restrições de Contingência de Unidades Geradoras}

A fim de atender o critério de segurança para perda de $K^{G}$ unidades geradoras e conseguente alocação de reserva de potência operativa, as expressões 2.42 a 2.46, garantem que para perda de unidades geradoras, obedecendo o critério de segurança $N-K^{G}$, as remanescentes no pós-contingência sejam capaz de suprir potência. $O$ detalhamento para tal problema pode ser observada no Apêndice B e [13]. Desta forma a formulação adotada não atende o ponto operativo no pós-contingência sob o ponto de vista das restrições de rede, que será apresentado na seção 2.4 .

$$
\begin{gathered}
V_{t}-E_{i, t} \leq g_{i, t}^{T}+r_{i, t}^{T_{u p}} ; \forall i \in I, \forall t \in T \\
r_{i, t}^{T_{u p}} \leq R_{i}^{u p} u_{i, t} ; \forall i \in I, \forall t \in T \\
\left(|/|+|J|-K^{G}\right) \gamma_{t}-{ }_{i \in I} E_{i, t}=d_{t} ; \forall i \in I, \forall t \in T \\
V_{t} \geq 0 ; \forall t \in T \\
E_{i, t} \geq 0 ; \forall i \in I, \forall t \in T
\end{gathered}
$$

onde: 
- $\gamma_{t}$ é a variável dual associada à restrições de segurança de geração em cada período $t$;

- $E_{i, t}$ é a variável dual associada ao limite superior de geração da unidade i sob o critério de segurança de geração.

Neste modelo, o limite para alocação de reserva em um determinado período $t$ é limitada pela máxima rampa de subida da unidade geradora. Essa é a rampa de variação de potência do gerador no intervalo de 30 minutos.

\section{4}

\section{Representação das Restrições da Rede de transmissão de Energia Elétrica}

Uma característica marcante no SIN é o sistema de transmissão de energia que interliga as regiões do país através de grandes troncos, compostos por linhas e trasnformadores. Esses equipamentos possibilitam o escoamento de energia de usinas que estão afastadas dos grandes centros de carga. Embora possibilite o beneficio de transferência de excedentes energéticos entre regiões, elas possuem um limite máximo de transporte de energia elétrica.

O conjunto de restrições energéticas estabelece, juntamente com as de contingência de unidades geradoras, os despachos de geração e alocação de reserva. A viabilidade do ponto de vista da rede se dá através da execução de um Fluxo de Potência Linearizado - FPL, [19], onde é verificado a existência de sobrecargas em circuitos. Uma vez identificado o circuito violado a restrição 2.47 é criada obtendo a matriz de sensibilidade $\beta, \ldots$

$$
-F_{I} \leq \sum_{n=1}^{\Lambda_{\text {tous }}} \beta_{l, n, c}\left[\left({\underset{i \in \text { lous }}{-}}_{g_{i, t}^{T}+}^{-} g_{j \in J_{\text {bus }}}^{-} g_{j, t}^{H}\right)-d_{\text {bus }, t}\right] \leq F_{;} ; \forall I \in L, \forall c \in C, \forall t \in T
$$

onde:

- $F_{l}$ é a capacidade de transmissão do equipamento de transmissão de energia $l$;

- $\beta_{l, n, c}$ é o fator de sensibilidade da injeção de potência na barra $n$ no fluxo da linha / para a contingência $c$;

- $d_{\text {bus }, t}$ é a demanda de energia na barra. 
O fator $\beta$ de sensibilidade da rede, relaciona a injeção de potência em todas as barras do sistema com todos os circuitos. Se efetuarmos um redespacho de potência de uma determinada unidade geradora conectada a uma determinada barra, cada equipamento tem seu fluxo de potência alterado de acordo com a sensibilidade $\beta$.

Por fim neste capitulo foi apresentado a formulação do problema de unit commitment para o programa diário de geração. Foi abordado o conjunto de restrições energéticas $R_{e s t}{ }^{E n e r}$, composto pelas restrições da seção 2.2, este conjunto garante o despacho para atendimento à carga, o despacho de unidades geradoras e atendimento aos limites operativos dos reservatórios hidráulicos. $O$ segundo conjunto $\operatorname{Rest}^{K^{G}}$ modelado no tópico 2.3, aloca a reserva girante caso ocorra a contingência de $K^{G}$ unidades geradoras. $O$ último grupo de restrições, $\operatorname{Rest}^{K^{L}}$, apresentado nesta seção, representa a rede de transmissão e o critério de segurança $N-K^{L}$ elementos. 


\section{3 \\ Método de Solução}

Como apresentado na seção anterior, o modelo proposto trata-se de um problema linear com variáveis inteiras, como, por exemplo, o estado das UG's de ligado ou desligado, onde a resolução passa por um processo de otimização conhecido na literatura por Mixed Integer Linear Programming (MILP), ou, Programação Linear Inteira Mista. Tal problema é altamente influenciado pela quantidade de variáveis inteiras e a quantidade de restrições. Ao simular um sistema de grande porte como o Sistema Elétrico Brasileiro, o tempo de processamento com todas as restrições pode tornar inviável sua aplicação. Desta forma, utilizamos uma metodologia de decomposição deste problema baseada em um algoritmo de geração de restrições [18].

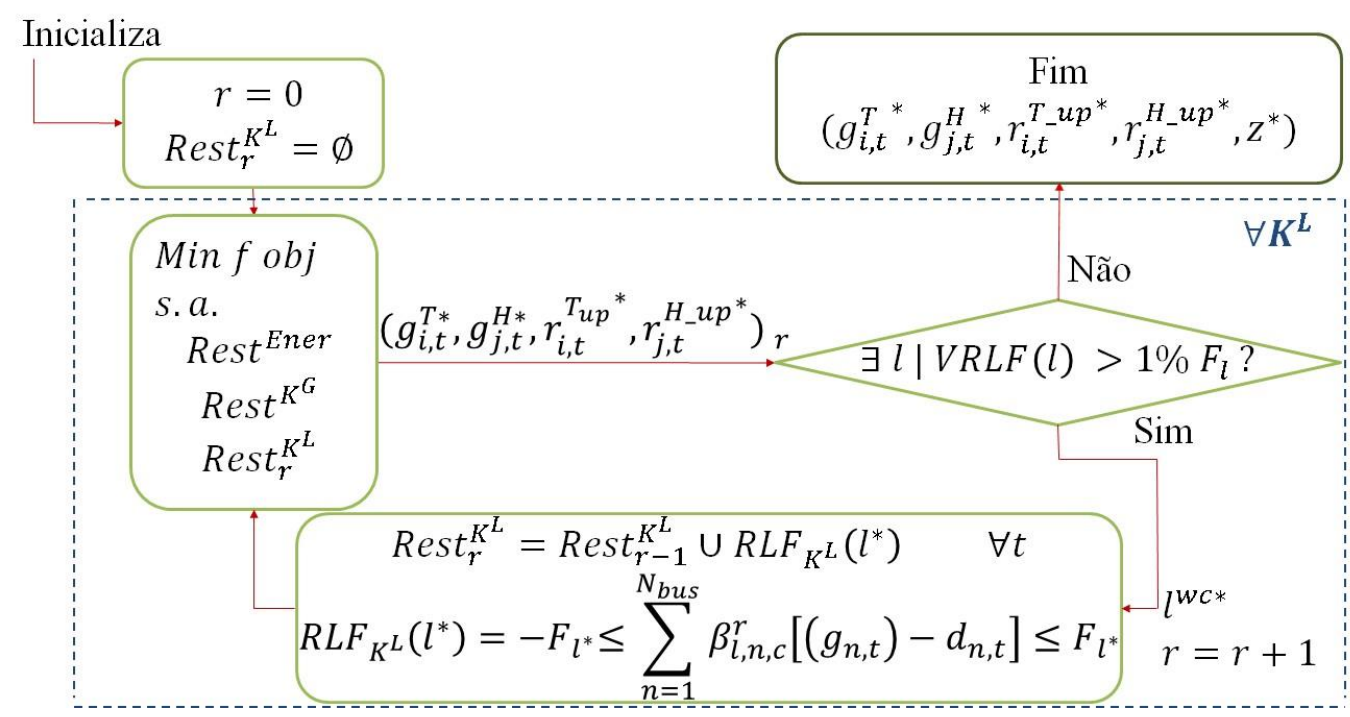

Figura 7: Algoritmo de solução para o Programa Diário de Operação

O algoritmo apresentado na figura 7 inicia com uma instância do problema original relaxada, com o conjunto de restrições de rede de transmissão vazio. Este problema passa a ter o nome de problema mestre. O contador de iterações $r$ é inicializado igual a zero. $O$ problema mestre é resolvido com o grupo de restrições energéticas e o de contingência de unidades geradoras em uma modelagem com barra infinita, [12] e [13]. No primeiro passo, a solução encontrada é um despacho ótimo de geração e reserva nas unidades geradoras 
térmicas e hidráulicas capaz de suportar apenas perdas de unidades geradoras. No segundo passo, as restrições elétricas da rede de transmissão (considerando fluxo DC neste trabalho) são verificadas para o despacho de geração obtido no primeiro passo. Essa verificação é realizada através da busca por alguma Violação de Restrição de Limite de Fluxo (VRLF) maior que $1 \%$ de sua capacidade, $F_{/}$. Caso exista um elemento de rede / com tal violação, a Restrição de Limite de Fluxo (RLF) deste equipamento é adicionado ao conjunto Rest ${ }^{K^{L}}$, o contador $r$ é incrementado e um novo ponto operativo é encontrado executando o modelo outra vez. Este processo continua até que não exista nenhuma VRLF dentro da tolerância de 1\% em nenhum estado pós-contingência.

O método de solução possibilita um número menor de restrições no problema mestre uma vez que a incorporação de restrições do tipo "pior caso", incluídas por apresentarem as piores violações, são cortes fortes (strong cuts) e, portanto, buscam descrever as restrições guarda chuva do problema (menor conjunto de restrições necessária para assegurar a solução ótima). O resultado é um despacho de energia e reservas que cumpra com o critério de segurança $N-K^{G}$, onde $K^{G}$ é o número de geradores que podem falhar, e que o ponto operativo pré-contingência do sistema seja possível de ser mantido inalterado mesmo que ocorra a perda de $K^{L}$ linhas de transmissão. Dessa forma, o critério obtido é um critério híbrido, $N-K^{G}-K^{L}$.

A fim de exemplificar o modelo e apresentar seu comportamento, foi simulado um sistema teste cujas características das unidades geradoras térmicas e hidráulicas estão apresentadas na tabela 1 e na tabela 2. O estudo inicial é formado por apenas um período a fim de auxiliar a compreensão da dinâmica das restrições e o funcionamento do método de solução.

_Tabela 1: Dados Unidades Hidráulicas Sistema teste 3 barras

\begin{tabular}{cccccccc} 
Unidades hidráulicas & $G_{j}^{H}$ & $G_{j}^{H}$ & $U T_{j}^{H}$ & $D T_{j}^{H}$ & $R_{j}$ & $C_{j}^{H}$ Uup \\
\hline hidr 1 e hidr 2 & 26 & 4.6 & 5 & 5 & 11 & $\mathrm{R} \$ 4.50$ \\
\hline
\end{tabular}

Tabela 2: Dados Unidades Térmicas Sistema teste 3 barras

\begin{tabular}{ccccccccc}
\hline Unidades & $\overline{G_{i}^{T}}$ & $G_{i}^{T}$ & $U T_{i}^{T}$ & $D T_{i}^{T}$ & $R_{i}^{u p}$ & $R_{i}^{\text {dn }}$ & $C_{i}^{\text {prod }}$ & $C_{i}^{T_{u p}}$ \\
térmicas & term 1 $^{47.6}$ & 1 & 6 & 6 & 10 & 25 & $\mathrm{R} \$ 122.64$ & $\mathrm{R} \$ 5.48$ \\
a term 8 & 47.48 &
\end{tabular}

O critério de segurança utilizado foi $K^{L}=K^{G}=1$, onde para a perda de equipamentos de transmissão deve ser considerado um valor que não leve ao isolamento de barras. As capacidades das linhas, bem como a localização das unidades geradoras estão apresentadas na figura 8 (a). 


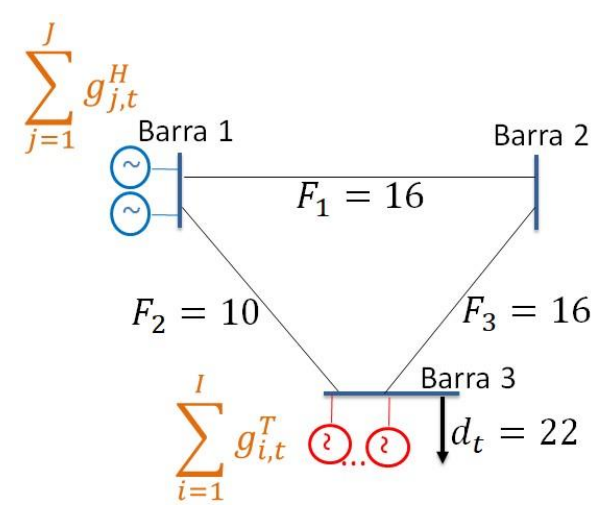

(a) Sistema teste 3 barras

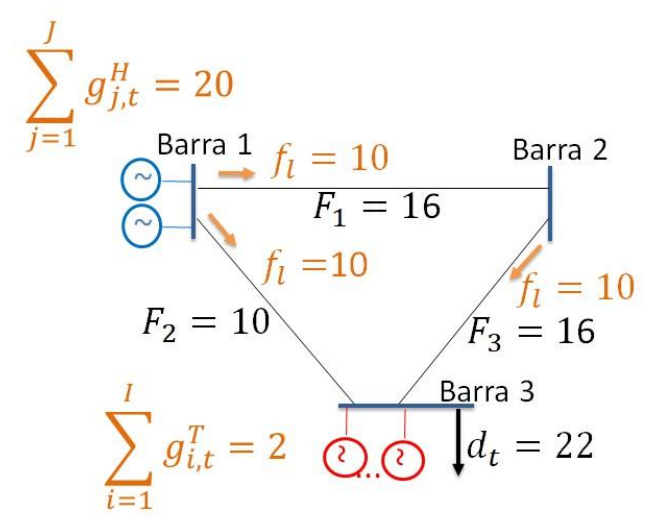

(c) Resultado iteração 1

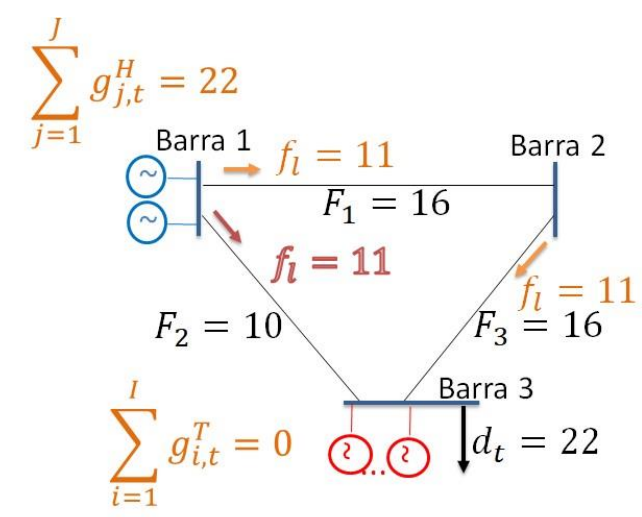

(b) Resultado iteração 0

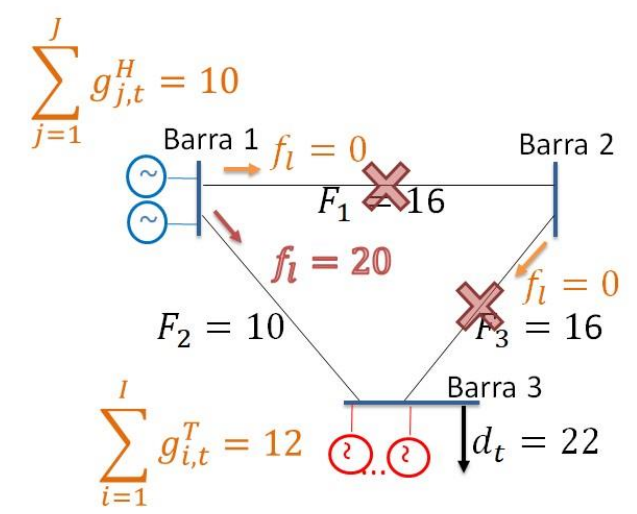

(d) Resultado no pós-contingência

Figura 8: Resultado do processo iterativo para o sistema de 3 barras

$\mathrm{O}$ caso consiste em um sistema que deve atender a carga de $22 \mathrm{MW}$ na barra 3 ao menor custo total de operação. Na interação 0 (Figura 8 (b)), a carga é totalmente atendida pelos 2 geradores hidráulicos, mais barato que os geradores térmicos, uma vez sincronizados um gerador é capaz de suportar a perda do outro e vice e versa. Dando sequência ao método, o despacho estabelecido na iteração 0 torna-se inviável do ponto de vista da rede de transmissão, neste momento $K^{L}=0$, pois viola o limite $F_{2}$ em $1 \mathrm{MW}(10 \%)$, onde a Restrição de Limite de Fluxo da linha 2, $R L F_{0}(2)$, é inserida no conjunto Rest $t_{1}^{K L}$ para a próxima iteração, $r=1$. Uma nova solução é obtida na interação 1 (Figura 8 (c)), onde os geradores térmicos são despachados em $2 \mathrm{MW}$ a fim de se eliminar a sobrecarga no circuito 2 . Uma vez eliminadas as violações para $K^{L}=0$ (caso pré-contingência), é realizada a verificação da rede para o caso de uma contingência $\left(K^{L}=1\right)$, onde $o$ despacho da iteração 1 não suporta a perda dos circuitos 1 ou 3 sem que haja violação novamente no circuito 2 (Figura 8 (d)). Uma nova Restrição de Limite de Fluxo da linha 2, $R L F_{1}(2)$, agora afim de suportar a perda de $I=1$ ou 3 , é inserida em $R e s t_{2}^{K^{L}}$ com outro valor de $\beta_{l, n, c}^{2}$, fator de sensibilidade que se modifica com a topologia da rede.

Desta forma a tabela 3 apresenta os resultados das iterações do sistema 


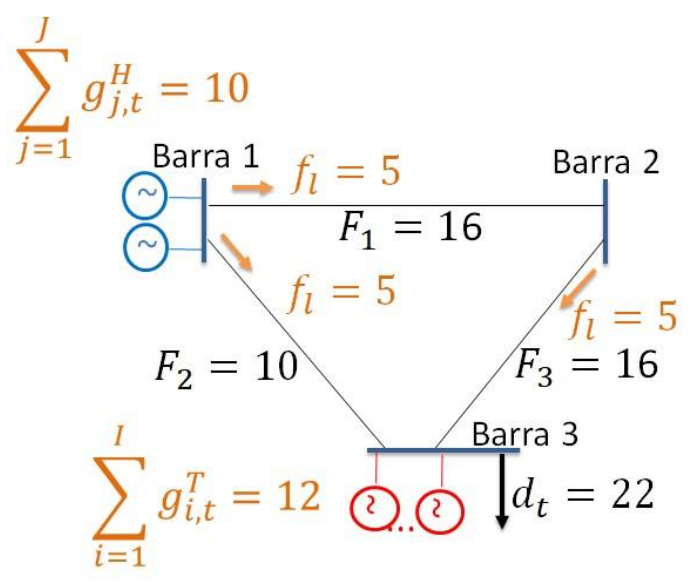

Figura 9: Ponto de operação final para o sistema de 3 barras

de 3 barras e a Figura 9 o ponto de operação final. A reserva fica alocada nas unidades térmicas despachadas, UG térmica 2 com reserva de $4 \mathrm{MW}$ e UG térmica $6 \mathrm{com} 1 \mathrm{MW}$, atendendo a restrição de rampa de $10 \mathrm{MW}$. Podemos perceber também que o sistema suporta a falha de qualquer gerador sem que ocorra violação de rede. Do ponto de vista do critério $K^{L}=1$, existe um novo fluxo na rede caso ocorra a saída intempestiva de qualquer equipamento de transmissão.

Tabela 3: Processo Iterativo do Método de Solução

\begin{tabular}{cccccccccccccc}
\hline iteração & $g_{1}^{H}$ & $g_{2}^{H}$ & $g_{1}^{T}$ & $g_{2}^{T}$ & $g_{3}^{T}$ & $g_{4}^{T}$ & $g_{5}^{T}$ & $g_{6}^{T}$ & $g_{7}^{T}$ & $g_{8}^{T}$ & $C$ & $L^{*}$ & $\begin{array}{c}\text { VRLF } \\
(\%)\end{array}$ \\
\hline 0 & 11 & 11 & 0 & 0 & 0 & 0 & 0 & 0 & 0 & 0 & 0 & 2 & 10 \\
1 & 10 & 10 & 0 & 0 & 0 & 0 & 0 & 1 & 0 & 1 & 1 & 2 & 100 \\
2 & 5 & 5 & 5 & 1 & 5 & 0 & 0 & 1 & 0 & 0 & 0 & 0 & 0 \\
\hline
\end{tabular}

Neste capítulo foi proposto o método de solução para o problema da programação do despacho e reservas para o dia seguinte. O método busca atender as restrições energéticas, restrições de contingência e restrições da rede de transmissão em um processo iterativo onde não necessariamente todas as restrições de linha precisam estar no problema. 


\section{4}

\section{Sistemas Simulados}

Nos capítulos 2 e 3 foram apresentadas as restrições utilizadas no modelo, a função objetivo de minimização do custo total de operação e como podemos usá-las para, não apenas obter a solução do problema do despacho de energia e reservas, mas como o método de geração de restrições e colunas insere as restrições de rede que compõem a região viável de solução, restrições guardachuva. Tal fato reduz significativamente o número de restrições de rede do problema. Neste capítulo serão apresentados os resultados para os sistemas teste de 3 barras e 30 barras, além do Subsistema Norte isolado. Ainda será apresentado os resultados para o Sistema Elétrico Brasileiro, sistema de grande porte, objetivo principal do presente trabalho.

Cabe destacar que para os estudos com o Subsistema Norte e o Sistema Interligado Nacional o acoplamento do custo é feito através da Função de Custo Futuro oriunda do modelo DECOMP.

\section{1}

\section{Sistema teste 3 barras}

O sistema apresentado no capítulo 3, onde para exemplificar o entendimento do algoritmo, foi simulado com apenas um intervalo de tempo. Nesta seção ampliaremos as análises deste caso de estudo teste ao horizonte da Programação Diária da Operação em intervalos semi-horários no total de 48 períodos.

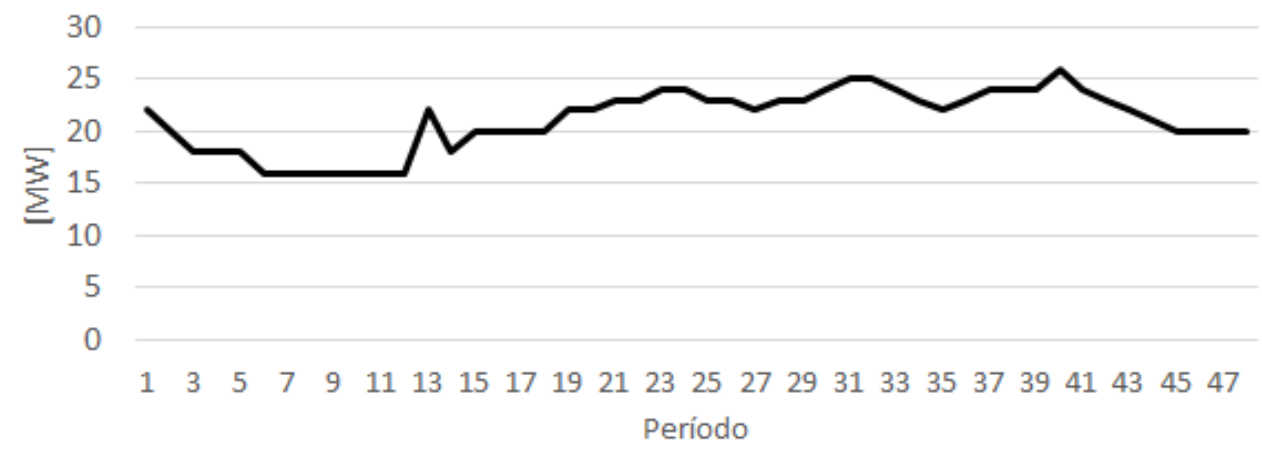

Figura 10: Curva de Carga utilizada no Sistema de 3 barras 
Os dados de entrada apresentados nas tabelas 1 e 2 , e a topologia de rede da figura 8 , continuam válidos neste estudo. Os critérios de segurança $N-K^{G}-K^{L}$ adotados foram $N-0-0, N-1-0$ e $N-1-1$ para a curva de carga da figura 10 .

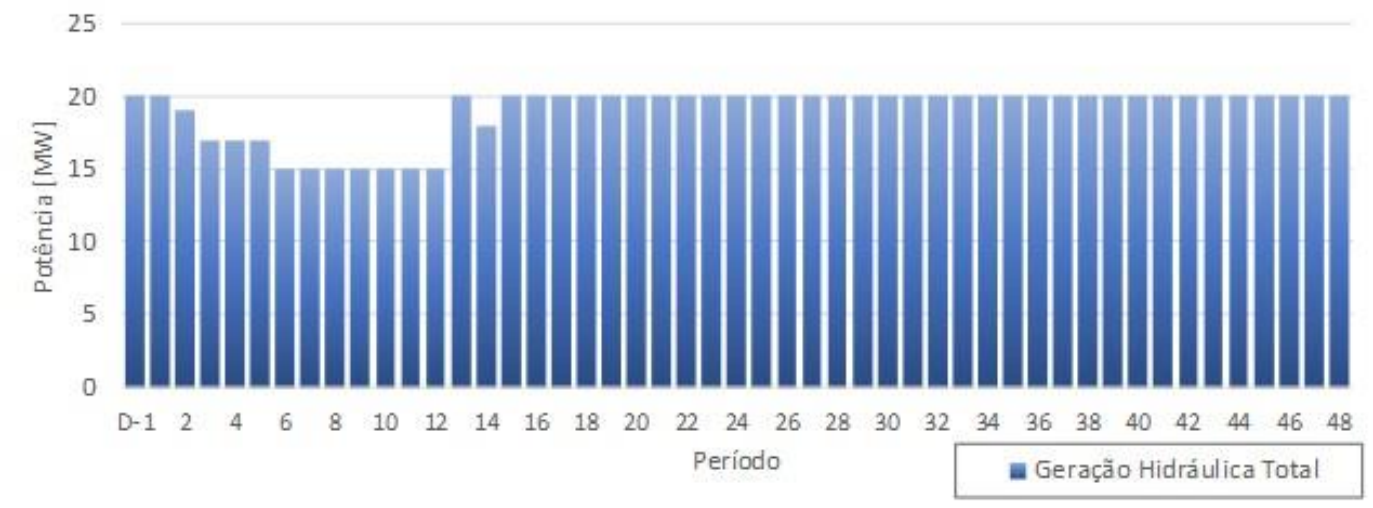

Figura 11: Resultado do despacho total hidráulico de potência - 3 barras $N-0-0$

O despacho hidráulico total apresentado na figura 11, referente primeiramente ao critério $N-0-0$, mostra a exploração dos recursos hidráulicos, fonte mais barata, até a capacidade máxima de escoamento de energia permitida pela rede, limite do circuito $2\left(F_{l}=10 \mathrm{MW}\right)$. Uma vez que as leis de Kirchhoff devem ser atendidas no fluxo de potência, o despacho das unidades hidráulicas causam uma distribuição de fluxo de energia, de modo que a linha 2 mais restritiva, impeça que este escoamento passe do valor de $20 \mathrm{MW}$.

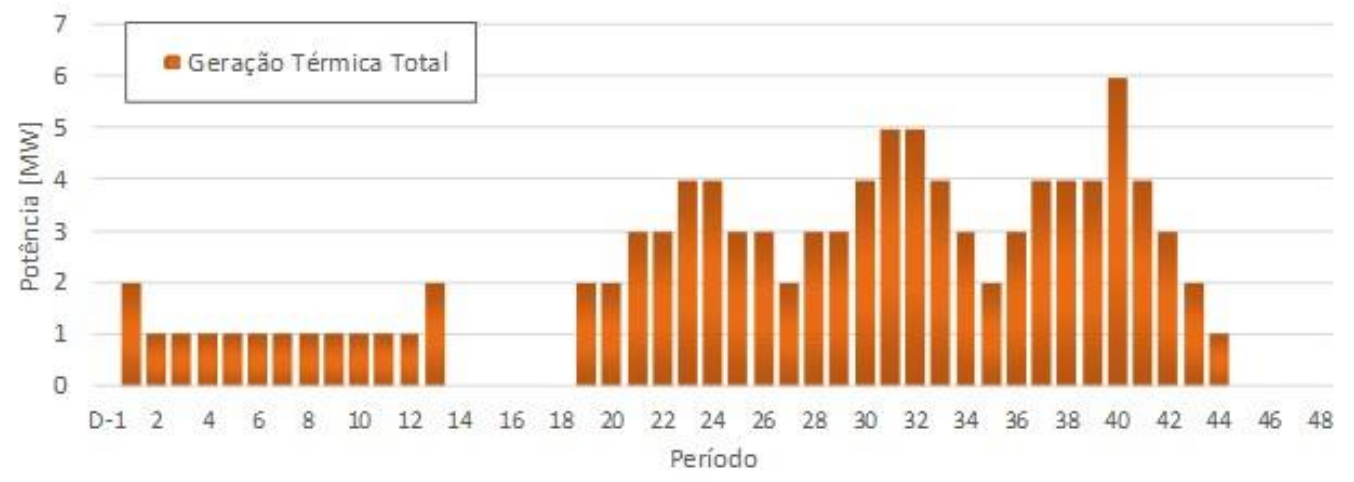

Figura 12: Resultado do despacho total térmico de potência e reservas - 3 barras $-N-0-0$

Uma vez que a geração de energia hidráulica da barra 1 está limitada pela restrição do circuito 2 , o despacho térmico localizado na barra 3 , complementa 
o atendimento à previsão de demanda. Tal fato pode ser observado na figura 12 , onde uma unidade geradora térmica é acionada logo no primeiro período, intervalo de meia-hora, e é desligada no estágio 13. Outras unidade térmica são acionadas a partir do patamar 19 até o 44. Analisando os despachos das unidades térmicas e hidráulicas, as restrições de unit commitment são respeitadas pelo modelo.

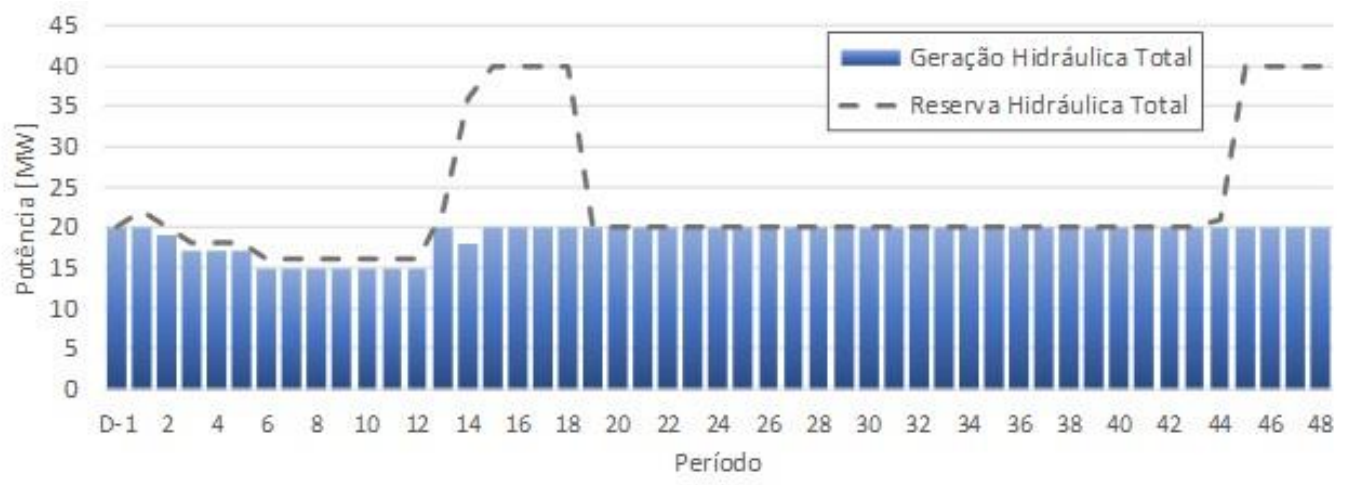

Figura 13: Resultado do despacho total hidráulico de potência e reservas Sistema 3 barras - N-1-0

Até o momento, pelo critério de segurança adotado $K^{G}=0$ e $K^{L}=0$, não foi alocada reserva de potência em unidades geradoras. Simulando o mesmo sistema, porém agora utilizando o critério para perda de uma unidade geradora. As figuras 13 e 14 apresentam os despachos totais hidráulicos e térmicos de energia, gráfico de barras, e as reservas alocadas correspondem ao valor do platô das barras até a linha pontilhada, ou seja, até que ponto a barra do despacho pode excursionar utilizando a reserva. Adicionalmente, no gráfico da figura 14, a linha em verde no gráfico da figura com o despacho térmico, mostra a diferença entre a energia com o critério de segurança diferentes, $N-0-0$ e $N-1-0$, mostrando que a geração é a mesmo nos dois critérios.

Comparando os despachos totais dos critérios adotados $\mathrm{N}-0-0$ e $\mathrm{N}-1-0$, as gerações ficam iguais, porém, os resultados agora estabelecem as reservas. As reservas ficam alocadas prioritariamente nas unidades geradoras térmicas, com exceção do período em que nenhuma UG térmica está sincronizada. No momento em que somente há UGs hidráulicas, a reserva fica totalmente alocada nas mesmas, pois uma unidade suporta a perda da outra atendendo suas respectivas rampas, gerações máximas e limite de transmissão dentro do critério adotado $N-1-0$. O balanço total de energia e das reservas da operação descrita dentro do critério de segurança $N-1-0$, é apresentado na figura 15 . 


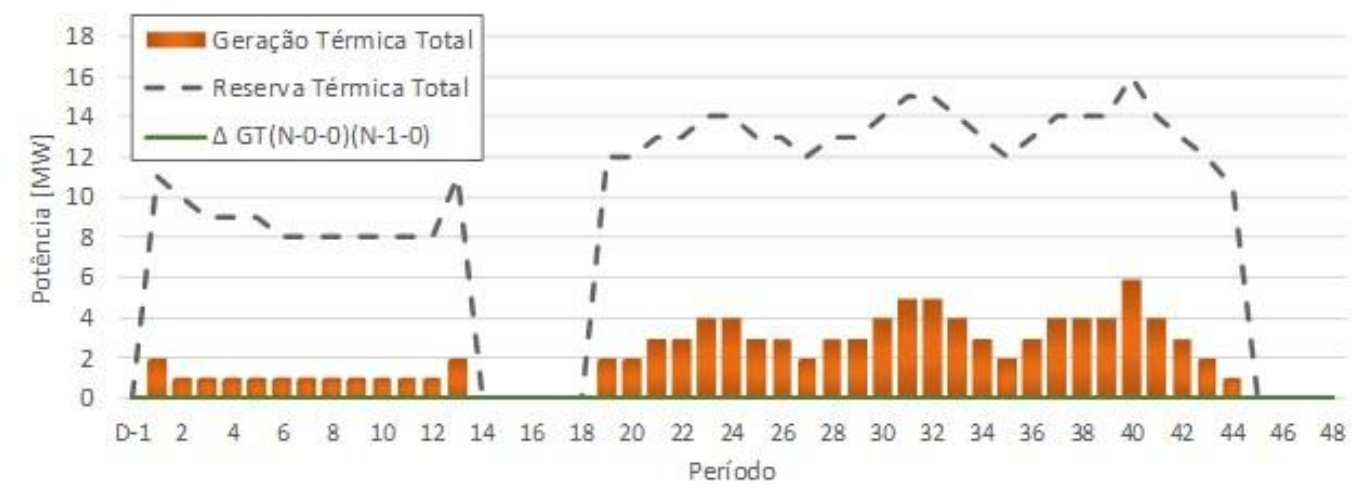

Figura 14: Resultado do despacho total térmico de potência e reservas - Sistema 3 barras $-N-1-0$

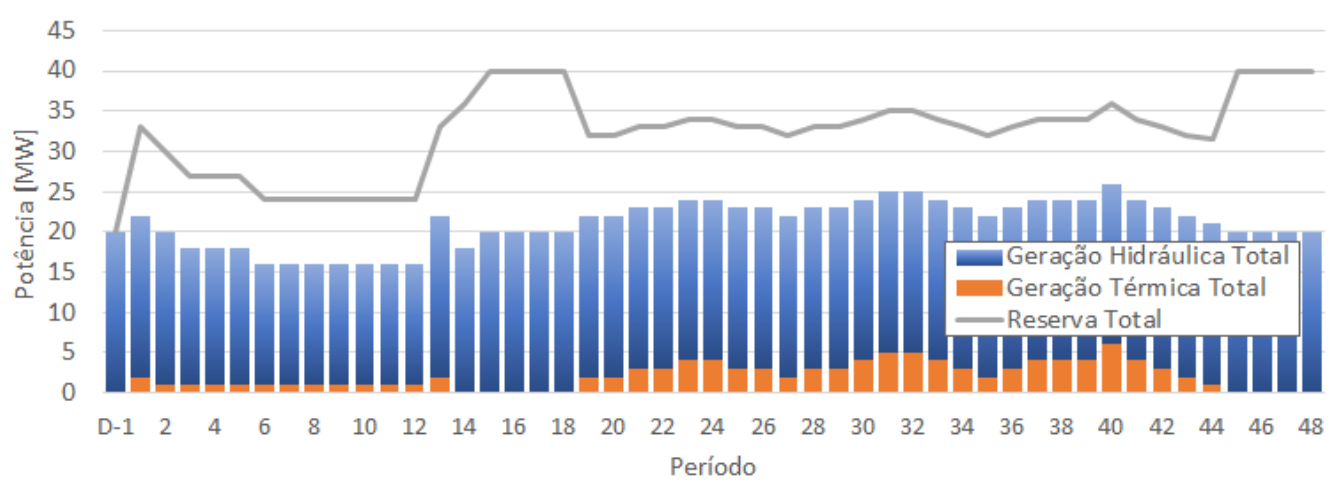

Figura 15: Balanço de potência e alocação de reservas - 3 barras - $N-1-0$

Ao alterar os critérios de segurança, dessa vez, para perda de uma unidade geradora e um elemento de transmissão, a restrição inserida no problema é a de carregamento do circuito 2 devido a perda dos circuitos 1 ou 3 . Com isso o despacho hidráulico da barra 1 fica ainda mais limitado, agora em $10 \mathrm{MW}$. Na figura 16 podemos observar o despacho total das UGs hidráulicas que inicia o estudo com $20 \mathrm{MW}$ e é reduzida para $10 \mathrm{MW}$, devido a restrição de rede citada anteriormente.

Notemos que o modelo não aloca reserva nas unidades hidráulicas. Caso fosse alocado reserva em alguma UG hidráulica todas as contingências não estariam cobertas. A UG1 hidráulica é capaz de assumir a potência da UG2 na perda da mesma e vice-versa, porém caso ocorra a perda de alguma UG térmica, as hidráulicas não podem responder sem que viole a restrição de rede. Sendo assim as restrições adotadas no modelo garantem a entregabilidade das reservas pela rede.

Com a energia das fontes hidráulicas limitada pela rede, o atendimento a demanda do sistema presente na barra 3 é complementada pelas unidades ge- 


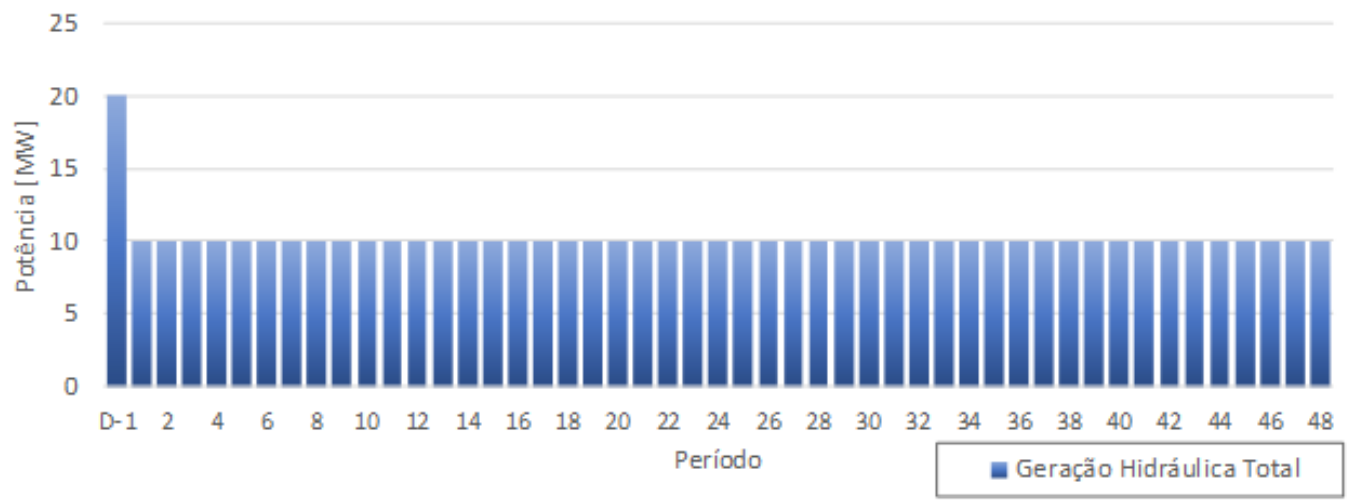

Figura 16: Resultado do despacho total hidráulico de potência e reservas - 3 barras $-N-1-1$

radoras térmicas conectadas nas mesmas barras. As reservas ficam totalmente alocadas nas unidades termelétricas pelo fato descrito no paragrafo anterior.

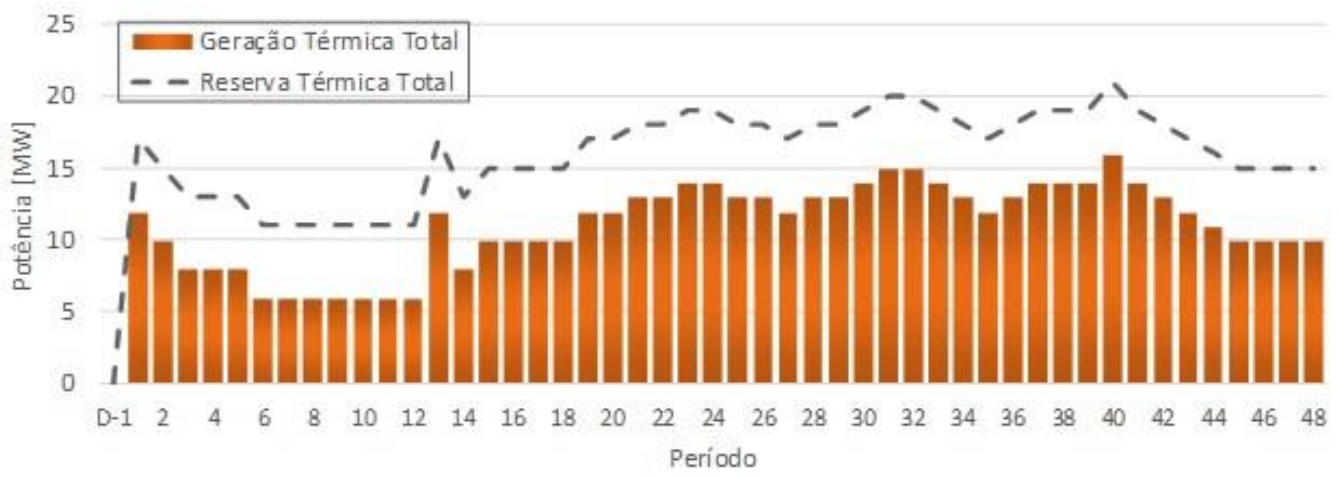

Figura 17: Resultado do despacho total térmico de potência e reservas - 3 barras $-N-1-1$

O balanço final de energia e reservas para o sistema dentro do critério de segurança $N-1-1$ é apresentado na figura 18. $O$ despacho individual das unidades geradoras térmicas pode ser observado mais detalhadamente nas figuras constantes no Apêndice B.

Avaliando os carregamentos dos equipamentos da rede de transmissão, entre os critérios usados neste sistema teste de 3 barras, a tabela 4 mostra as variáveis duais da restrição do circuito 2 , elemento limitante no sistema. Uma vez que a variável dual é diferente de zero indica que o carregamento da linha está sendo explorada ao máximo.

Nos dois primeiros critérios de segurança, encontramos na maior parte dos períodos a linha 2 com seu carregamento no máximo. Para o critério que contempla a perda de equipamentos de transmissão o dual fica igual a zero, pois 


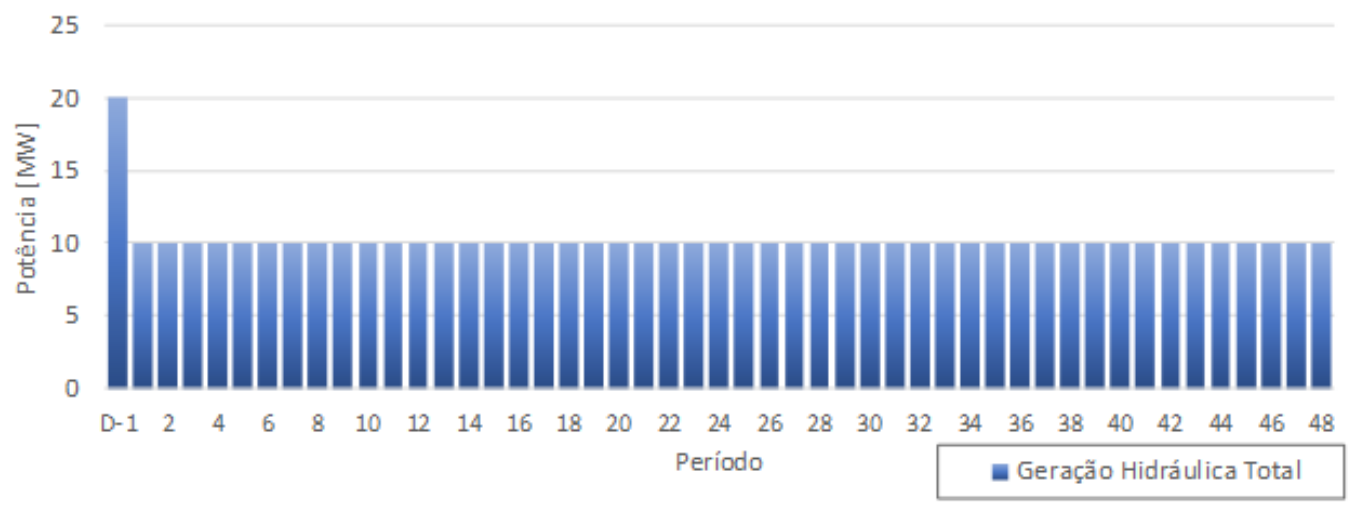

Figura 18: Balanço de potência e alocação de reservas - 3 barras - $N-1-1$

Tabela 4: Variável Dual Circuito 2 dentro dos critérios simulados - Sistema 3 barras

\begin{tabular}{|l|l|l|l|l|l|l|l|}
\hline $\mathrm{t}$ & $\mathrm{N}-0-0$ & $\mathrm{~N}-1-0$ & $\mathrm{~N}-1-1$ & $\mathrm{t}$ & $\mathrm{N}-0-0$ & $\mathrm{~N}-1-0$ & $\mathrm{~N}-1-1$ \\
\hline 1 & -256.24 & -250.76 & 0 & 25 & -256.24 & -250.76 & 0 \\
\hline 2 & 0 & 0 & 0 & 26 & -256.24 & -250.76 & 0 \\
\hline 3 & 0 & 0 & 0 & 27 & -256.24 & -250.76 & 0 \\
\hline 4 & 0 & 0 & 0 & 28 & -256.24 & -250.76 & 0 \\
\hline 5 & 0 & 0 & 0 & 29 & -256.24 & -250.76 & 0 \\
\hline 6 & 0 & 0 & 0 & 30 & -256.24 & -250.76 & 0 \\
\hline 7 & 0 & 0 & 0 & 31 & -256.24 & -250.76 & 0 \\
\hline 8 & 0 & 0 & 0 & 32 & -256.24 & -250.76 & 0 \\
\hline 9 & 0 & 0 & 0 & 33 & -256.24 & -250.76 & 0 \\
\hline 10 & 0 & 0 & 0 & 34 & -256.24 & -250.76 & 0 \\
\hline 11 & 0 & 0 & 0 & 35 & -256.24 & -250.76 & 0 \\
\hline 12 & 0 & 0 & 0 & 36 & -256.24 & -250.76 & 0 \\
\hline 13 & -256.24 & -250.76 & 0 & 37 & -256.24 & -250.76 & 0 \\
\hline 14 & 0 & 0 & 0 & 38 & -256.24 & -250.76 & 0 \\
\hline 15 & 0 & 0 & 0 & 39 & -256.24 & -250.76 & 0 \\
\hline 16 & 0 & 0 & 0 & 40 & -256.24 & -250.76 & 0 \\
\hline 17 & 0 & 0 & 0 & 41 & -256.24 & -250.76 & 0 \\
\hline 18 & 0 & 0 & 0 & 42 & -256.24 & -250.76 & 0 \\
\hline 19 & -256.24 & -250.76 & 0 & 43 & -256.24 & -250.76 & 0 \\
\hline 20 & -256.24 & -250.76 & 0 & 44 & -256.24 & -250.76 & 0 \\
\hline 21 & -256.24 & -250.76 & 0 & 45 & 0 & 0 & 0 \\
\hline 22 & -256.24 & -250.76 & 0 & 46 & 0 & 0 & 0 \\
\hline 23 & -256.24 & -250.76 & 0 & 47 & 0 & 0 & 0 \\
\hline 24 & -256.24 & -250.76 & 0 & 48 & 0 & 0 & 0 \\
\hline
\end{tabular}

a modelagem proposta não contempla um redespacho de geração em caso de contingência de linhas, caso ocorra a perda de algum equipamento haverá um novo fluxo na rede sem que haja sobrecarga nos circuitos remanescentes. Desta forma o fluxo na linha 2 não fica em sua capacidade máxima. Tal procedimento 
está de acordo com o adotado nos estudos elétricos da Programação Diária da Operação.

\section{2}

\section{Sistema teste 30 barras}

Neste tópico serão apresentadas as análises relativas ao sistema teste com 30 barras. Este sistema puramente térmico, constante na figura 19, possui 10 unidades geradoras com as características apresentadas conforme tabela 5 .

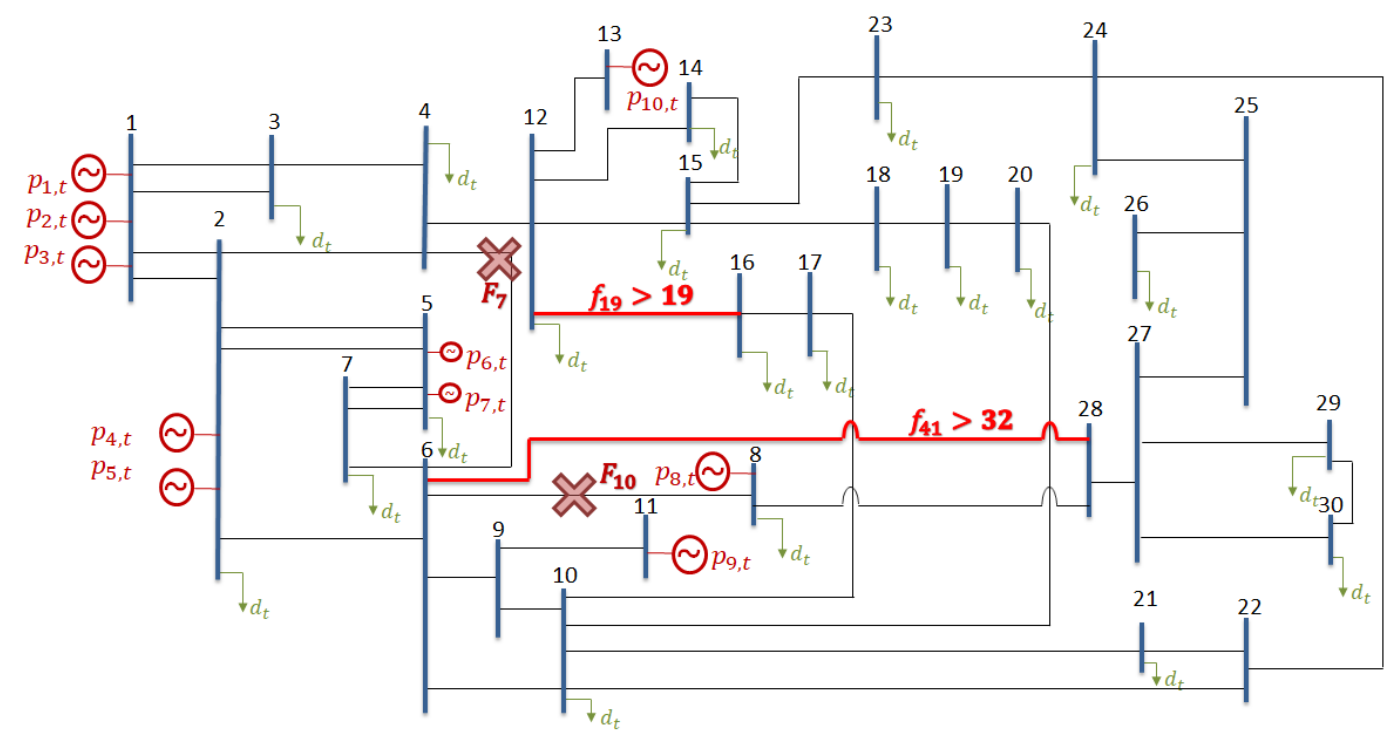

Figura 19: Sistema teste 30 barras e violações para o critério $N-1-1$

As simulações deste sistema não apresentaram violações na rede para os critérios de segurança $N-0-0$ e $N-1-0$, como será apresentado mais adiante na tabela 8. Para o critério com perda de uma UG e um elemento de rede, ocorrem duas violações para perda dos circuitos 10 e 7. Tais informações podem ser vistas na tabela 6 com o processo iterativo do sistema.

Os resultados para esse sistema são encontrados em 2 iterações, critério $N-1-1$. Seguindo o algoritmo, na iteração 0 é estabelecido o despacho, primeiramente para $K^{G}=1$ e $K^{L}=0$, sem que ocorram sobrecargas em circuitos. Na iteração 1 e 2 , onde $K^{G}=1$ e $K^{L}=1$, as contingências dos elementos de transmissão 10 e 7 causam sobrecargas nos circuitos 41 e 19 , respectivamente.

A fim de eliminar a sobrecarga na primeira iteração a unidade térmica 8 é acionada, UG mais cara, pois sua sensibilidade no circuito 41 é de $\beta_{l, n, c}=-0.95$, ou seja, o carregamento do circuito reduz em $95 \%$ em relação ao MW gerado na UG 8. Este processo, como é esperado, causa um aumento no custo total de operação, na tabela 6 é possível ver a evolução dos custos em 
Tabela 5: Dados Unidades Térmicas Sistema com 30 barras

\begin{tabular}{ccccccccc}
\hline térmicas & $\overline{G_{i}^{T}}$ & $G_{i}^{T}$ & $U T_{i}^{T}$ & $D T_{i}^{T}$ & $R_{i}^{u p}$ & $R_{i}^{d n}$ & $C_{i}^{\text {prod }}$ & $C_{i}^{T_{\text {up }}}$ \\
\hline term 1 & 67 & 17 & 1 & 1 & 50 & 50 & $\mathrm{R} \$ 200.00$ & $\mathrm{R} \$ 3.02$ \\
\hline term 2 & 67 & 17 & 1 & 1 & 50 & 50 & $\mathrm{R} \$ 200.00$ & $\mathrm{R} \$ 3.02$ \\
\hline term 3 & 67 & 17 & 1 & 1 & 50 & 50 & $\mathrm{R} \$ 200.00$ & $\mathrm{R} \$ 3.02$ \\
\hline term 4 & 40 & 10 & 1 & 1 & 30 & 30 & $\mathrm{R} \$ 175.00$ & $\mathrm{R} \$ 3.09$ \\
\hline term 5 & 40 & 10 & 1 & 1 & 30 & 30 & $\mathrm{R} \$ 175.00$ & $\mathrm{R} \$ 3.09$ \\
\hline term 6 & 25 & 7.5 & 1 & 1 & 35 & 35 & $\mathrm{R} \$ 100.00$ & $\mathrm{R} \$ 2.98$ \\
\hline term 7 & 25 & 7.5 & 1 & 1 & 35 & 35 & $\mathrm{R} \$ 100.00$ & $\mathrm{R} \$ 2.98$ \\
\hline term 8 & 35 & 10 & 1 & 1 & 25 & 25 & $\mathrm{R} \$ 325.00$ & $\mathrm{R} \$ 2.96$ \\
\hline term 9 & 30 & 10 & 1 & 1 & 20 & 20 & $\mathrm{R} \$ 300.00$ & $\mathrm{R} \$ 3.00$ \\
\hline term 10 & 40 & 12 & 1 & 1 & 28 & 28 & $\mathrm{R} \$ 150.00$ & $\mathrm{R} \$ 5.00$ \\
\hline
\end{tabular}

Tabela 6: Resultado do processo iterativo - Sistema 30 barras

\begin{tabular}{|l|l|l|l|l|}
\hline Iteração & Contingência $C$ & $R L F\left({ }^{*}\right)$ & $V R F L(\Lambda)[\%]$ & Custo Total [R\$] \\
\hline 0 & 0 & 0 & 0 & $1,839,871.28$ \\
\hline 1 & 10 & 41 & 39.9 & $1,884,814.97$ \\
\hline 2 & 7 & 19 & 4.9 & $1,887,181.77$ \\
\hline
\end{tabular}

cada iteração. Os despachos individuais das unidades geradoras deste sistema estão disponíveis no Apêndice B.

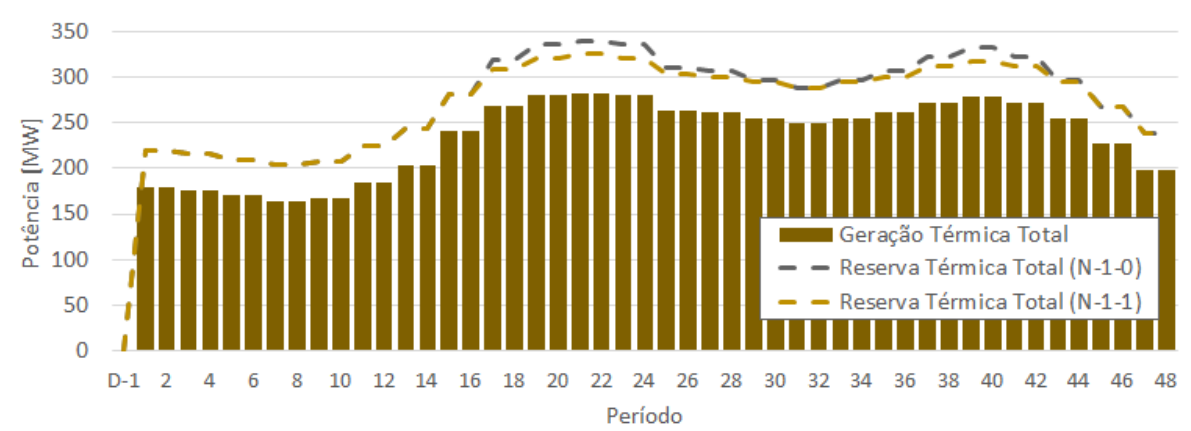

Figura 20: Balanço de potência e alocação de reservas - 30 barras

Comparando os critérios adotados neste sistema, podemos perceber uma redução da alocação de reservas no critério $N-1-1$ em relação ao $N-1-0$. No gráfico da figura 20, podemos verificar essa redução, no período $t=21$ o maior despacho em uma unidade geradora é de $56.5 \mathrm{MW}$, para $N-1-0$, com os re-despachos visando atender ao $N-1-1$ a maior potência em uma unidade geradora passa a ser 43.6 MW, reduzindo desta forma a necessidade de uma maior reserva. 


\section{3}

\section{Subsistema Norte do SIN isolado}

O sistema elétrico em questão neste tópico é o Subsistema Norte que para as primeiras análises e verificações do modelo, foi isolado do restante do SIN. Ele é composto pelas unidades desta região totalizando 77 UGs termelétricas e 50 UGs hidráulicas. A rede de transmissão é composta de 437 barras e 605 circuitos. Foram monitoradas as tensões de 500 e $230 \mathrm{kV}$, que são tensões da rede básica existentes na região Norte.

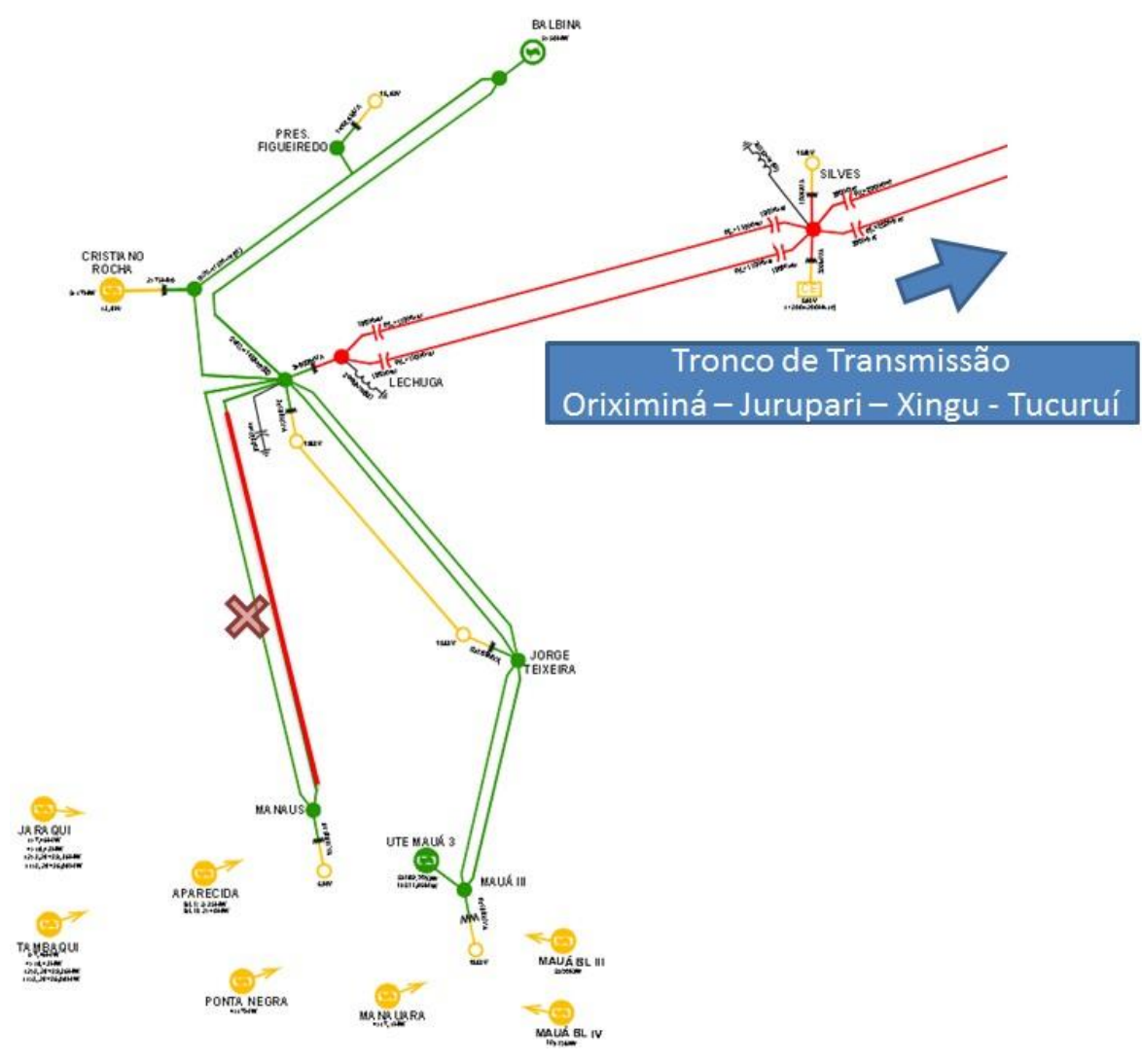

Figura 21: Contingência Linha 230 kV SE Lechuga-Manaus com sobrecarga no circuito remanescente - Subsistema Norte $-N-1-1$

As diversas regiões do SIN são sub divididas em áreas elétricas. Essa divisão é feita de acordo com critérios de topologia de rede e localização das cargas. O Subsistema Norte é composto pelas áreas elétricas conhecidas como área Manaus, área Macapá, área Tucuruí-Belém, área Maranhão e demais consumidores livres.

Neste caso de estudo, pelo ponto de vista da rede e adotando o critério de perda simples $K^{L}=1$, a operação para atendimento à demanda da área Manaus é bem caraterizada pelo despacho térmico interno. Na figura 21, ilustra a área Manaus, onde o atendimento é feito pelo despacho térmico das usinas de Jaraqui, Tambaqui, Aparecida, Ponta Negra, Flores e Iranduba, e pelo 
tronco de transmissão chegando na Subestação de 500/230 kV Lechuga e posteriormente pelo circuito duplo de $230 \mathrm{kV}$ Lechuga-Manaus. Caso ocorra a perda de uma das linhas Lechuga-Manaus, a fim de não haver sobrecarga no circuito remanescente, é inserida a restrição para tal contingência. Com essa restrição o modelo redespacha as térmicas internas à área Manaus.

É importante destacar que o despacho interno à área Manaus é uma prerrogativa da Programação Diária [5], mesmo que alguma térmica não seja despacha por ordem de mérito de custo indicada pelos modelos de médio e longo prazo. A incorporação de tais restrições na formação de preço traduzem o sinal econômico para a região, atraindo reforços de transmissão ou geração.

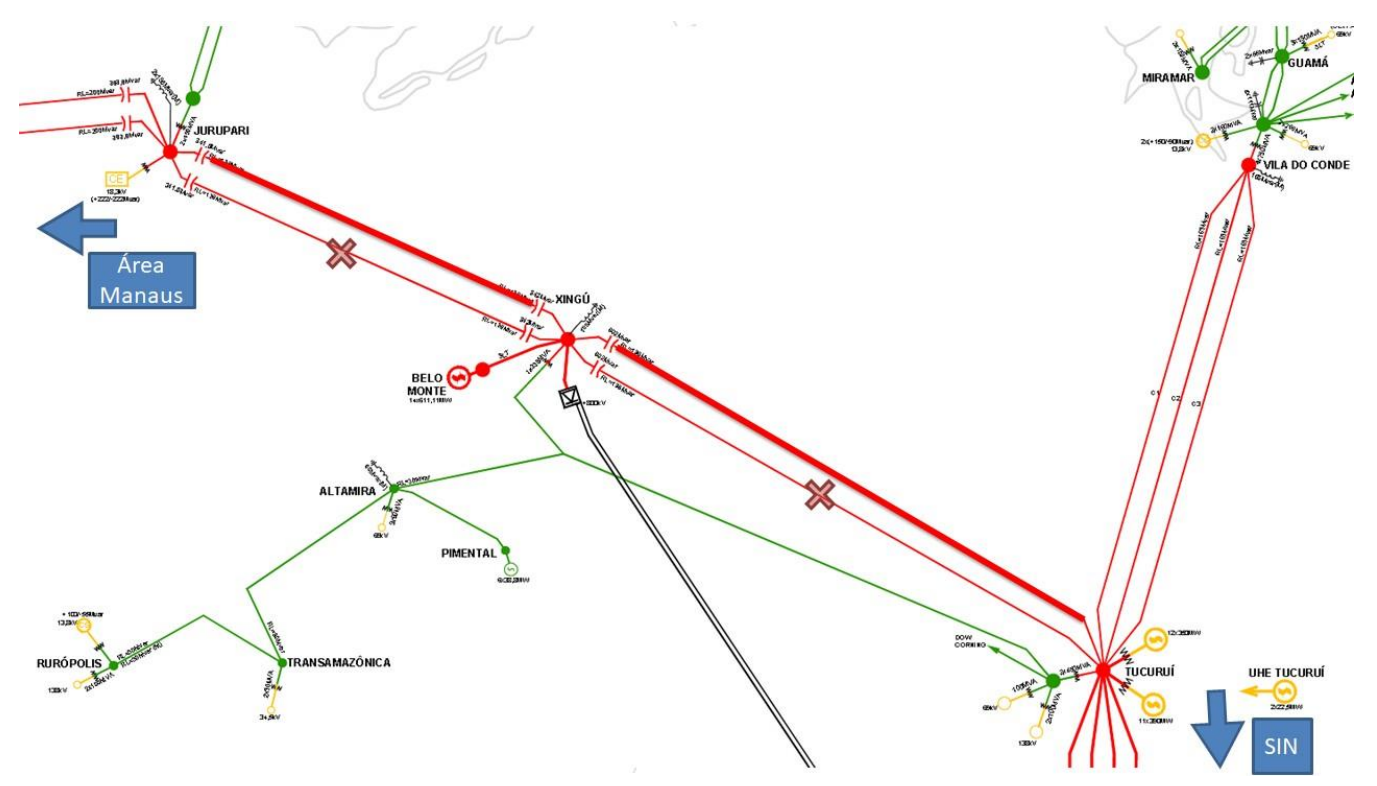

Figura 22: Contingência das Linhas 500 kV SE Tucuruí-Xingú e Xingú-Jurupari com sobrecarga no circuito remanescente - Subsistema Norte - N-1-1

Outra restrição característica de rede contemplada na etapa de programação é a violação dos fluxo das Linhas de 500kV Tucuruí-Xingú e XingúJurupari. Para cenários energéticos de baixas afluências a UHE Belo Monte, no rio Xingu, e conseguente perda de potência desta usina, a perda de uma linha ocorre sobrecarga no circuito remanescente. Tal restrição foi adicionada ao problema mestre neste caso de estudo, figura 22.

O resultado do balanço de potência e reservas para o estudo de caso do Subsistema Norte ao longo dos 48 períodos é apresentado na figura 23. Pode-se observar o atendimento a equação de balanço de energia uma vez que o gráfico de barras coincide com o gráfico da linha continua preta, a reserva alocada é o gráfico com linha tracejada, ou seja, o quanto a barra de energia pode excursionar ocupando a reserva. 


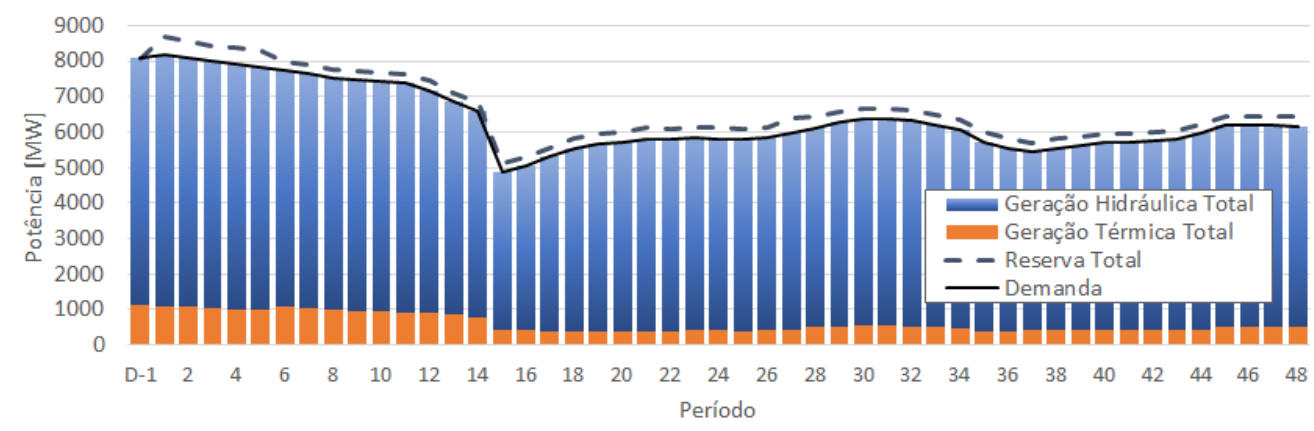

Figura 23: Balanço de potência e reservas - Subsistema Norte - N - 1- 1

As análises do caso de estudo do Subsistema Norte apresentaram proximidade as restrições de limite de fluxo que para alguns dias do ano estão ativas na etapa de Programação Diária. Estas restrições foram identificadas e incorporadas ao problema mestre do algoritmo proposto. Assim, aproxima-se os resultados dos modelos computacionais, utilizados para a programação da operação, à necessidade operativa em tempo real.

\section{4 \\ Sistema Interligado Nacional}

Neste item daremos início as análises do caso de estudo foco do presente trabalho (programação de energia e reservas para o Sistema Interligado Nacional), aplicável como ferramenta de apoio à etapa de Programação Diária da Operação. Um modelo em código aberto para despacho de unidades geradoras térmicas e hidráulicas atendendo a critérios de segurança para perda de unidades geradoras e de elementos de transmissão.

Como descrito na parte introdutória, o SIN é divido em 4 Subsistemas, interligados por grandes troncos de transmissão. Essa característica de interligações possibilitam uma troca de energia entre elas, havendo uma complementariedade entre os períodos hidrologicamente favoráveis de uma região em relação a outra. Em outras palavras, existem épocas do ano que um subsistema tem maior ocorrência de chuvas e consequente elevação nas afluências aos reservatórios, aumentando assim suas disponibilidades energéticas. Essa região fica apta, dentro dos limites de intercâmbio de energia, rede de transmissão, a auxiliar outra região que pode estar em um momento de estiagem.

A figura 24, apresenta de forma como os modelos de médio e longo prazo representam as interligações entre os Subsistemas. Essas interligações são modeladas por restrições de limites de fluxo na etapa de programação adotando critérios de segurança de rede, e estão ativas de acordo como cenário energético do SIN ao longo do ano. 


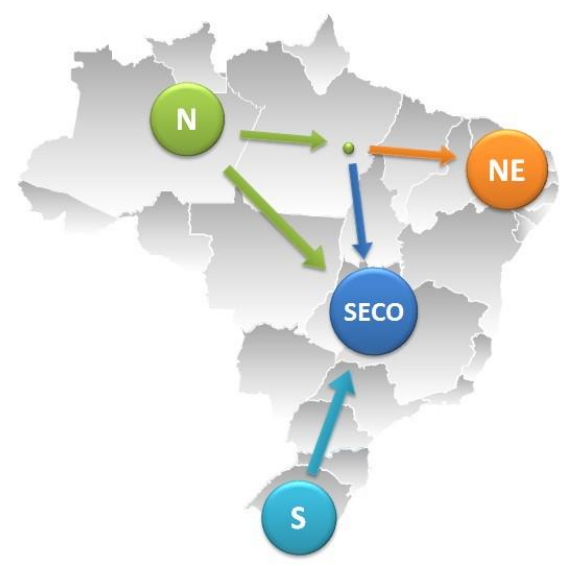

Figura 24: Subsistemas e Conexões do Sistema Interligado Nacional

A alocação de reserva de potência é feita em usinas hidrelétricas específicas, que operam no Controle Automático de Geração - CAG, e são remuneradas via um valor fixo conhecido por Serviço Ancilar. Outro mecanismo de remuneração adotado, resolução da ANEEL [8], consiste em valorar o CVU das usinas térmicas em até $30 \%$ acima do seu CVU vigente, a fim reduzir a geração nas usinas hidráulicas conectadas ao CAG, e, assim recompor a reserva de potência. A cootimização de energia e reservas com a possibilidade de um mercado de ofertas para alocação de reserva de potência, modelo proposto neste trabaIho, traz um sinal não só para o mercado deste importante serviço ancilar mas também para a operação.

Para o caso de estudo do Sistema Interligado Nacional foram feitas simulações para os dias 03 de agosto de 2018 e 18 de janeiro de 2019. Primeiramente um dia de inverno, com período seco no Sudeste/Centro-Oeste, Nordeste e Norte, com consumo baixo de energia devido as baixas temperaturas. Em seguida um dia de verão, estação chuvosa no Sudeste/Centro-Oeste e Norte, alta demanda de energia no SIN devido a altas temperaturas. As simulações apresentaram uma aderência as violações de rede encontradas na etapa da Programação Diária da Operação, no critério de segurança para $K^{L}=1$, dentre elas os gargalos da transmissão entre regiões:

- Linha 500 kV Tucuruí-Xingu (Subsistema Norte)

- Linha 500 kV Xingu-Jurupari (Subsistema Norte)

- Linha 500 kV Gurupi-Peixe2 (Fluxo Norte-Sul)

- Linha 500 kV P. Dutra-Teresina 2 (Subsistema Nordeste)

- Bipolo 600 kV cc Porto Velho-Araraquara (Bipolo Usinas do Madeira)

As figuras 25 e 26 apresenta o despacho térmico total de energia e reserva por subsistema para o caso de estudo do dia 03 de agosto de 2018. As 


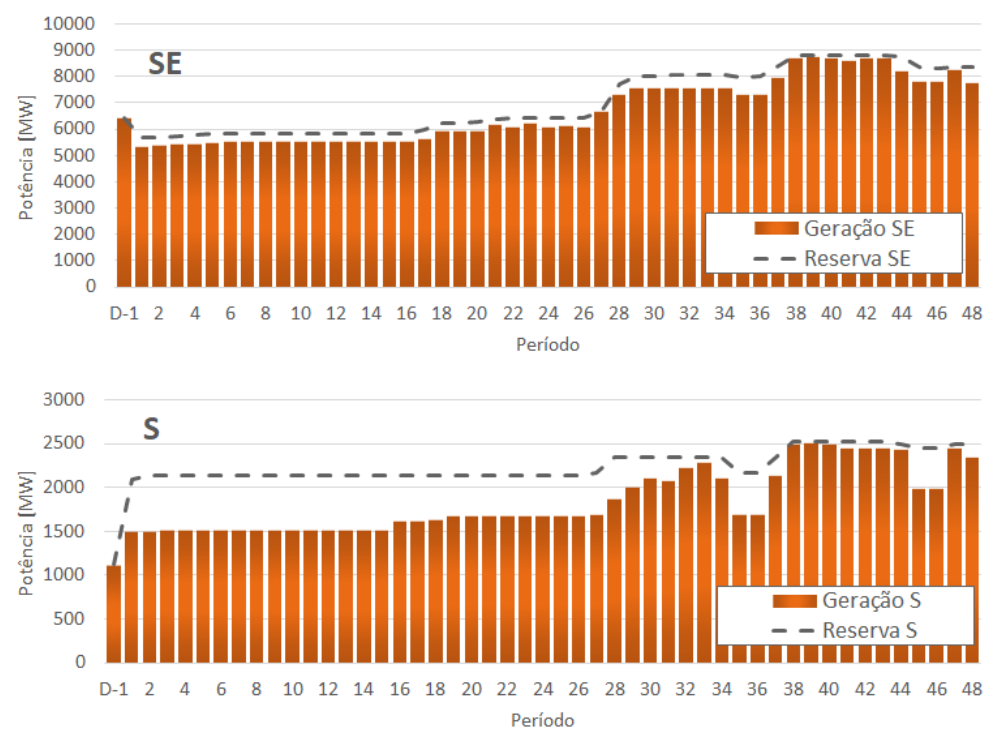

Figura 25: Resultado do despacho total térmico de potência e reservas - Sudeste e Sul - N-1-1

restrições representadas neste modelo capturam as características físicas das unidades geradoras além das restrições de transmissão. O objetivo é minimizar o custo total de operação (Função Objetivo constante na seção 2.1), desta forma não ocorre o empilhamento do despacho térmico por custo do mais barato para o mais caro. Os resultados apresentaram despachos de unidades térmicas mais caras visando $o$ atendimento de violações de limite de fluxo ou por características físicas mais flexíveis como um menor tempo mínimo de permanência ligado ou uma taxa de variação de tomada de carga maior em comparação as que ficaram desligadas.

Aprofundando as observações na decisão de despacho das unidades geradoras térmicas, e a fim de exemplificar o atendimento às diversas restrições de unit commitment, a figura 27 mostra a decisão do modelo no despacho individualizado da UG 1 da UTE Governador Leonel Brizola e da UG 1 da UTE Celso Furtado. As restrições de comprometimento das unidades geradoras foram atendidas e as reservas aderem as máximas variações permitidas pelas rampas das unidades. Desta forma a reserva pode ser ocupada sem que ocorra violação da taxa de variação de tomda de carga, rampa de subida da UG.

O resultado do balanço de energia bem como as reservas alocadas, por subsistema, estão apresentadas nas figuras 28 e 29. É possível notar os momentos onde o subsistema é exportador de energia (Regiões Sudeste e Norte) e quando é recebedor (Região Sul). Quando a linha contínua do gráfico, que representa a carga da região, fica por baixo do gráfico de barras (que é o somatório dos despachos térmicos, hidráulicos e injeção de pequenas usinas) 


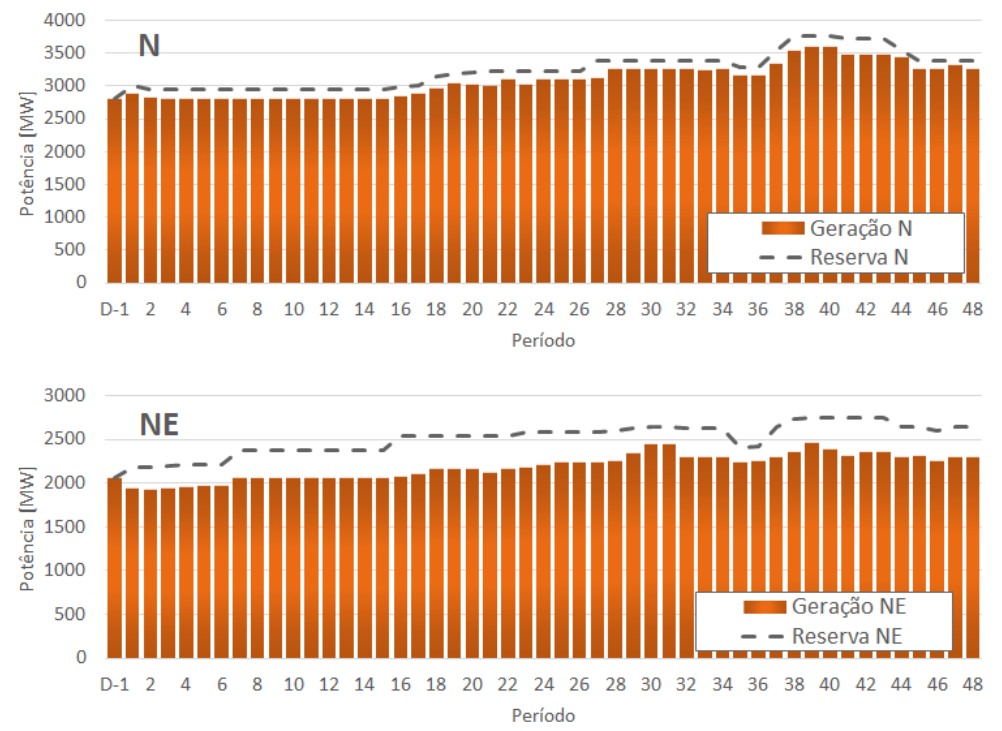

Figura 26: Resultado do despacho total térmico de potência e reservas - Norte e Nordeste $-N-1-1$
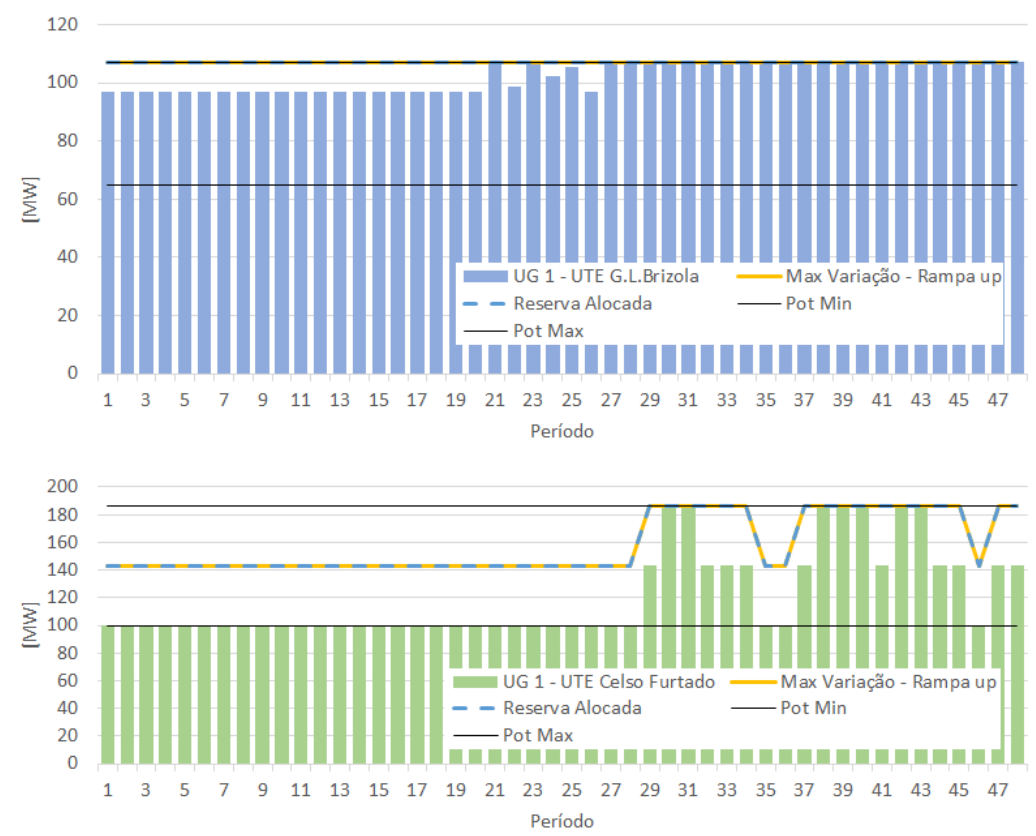

Figura 27: Operação da UG 1 da UTE Gov. Leonel Brizola e UG 1 da UTE Celso Furtado $-N-1-1$

significa que a região atendeu sua demanda de energia e ainda, por decisão do modelo, exportou para outras regiões.

É interessante notar o volume de energia de pequenas usinas na Região NE referente a geração de unidades geradoras eólicas. Essa alta inserção de eólicas no Subsistema NE possibilita não só o atendimento à demanda desta região mas a exportação de energia em alguns momentos para o restante 


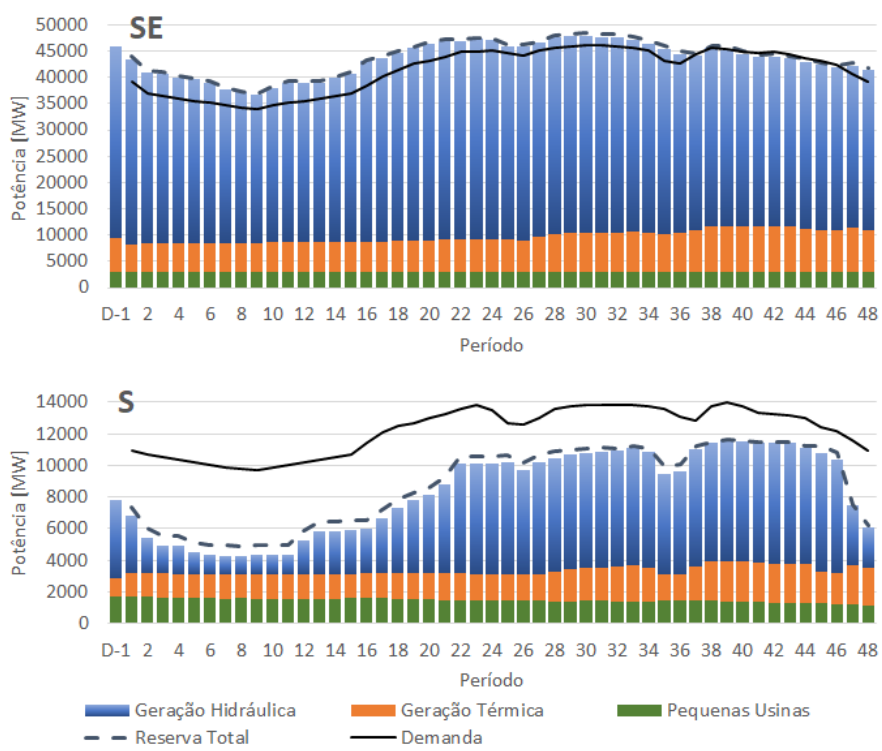

Figura 28: Resultado do despacho balanço potência e reservas por Subsistema - Brasil - N - 1-1

do SIN. A região nordeste, desde 2012, atravessa uma crise hídrica onde os recursos hidráulicos são preservados no curto prazo com decisões do Grupo de monitoramento dos usos múltiplos da água na bacia do rio São Francisco.

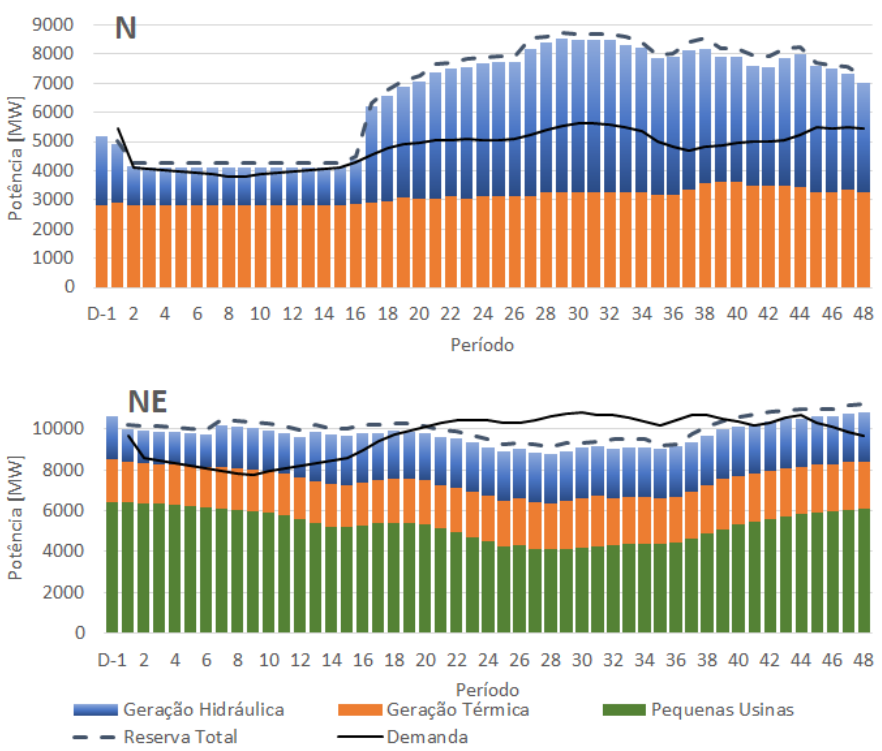

Figura 29: Resultado do despacho balanço potência e reservas por Subsistema - Brasil - N - 1-1

A alocação das reservas pode ser vista no gráfico da figura 30. O recurso hidráulico ficou com uma reserva alocada menor que o gerador térmico, ficando próximo a zero em algumas regiões. Uma vez que o modelo atual do setor elétrico brasileiro não contempla ofertas para reserva de potência por parte dos 


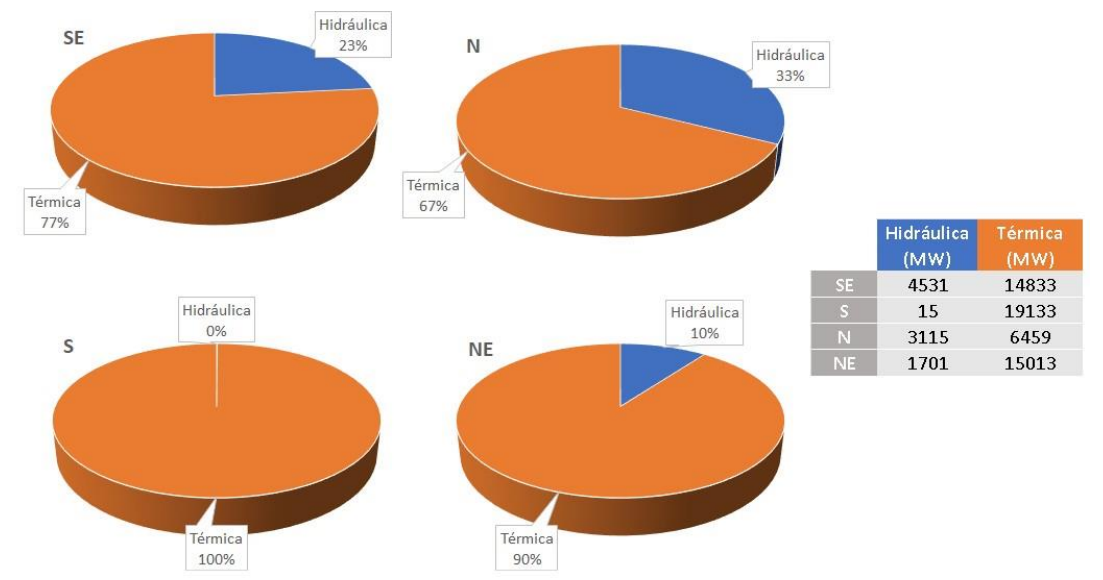

Figura 30: Reservas alocadas por Subsistema - Brasil - N-1-1

geradores, tais dados de entrada foram gerados aleatoriamente. Observando os custos ofertados, por parte dos geradores hidráulicos, estes valores se apresentaram maiores em comparação as unidades térmicas.

\section{5 \\ Índices de Desempenho e Sinal Econômico}

Simulados os casos de estudos explanados nesse capítulo, podemos apresentar nas tabelas 7, 8 e 9 os tempos de processamento, os custos, índices de desempenho e sinal econômico dentro dos critérios de segurança adotados.

O fator de compactação indica quantas restrições foram adicionadas ao problema pelo método em relação a todas as restrições que seriam necessárias caso fosse utilizado o modelo clássico, onde todas as restrições para todas as contingências são consideradas. No exemplo de três barras, o caso $N-0-0$, a modelagem clássica contemplaria 3 restrições, uma para cada linha. Utilizando o algoritmo proposto foi inserida a restrição $R L F_{1}(2)$. Dessa forma, o fator é igual a $33 \%$. Para $N-1-1$, o total de restrições seriam uma para cada linha somadas a uma restrição por linha em cada contingência. No entanto, o algoritmo proposto adicionou apenas 2 restrições, produzindo um fator igual a $22 \%$.São apresentados ainda o custo imediato, relativo aos períodos do dia em estudo, e o custo total de operação, função objetivo, que é a soma dos custos imediatos e futuro (proveniente da função de custo futuro do planejamento de médio prazo). $O$ fator de segurança é calculado utilizando o custo imediato. Este fator representa o aumento percentual do custo imediato ao considerarmos o critério de segurança em relação ao custo sem segurança $(N-0-0)$. $O$ fator de reserva é o percentual que as reservas totais representam com relação à demanda total do sistema. 


\begin{tabular}{|c|c|c|c|}
\hline $\begin{array}{l}\text { Caso de } \\
\text { Estudo }\end{array}$ & $\begin{array}{c}\text { Critério } \\
N-K^{G}-K^{L}\end{array}$ & $\begin{array}{c}\text { Processamento } \\
\text { (hh:mm:ss) }\end{array}$ & $\begin{array}{l}\text { Número de } \\
\text { Iterações }\end{array}$ \\
\hline \multirow{4}{*}{3 Barras } & $N-0-0$ & 00:00:33 & 1 \\
\hline & $N-0-1$ & 00:01:29 & 2 \\
\hline & $N-1-0$ & 00:00:40 & 1 \\
\hline & $N-1-1$ & $00: 00: 45$ & 2 \\
\hline \multirow{4}{*}{30 Barras } & $N-0-0$ & 00:00:53 & 0 \\
\hline & $N-0-1$ & 00:04:52 & 2 \\
\hline & $N-1-0$ & 00:01:09 & 0 \\
\hline & $N-1-1$ & 00:02:03 & 2 \\
\hline \multirow{4}{*}{$\begin{array}{l}\text { Subsist } \\
\text { Norte }\end{array}$} & $N-0-0$ & 00:01:58 & 0 \\
\hline & $N-0-1$ & 01:18:20 & 2 \\
\hline & $N-1-0$ & $00: 01: 45$ & 0 \\
\hline & $N-1-1$ & $00: 47: 12$ & 2 \\
\hline \multirow{3}{*}{ SIN } & $N-0-0$ & $\begin{array}{c}02: 30: 08 \\
(01: 55: 12)\end{array}$ & 1 \\
\hline & $N-0-1$ & $\begin{array}{c}98: 50: 00 \\
(13: 51: 00)\end{array}$ & 6 \\
\hline & $N-1-0$ & $\begin{array}{c}04: 39: 01 \\
(02: 45: 00)\end{array}$ & 1 \\
\hline 03/08/2018 & $N-1-1$ & $\begin{array}{c}104: 53: 00 \\
(15: 04: 48)\end{array}$ & 6 \\
\hline \multirow[b]{3}{*}{ 18/01/2019 } & $N-0-0$ & $\begin{array}{c}04: 00: 32 \\
(01: 10: 38)\end{array}$ & 2 \\
\hline & $N-0-1$ & $\begin{array}{r}149: 56: 00 \\
(19: 26: 36)\end{array}$ & 7 \\
\hline & $N-1-0$ & $\begin{array}{c}04: 28: 25 \\
(01: 20: 00)\end{array}$ & 2 \\
\hline
\end{tabular}

Note que para o caso SIN, $N-1-1$, apesar do tempo computacional de se resolver o método completo ter se mostrado superior ao tempo da aplicação, que precisa executar em poucas horas para ser utilizada na programação do dia seguinte, o tempo de se executar o modelo com as restrições précalculadas, encontradas previamente em estudos off-line, é bastante inferior, igual a 54.300 segundos. Isso não seria possível sem o método desenvolvido neste trabalho, que permitiu a redução do conjunto de restrições em mais de um milhão de vezes (fator de compactação). Dessa forma, a utilização prática deste método se dá através de estudos off-line e subsequente carregamento das restrições encontradas no modelo que será utilizado para produzir o cronograma do dia seguinte, tal pratica pode ser inserida nas rotinas do Operador Nacional do Sistema Elétrico para manutenção das restrições guardachuva. Além disso, vale ressaltar que as restrições são robustas a variações da demanda e outros parâmetros do lado direito do problema. Por fim, é 
Tabela 8: Índices de Desempenho e Sinal Econômico para os Casos de Estudo Simulados

\begin{tabular}{|c|c|c|c|c|}
\hline $\begin{array}{l}\text { Caso de } \\
\text { Estudo }\end{array}$ & $\begin{array}{c}\text { Critério } \\
N-K^{G}-K^{L}\end{array}$ & $\begin{array}{c}\text { Fator de } \\
\text { Compactação } \\
(\%)\end{array}$ & $\begin{array}{c}\text { Fator de } \\
\text { Segurança } \\
(\%)\end{array}$ & $\begin{array}{c}\text { Fator de } \\
\text { Reserva } \\
(\%)\end{array}$ \\
\hline \multirow{4}{*}{3 Barras } & $N-0-0$ & 33 & - & - \\
\hline & $N-0-1$ & 22 & 428.71 & - \\
\hline & $N-1-0$ & 33 & 21.97 & 54.58 \\
\hline & $N-1-1$ & 22 & 438.88 & 23.67 \\
\hline \multirow{4}{*}{30 Barras } & $N-0-0$ & 0 & - & - \\
\hline & $N-0-1$ & 0.1 & 2.60 & - \\
\hline & $N-1-0$ & 0 & 0.65 & 19.10 \\
\hline & $N-1-1$ & 0.1 & 3.17 & 17.05 \\
\hline \multirow{4}{*}{$\begin{array}{l}\text { Subsist } \\
\text { Norte }\end{array}$} & $N-0-0$ & 0 & - & - \\
\hline & $N-0-1$ & 0.00055 & $16,842.89$ & - \\
\hline & $N-1-0$ & 0 & 711.06 & 4.13 \\
\hline & $N-1-1$ & 0.00055 & $28,190.20$ & 4.66 \\
\hline \multirow{4}{*}{$\begin{array}{c}\text { SIN } \\
03 / 08 / 2018\end{array}$} & $N-0-0$ & 0.011 & - & - \\
\hline & $N-0-1$ & 0.000000107 & 12.03 & - \\
\hline & $N-1-0$ & 0.011 & 3.95 & 2.3 \\
\hline & $N-1-1$ & 0.000000107 & 15.43 & 2.3 \\
\hline \multirow{3}{*}{$\begin{array}{c}\text { SIN } \\
18 / 01 / 2019\end{array}$} & $N-0-0$ & 0.022 & - & - \\
\hline & $N-0-1$ & 0.00000867 & 1.7 & - \\
\hline & $N-1-0$ & 0.022 & 1.8 & 2.1 \\
\hline
\end{tabular}

importante mencionar que a quantidade de reserva, $2.3 \%$ da demanda, foi endogenamente encontrada pelo modelo, sendo, portanto, a menor possível para cumprir com o critério estabelecido. Para isso, o modelo encontrou a melhor alocação entre os geradores que permitisse a minimização dos custos tanto da energia quanto das reservas. Esse é um dos principais resultados do modelo. 
Tabela 9: Custos de Operação para os Casos de Estudo

\begin{tabular}{|c|c|c|c|}
\hline $\begin{array}{l}\text { Caso de } \\
\text { Estudo }\end{array}$ & $\begin{array}{c}\text { Critério } \\
N-K^{G}-K^{L}\end{array}$ & $\begin{array}{c}\text { Custo } \\
\text { Imediato }(\mathrm{R} \$)\end{array}$ & $\begin{array}{c}\text { Custo } \\
\text { Futuro(R\$) }\end{array}$ \\
\hline \multirow{4}{*}{3 Barras } & $N-0-0$ & $12,940.12$ & 0.00 \\
\hline & $N-0-1$ & $68,416.08$ & 0.00 \\
\hline & $N-1-0$ & $15,783.18$ & 0.00 \\
\hline & $N-1-1$ & $69,731.28$ & 0.00 \\
\hline \multirow{4}{*}{30 Barras } & $N-0-0$ & $1,827,950.00$ & 0.00 \\
\hline & $N-0-1$ & $1,875,503.41$ & 0.00 \\
\hline & $N-1-0$ & $1,839,871.28$ & 0.00 \\
\hline & $N-1-1$ & $1,905,900.64$ & 0.00 \\
\hline \multirow{4}{*}{$\begin{array}{l}\text { Subsist } \\
\text { Norte }\end{array}$} & $N-0-0$ & $5,940.55$ & $8,180,939,829.76$ \\
\hline & $N-0-1$ & $1,006,501.32$ & $8,180,933,011.47$ \\
\hline & $N-1-0$ & $48,181.36$ & $8,180,962,401.26$ \\
\hline & $N-1-1$ & $1,680,593.65$ & $8,180,952,045.47$ \\
\hline \multirow{4}{*}{$\begin{array}{c}\text { SIN } \\
03 / 08 / 2018\end{array}$} & $N-0-0$ & $100,721,607.91$ & $1,183,992,088,790.07$ \\
\hline & $N-0-1$ & $112,842,846.01$ & $1,183,992,558,376.05$ \\
\hline & $N-1-0$ & $104,700,133.32$ & $1,183,994,460,764.71$ \\
\hline & $N-1-1$ & $116,261,991.36$ & $1,183,990,778,393.52$ \\
\hline \multirow{3}{*}{$\begin{array}{c}\text { SIN } \\
18 / 01 / 2019\end{array}$} & $N-0-0$ & $29,063,293.03$ & $8,490,793,024,177.86$ \\
\hline & $N-0-1$ & $29,559,047.81$ & $8,490,772,263,300.28$ \\
\hline & $N-1-0$ & $29,589,360.41$ & $8,490,790,524,817.98$ \\
\hline
\end{tabular}




\section{Conclusão}

Este trabalho apresentou os resultados de um modelo computacional programado em código aberto (implementado na linguagem Julia) para realizar a cootimização do despacho de geração e níveis de reserva alocadas em cada unidade geradora do SIN. Tal modelo possibilita um ponto de operação ótimo e a alocação endógena e cootimizada das reservas para contornar falhas de equipamentos, além de, capturar as premissas utilizadas na etapa de programação diária do ONS. Desta forma, a metodologia possibilita a entrega de uma programação mais próxima a necessidade operativa do sistema para as diversas salas de controle em tempo real e contribui com a transparência e reprodutibilidade da alocação de recursos eletro-energéticos por parte do operador. Além disso, o modelo permite a consideração de declaração de ofertas de custos tanto para a energia como para as reservas de cada gerador e, podendo, inclusive, ser utilizado para produzir preços para ambos os mercados (energia e reserva).

A metodologia de decomposição deste problema se mostrou eficaz reduzindo o tamanho do problema, produzindo um modelo equivalente um milhão de vezes menor para o caso brasileiro com critério de segurança N-1-1. Contudo, a aplicação prática deste método se dá em duas etapas, onde as restrições mais violadas são pré-calculadas em estudos off-line e carregadas no modelo para o seu uso efetivo na programação diária. Com tal processo, encontramos níveis de reserva médios de $2.3 \%$ para o SIN em um estudo de caso utilizando dados oficiais para um dia típico de operação.

O caso aplicado ao Sistema Elétrico Brasileiro adotando o critério para perda de elementos de transmissão apresentaram aderência as restrições encontradas na etapa de Programação Diária da Operação, devido as violações de equipamentos das interligações e troncos de transmissão de energia (Bipolo do Madeira), inseridas ao problema mestre. A alocação de reserva proposta altera o ponto operativo com um despacho robusto para perda de $K^{G}$ geradores. Modifica o procedimento vigente de alocação de $5 \%$ da demanda em usinas conectadas ao CAG, um paradigma no setor, ao abrir para ofertas dos agentes de geração, além de refletir no custo da operação. Cabe ressaltar que variações de carga não são contemplados na modelagem. 
O processo de verificação de violações da rede mostrou-se um limitador no tempo de processamento. A utilização de processadores em paralelo nesta etapa de teste do atendimento à rede de transmissão pode trazer ganhos de tempo. Cabe ainda ressaltar que a utilização de máquinas mais modernas e dedicadas exclusivamente as simulações podem auxiliar na viabilidade do processo.

O Setor Elétrico Brasileiro está em constante evolução e amadurecimento dos procedimentos operacionais, comerciais e regulatórios. Podemos sugerir aprimoramentos e outras formas de modelagem para cada vez mais aproximar as ações de planejamento e programação à operação em tempo real.

As variáveis de decisão deste modelo aplicam-se apenas às unidades geradoras térmicas e hidráulicas, sendo o restante dos recursos, pequenas usinas, dentre elas eólicas e fotovoltaicas, tratadas como gerações compulsória. Desta forma pode-se modelar a utilização desses recursos como variáveis de decisão a fim de se retirar violações de restrições de rede e encontrar em alguns casos um ponto operativo mais barato. Metodologias alternativas de alocação de reserva podem ser utilizadas para endereçar a variabilidade das fontes intermitentes.

Estudos de caso em um período maior de operação podem ser utilizados para obtenção de sensibilidades do modelo, bem como se comporta o sistema executando uma operação encadeada de longo prazo. Análises referentes a volatilidade dos custos e impactos podem ser observados em tal estudo.

Aperfeiçoamentos podem ser feitos na representação das modalidades de operação em ciclo combinado, aberto ou dependente das usinas térmicas. Esses aperfeiçoamentos podem trazer uma aproximação das rampas das unidades que operam neste tipo de modalidade. 


\section{Referências bibliográficas}

[1] BRASIL. Lei $n .^{\circ}$ 9648, de 26 de agosto de 1998. Altera dispositivos das Leis no 3.890-A, de 25 de abril de 1961, no 8.666, de 21 de junho de 1993, no 8.987, de 13 de fevereiro de 1995, no 9.074, de 7 de julho de 1995, no 9.427, de 26 de dezembro de 1996, e autoriza o Poder Executivo a promover a reestruturação da Centrais Elétricas Brasileiras - ELETROBRÁS e de suas subsidiárias e dá outras providências. Diário Oficial da Republica Federativa do Brasil, 28 mai. 1998. Seção 1, p.1.

[2] BRASIL. Lei n. 10848 , de 15 de março de 2004. dispõe sobre a comercialização de energia elétrica, altera as leis nos 5.655, de 20 de maio de 1971, 8.631, de 4 de março de 1993, 9.074, de 7 de julho de 1995, 9.427, de 26 de dezembro de 1996, 9.478, de 6 de agosto de 1997, 9.648, de 27 de maio de 1998, 9.991, de 24 de julho de 2000, 10.438, de 26 de abril de 2002, e dá outras providências. Diário Oficial da Republica Federativa do Brasil, 16 mar. 2004. Seção 1, p.2.

[3] BRASIL. Decreto $n .^{\circ}$ 5081, de 14 de maio de 2004, regulamenta os arts. 13 e 14 da lei no 9.648, de 27 de maio de 1998, e o art. 23 da lei no 10.848, de 15 de março de 2004, que tratam do operador nacional do sistema elétrico - ons. Diário Oficial da Republica Federativa do Brasil, 17 mai. 2004. Seção 1, p.1.

[4] Operador Nacional do Sistema Elétrico ONS. Procedimento de Rede Submodulo 18.2, Relação dos sistemas e modelos computacionais. Rev. Dez., Brasil, 2016.

[5] Operador Nacional do Sistema Elétrico ONS. Procedimento de Rede Submodulo 8.1, Programação Diária da Operação Eletroenergética. Rev. Dez., Brasil, 2016.

[6] Operador Nacional do Sistema Elétrico ONS. Procedimento de Rede Submodulo 14.2, Arranjos comerciais para os serviços ancilares prestados pelos agentes de geração, de transmissão e de distribuição. Rev. Dez., Brasil, 2016. 
[7] BRASIL. AGÊNCIA NACIONAL DE ENERGIA ELÉTRICA - ANEEL. Resolução normativa $n$ ㅇ 697, 16 de dezembro de 2015. estabelece os procedimentos para prestação de serviços ancilares e adequação de instalações de centrais geradoras motivada por alteração na configuração do sistema elétrico. Diário Oficial da Republica Federativa do Brasil.

[8] BRASIL. Resolução normativa no 822, de 26 de junho de 2018. Altera a resolução normativa no 697-A, de 24 de abril de 2018. Diário Oficial da Republica Federativa do Brasil, 19 jul. 2018. Seção 1, p.36.

[9] FEDERAL ENERGY REGULATORY COMMISSION. Price formation in organized wholesale electricity markets docket no ad1414-000. operator-initiated commitments in rto and isso markets. Washington. December, 2014. Acesso em 04/02/2019. Disponível em: https://www.ferc.gov/legal/staff-reports/2014/AD14-14-operatoractions.pdf, dez 2014.

[10] T. GÓMEZ, E. A.. European Union Electricity Markets. IEEE Power and Energy Magazine, 17:20-31, jan 2019.

[11] CARRIÓN, M.; ARROYO, J. M.. A computationally efficient mixedinteger linear formulation for the thermal unit commitment problem. IEEE Transactions on Power Systems, 21:1371-1378, 2006.

[12] STREET, A.; OLIVEIRA, F. ; ARROYO, J. M.. Contingency-constrained unit commitment with $\mathbf{n}-\mathbf{k}$ security criterion: $A$ robust optimization approach. IEEE Transactions on Power Systems, 26:1581-1590, 2011.

[13] A. STREET, A. M.; ARROYO, J. M.. Energy and reserve scheduling under a joint generation and transmission security criterion: An adjustable robust optimization approach. IEEE Transactions on Power Systems, 5:4743-4746, 2005.

[14] K. W. HEDMAN, M. C. FERRIS, R. P. O. E. B. F.; OREN, S. S.. Cooptimization of generation unit commitment and transmission switching with $\mathbf{n - 1}$ reliability. IEEE Transactions on Power Systems, 25:1052-1063, 2010.

[15] PEREIRA, M. V. F.; PINTO, L. M. V. G.. Multi-stage stochastic optimization applied to energy planning. Mathematical programming, 52:359-375, 1991. 
[16] DINIZ, A.. Processo iterativo de construção da função de produção das usinas hidroelétricas para o problema de coordenação hidrotérmica. XX Seminário Nacional de Produção e Transmissão de Energia Elétrica - SNPTEE, 5:4743-4746, 2009.

[17] A.L. DINIZ, M. M.. A four-dimensional model of hydro generation for the short-term hydrothermal dispatch problem considering head and spillage effects. IEEE Transactions on Power Systems, 23:10521063, 2010.

[18] ZENGO, B.; ZHAO, L.. Solving two-stage robust optimization problems using a column-and-constraint generation method. Operations Research Letters, 23:1298-1308, 2013.

[19] MONTICELLI, J. A. Fluxo de Carga em Redes de Energia Elétrica. Edgar Blucher Ltda, São Paulo, 1983. 
A

\section{Apêndice A}

As restrições para contingência de unidades geradoras utilizadas no presente trabalho pode ser explicada pela modelagem equivalente, formulada em A.1 a A.10, para um sistema de barra infinita aplicada em apenas um período.

Sujeito a:

$$
\operatorname{minimize}_{u_{i, g_{i}, r_{i}^{T}} r_{i p}}-\left(C_{i \in I}^{\text {prod }} g_{i}^{T}+C_{i}^{T_{u p}} r_{i}^{T_{u p}}\right)
$$

$$
\begin{aligned}
& g_{i \in I}^{T}=d \\
& \underline{G_{i}^{T}} u_{i} \leq g_{i}^{T} \leq \overline{G_{i}^{T}} u_{i} ; \forall i \in I \\
& g_{i}^{T}+r_{i}^{T u p} \leq \overline{G_{i}^{T}} u_{i} ; \forall i \in \text { I } \\
& 0 \leq r_{i}^{T_{u p}} \leq R_{i}^{u p} u_{i} ; \forall i \in I \\
& u_{i} \in\{0,1\} ; \forall i \in I \\
& D^{*} \geq d \\
& D^{*}=\underset{a_{i}^{G}}{\operatorname{minimize}}{ }_{i \in I} a_{i}^{G}\left(g_{i}^{T}+r_{i}^{T_{u p}}\right)
\end{aligned}
$$

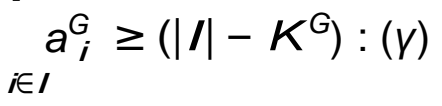

$$
\begin{aligned}
& 0 \leq a_{i}^{G} \leq 1:\left(E_{i}\right) ; \forall i \in \text { I }
\end{aligned}
$$

Sujeito a:

Para estabelecer a programação de energia e reservas com menor custo é utilizado o problema de nível superior A.1 a A.7. A variável $D^{*}$ representa a máxima potência fornecida para o pior caso. O problema de nível inferior A.8 a A.10 determina o valor de $D^{*}$ sob o critério de segurança estabelecido.

O lado esquerdo de A.7 e o problema de nível inferior podem ser equivalentemente substituídos pelo dual da função de objetivo e o dual das restrições associadas, A.8 a A.10, conforme pode ser observado em [13]. Desta forma, o problema equivalente, com único nível, pode ser formulado em A.11 a A.15. 
Sujeto a:

$$
\operatorname{minimize}_{u_{i, g_{i}^{T}, r_{i}^{T u p}}}{ }_{i \in I}\left(C_{i}^{\text {prod }} g_{i}^{T}+C_{i}^{T_{u p}} r_{i}^{T_{u p}}\right)
$$

Restrições pré-contingencia

$$
\begin{aligned}
& \left(|/|-K^{G}\right) Y-{ }_{i \in I}^{-} E_{i}=d \\
& V-E_{i} \leq g_{i}^{T}+r_{i}^{T_{u p}} ; \forall i \in \text { I } \\
& y \geq 0 \\
& E_{i, t} \geq 0 ; \forall i \in I
\end{aligned}
$$

As expressões apresentadas em A.7 a A.10 e seus equivalentes A.11 a A.15 garantem que a energia no estado pós-contingência atenda todas as contingências de $K^{G}$ unidades geradoras. Para um modelo de barramento único, o conjunto de restrições, A.12 a A.15, são condições necessárias para garantir um programa de despacho viável no pós-contingência, porém insuficientes do ponto de vista das restrição de rede. Portanto, constituem restrições válidas que podem ser adicionadas ao modelo original. 
B

\section{Apêndice B}

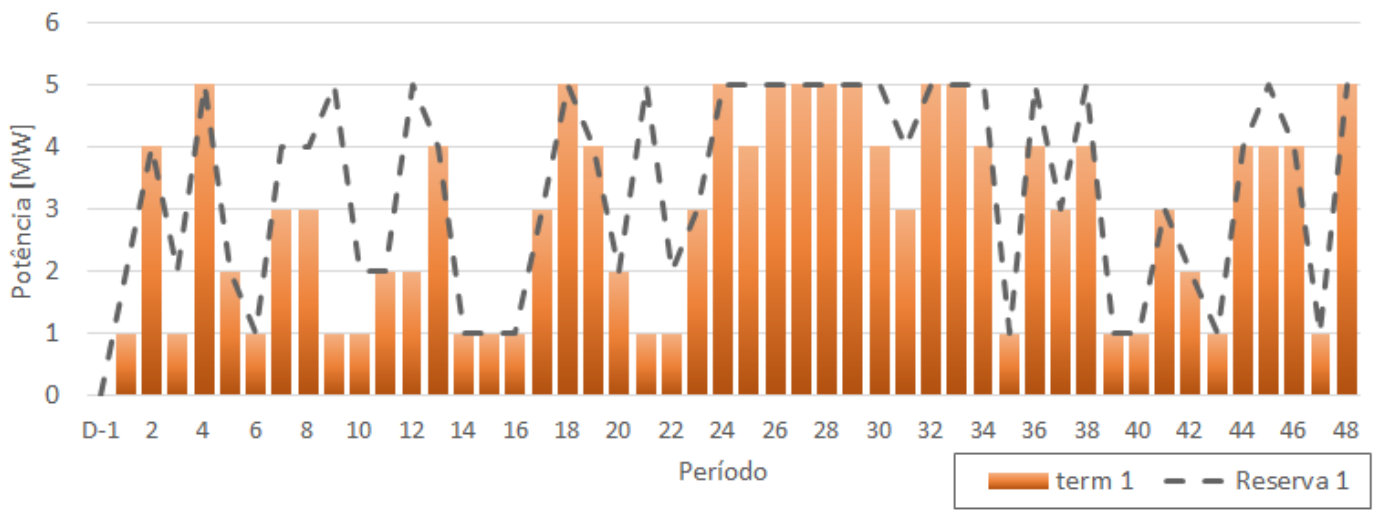

Figura 31: Resultado do despacho de potência e reservas UG térmica 1 - 3 barras $-N-1-1$

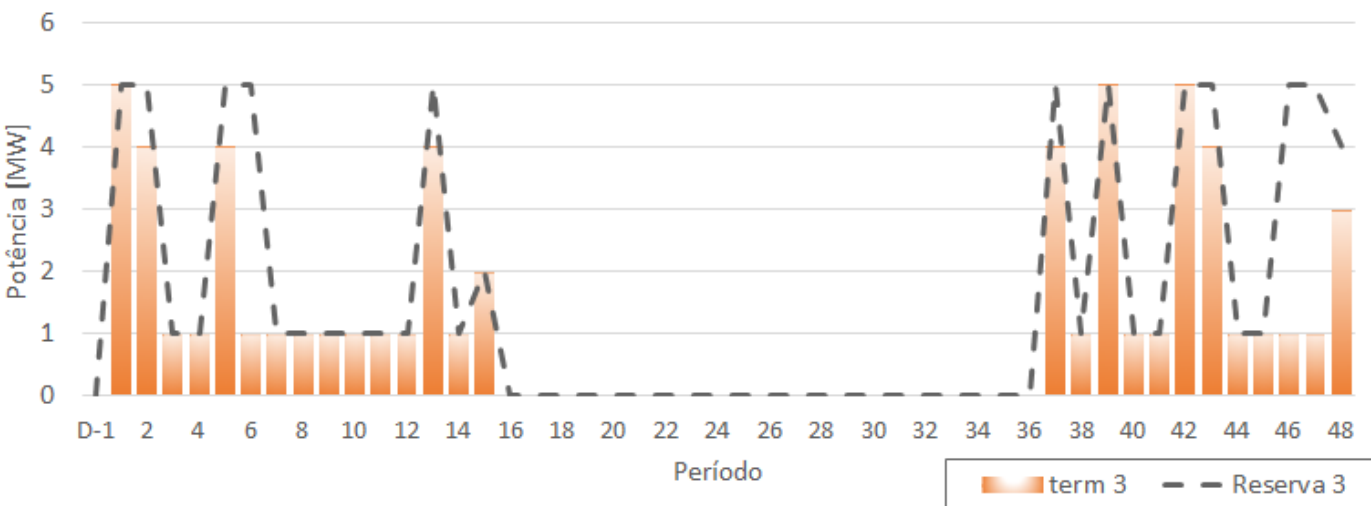

Figura 32: Resultado do despacho de potência e reservas UG térmica 3 - 3 barras - $N-1-1$ 


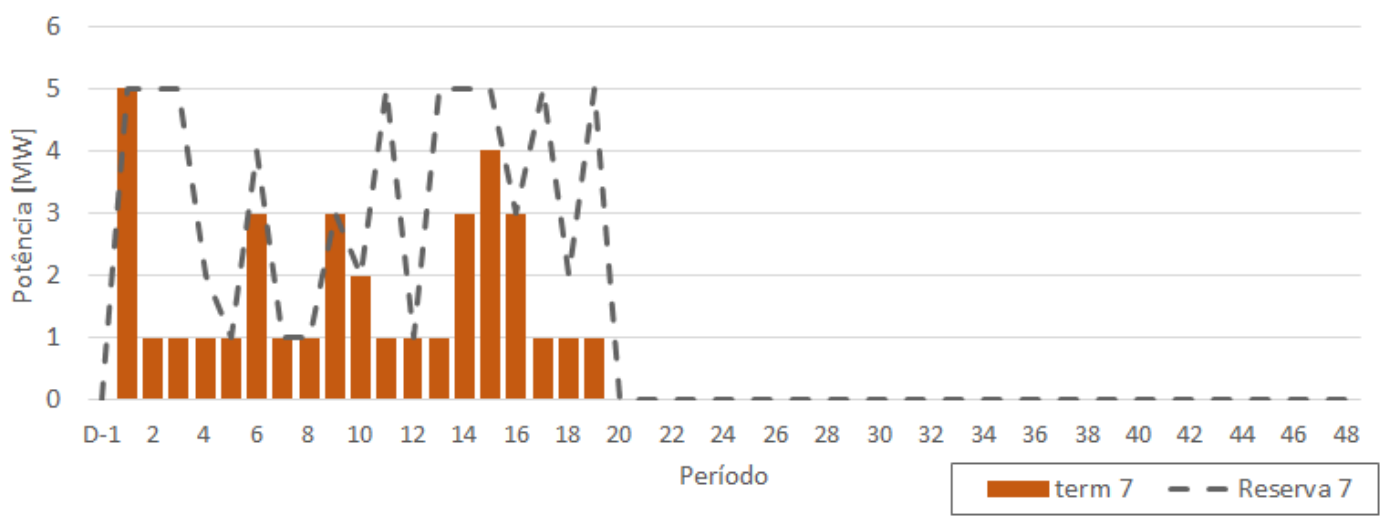

Figura 33: Resultado do despacho de potência e reservas UG térmica 7 - 3 barras $-N-1-1$

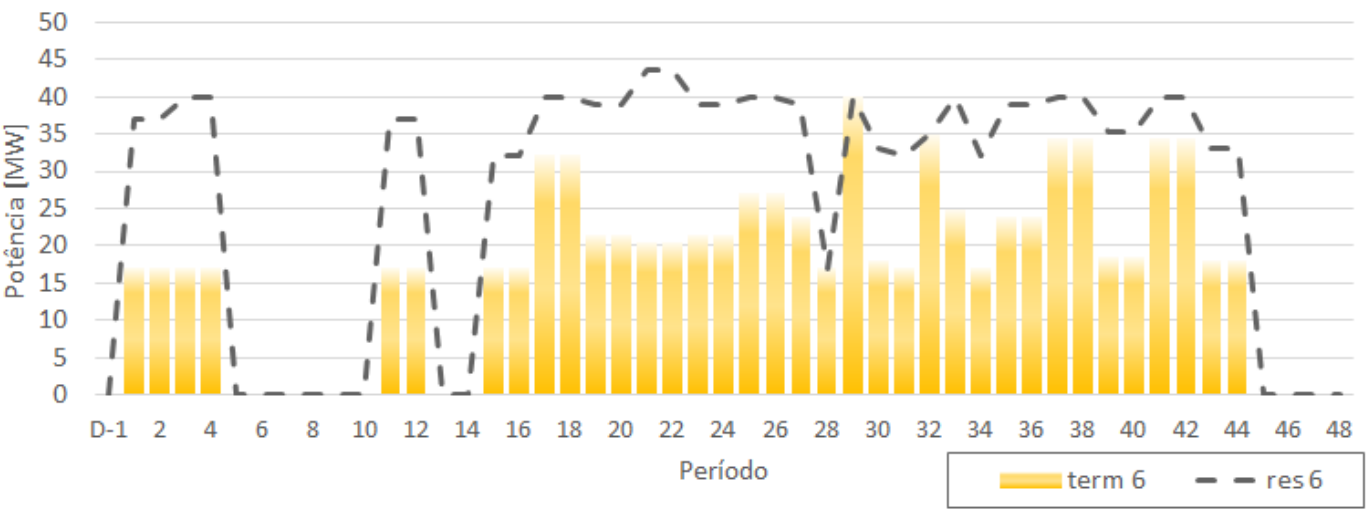

Figura 34: Resultado do despacho de potência e reservas UG térmica 6 - 30 barras $-N-1-1$

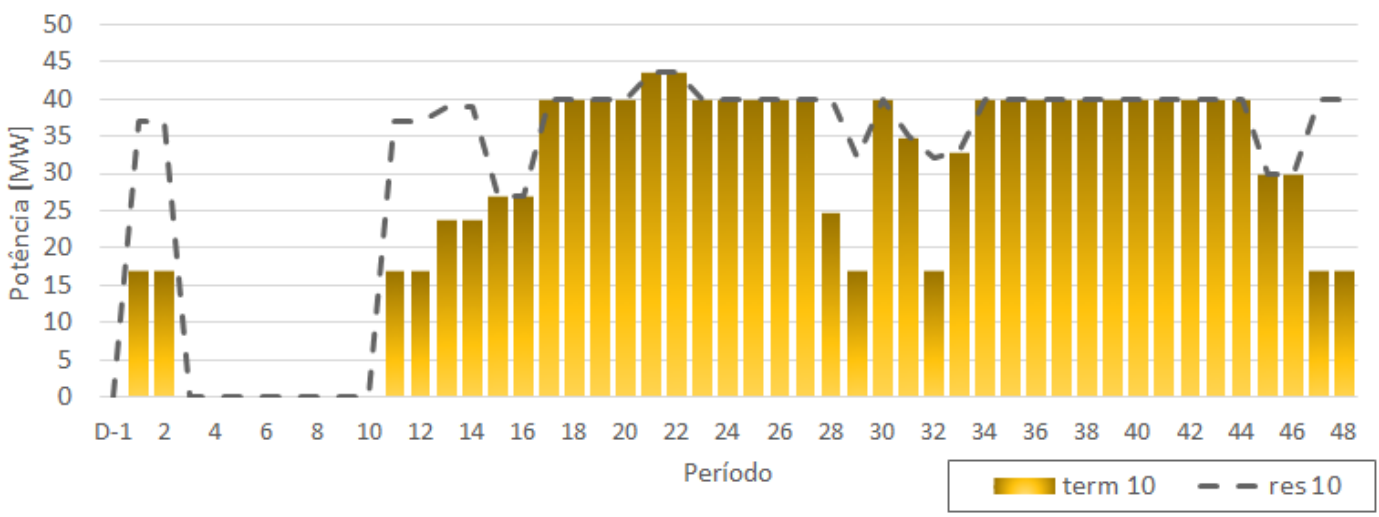

Figura 35: Resultado do despacho de potência e reservas UG térmica 10 - 30 barras $-N-1-1$ 


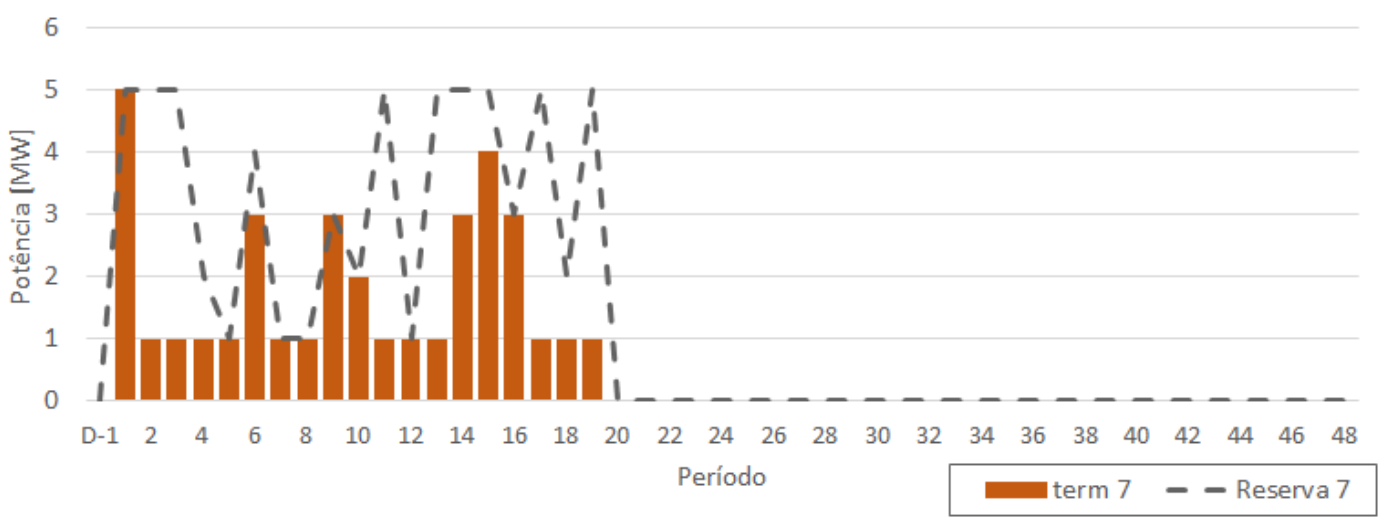

Figura 36: Resultado do despacho de potência e reservas UG térmica 4 - 30 barras $-N-1-1$

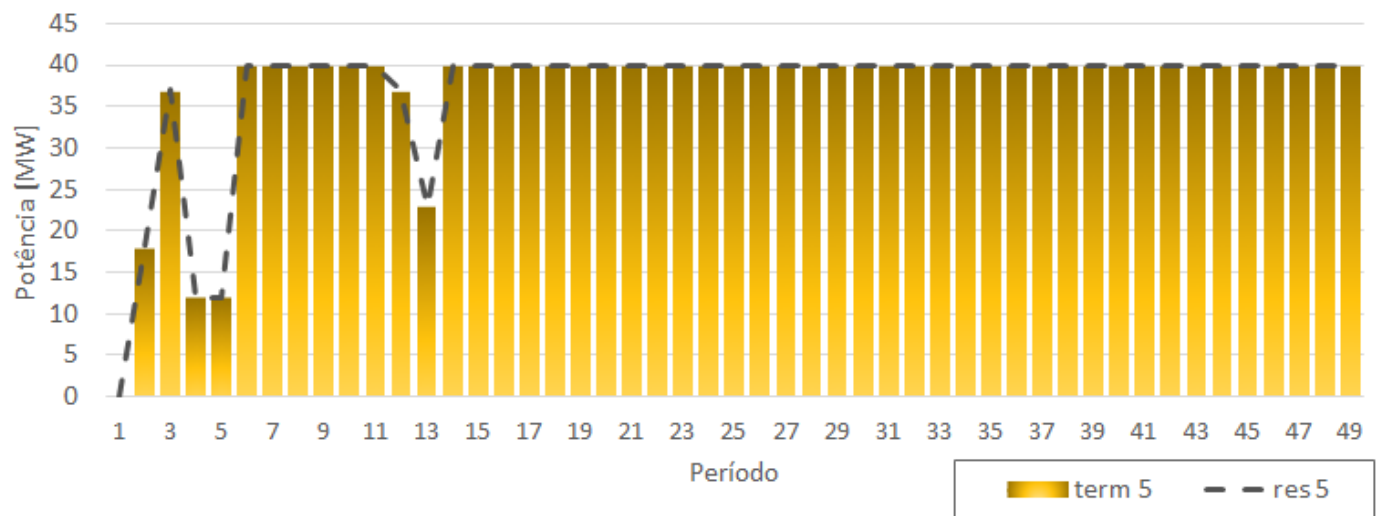

Figura 37: Resultado do despacho de potência e reservas UG térmica 5 - 30 barras $-N-1-1$

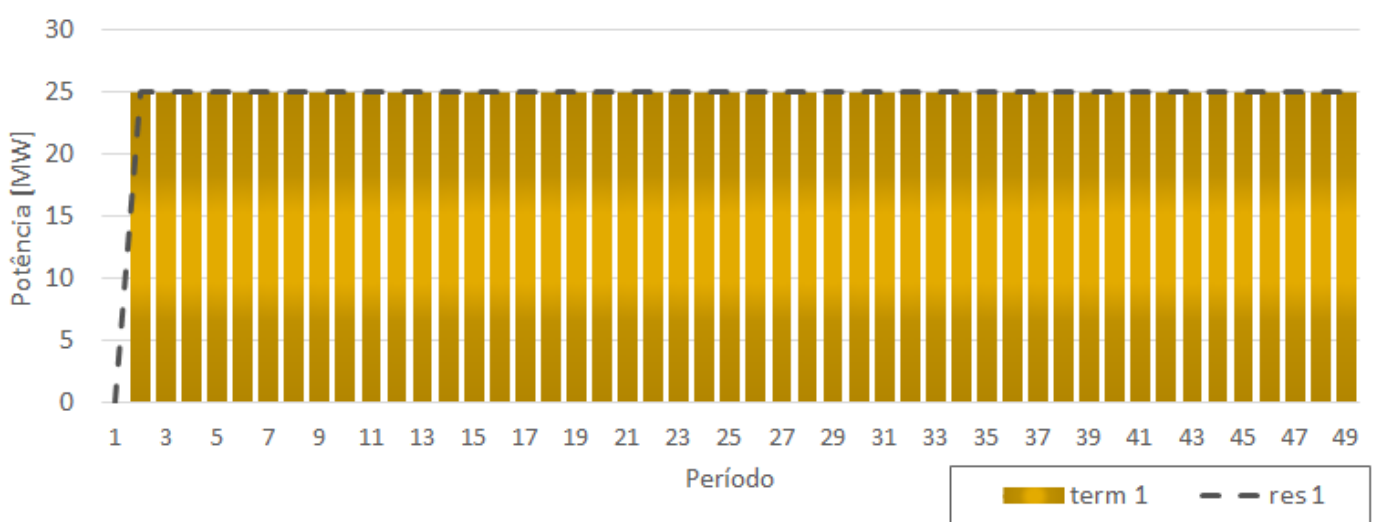

Figura 38: Resultado do despacho de potência e reservas UG térmica 1 - 30 barras $-N-1-1$ 


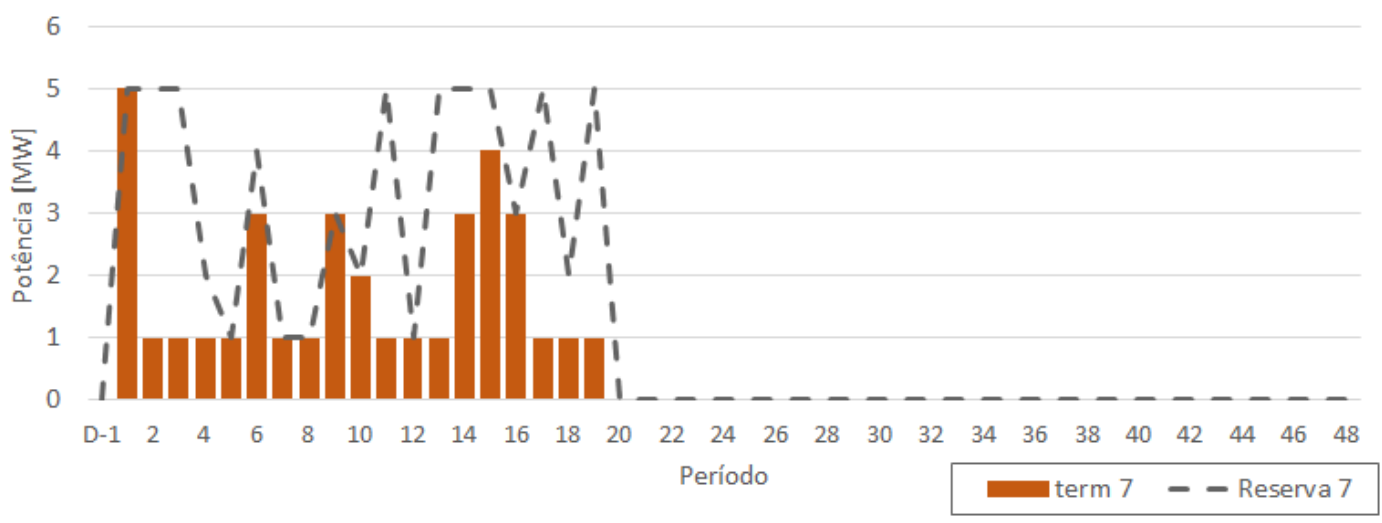

Figura 39: Resultado do despacho de potência e reservas UG térmica 2 - 30 barras $-N-1-1$

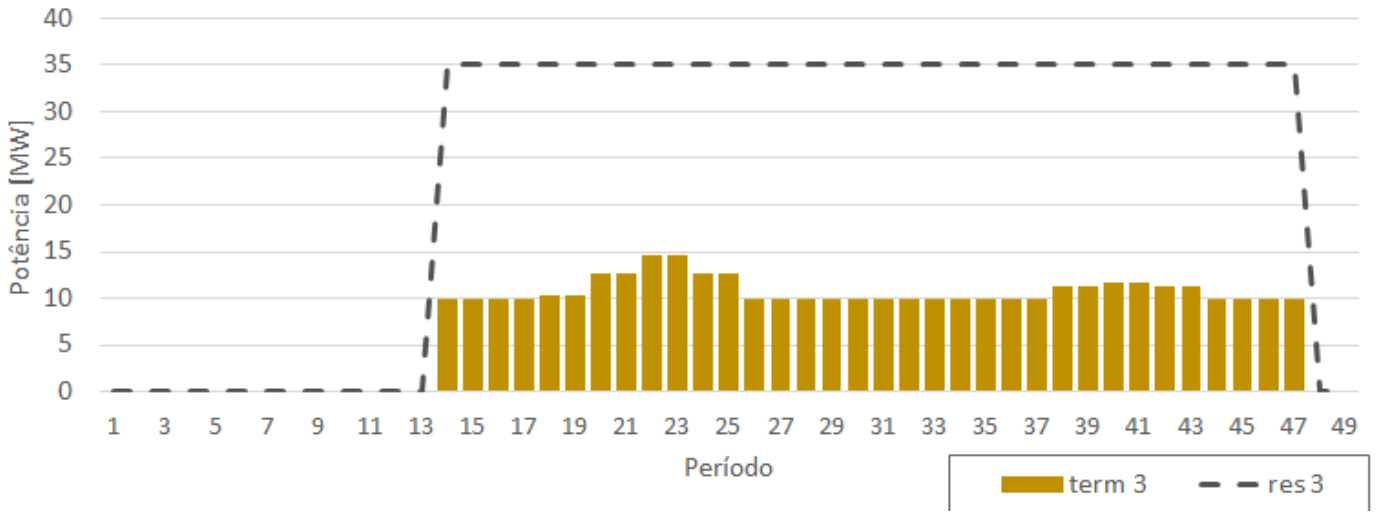

Figura 40: Resultado do despacho de potência e reservas UG térmica 3 - 30 barras - $N-1-1$

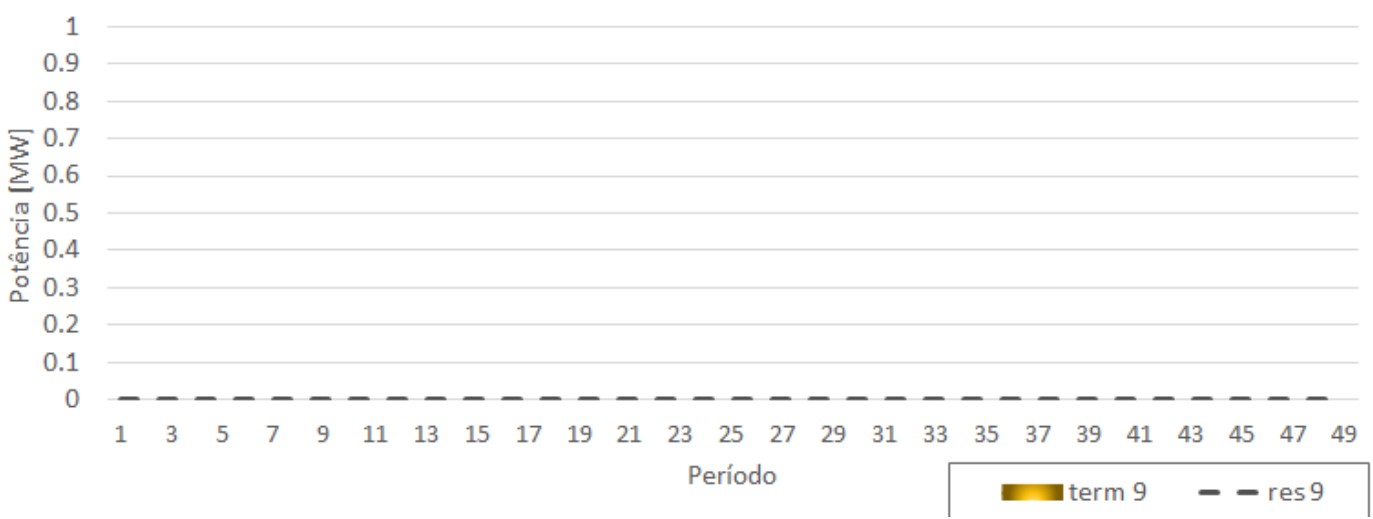

Figura 41: Resultado do despacho de potência e reservas UG térmica 9 - 30 barras $-N-1-1$ 
Apêndice B. Apêndice $B$

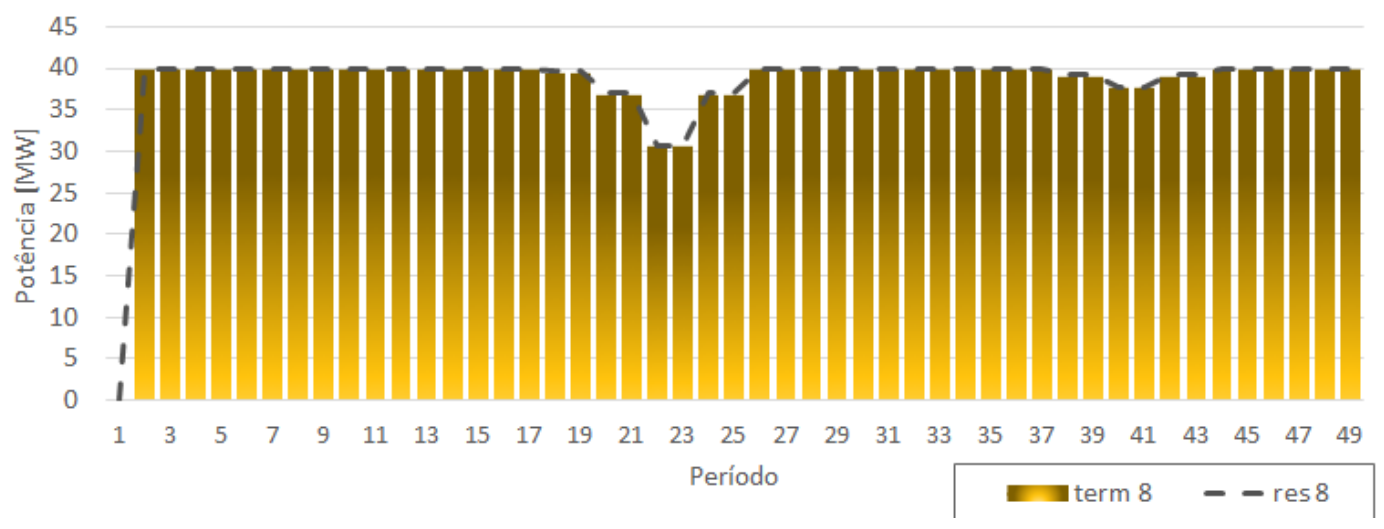

Figura 42: Resultado do despacho de potência e reservas UG térmica 8 - 30 barras $-N-1-1$ 